UNIVERSIDADE DE SÃO PAULO

FACULDADE DE ECONOMIA, ADMINISTRAÇÃO E CONTABILIDADE DEPARTAMENTO DE ADMINISTRAÇÃO

PROGRAMA DE PÓS-GRADUAÇÃO EM ADMINISTRAÇÃo

Corpo Docente: Fatores determinantes do desempenho discente no ENADE

Tainá Fernandes de Brito

Orientador: Prof. Dr. Nuno Manoel Martins Dias Fouto

SÃO PAULO

2015 
Prof. Dr. Marco Antonio Zago Reitor da Universidade de São Paulo

Prof. Dr. Adalberto Américo Fischmann Diretor da Faculdade de Economia, Administração e Contabilidade

Prof. Dr. Roberto Sbragia

Chefe do Departamento de Administração

Prof. Dr. Moacir de Miranda Oliveira Júnior Coordenador do Programa de Pós-Graduação em Administração 
Tainá Fernandes de Brito

\section{Corpo Docente: Fatores determinantes do desempenho discente no ENADE}

Dissertação apresentada ao Programa de PósGraduação em Administração do Departamento de Administração da Faculdade de Economia, Administração e Contabilidade da Universidade de São Paulo, como requisito parcial para a obtenção do título de Mestre em Ciências.

Orientador: Prof. Dr. Nuno M. M. D. Fouto

\section{Versão Corrigida}

(versão original disponível na Faculdade de Economia, Administração e Contabilidade)

São Paulo 


\section{FICHA CATALOGRÁFICA}

Elaborada pela Seção de Processamento Técnico do SBD/FEA/USP

Brito, Tainá Fernandes de.

Corpo docente: fatores determinantes do desempenho discente no ENADE / Tainá Fernandes de Brito. - São Paulo, 2015.

$98 \mathrm{p}$.

Dissertação (Mestrado) - Universidade de São Paulo, 2016.

Orientador: Nuno Manoel Martins Dias Fouto.

1. Ensino superior. 2. Administração. 3. Avaliação da educação.

I. Universidade de São Paulo. Faculdade de Economia, Administração e Contabilidade. II. Título.

CDD -378 


\section{AGRADECIMENTOS}

Em especial, agradeço aos meus pais (os heróis da vida real), que participaram desta jornada, fazendo o possível (e o impossível) para que eu chegasse até aqui. Esta conquista é nossa! Devo a vocês tudo o que sou.

Ao meu orientador, Prof. Dr. Nuno M. M. D. Fouto, que acreditou em mim e sempre esteve disponível para ouvir e discutir novas ideias.

Agradeço ao Prof. Dr. Claudio Felisoni de Angelo e ao Prof. Dr. André Taue Saito, pela atenção e pelas significativas contribuições ao trabalho.

Agradeço à FEA e ao $\mathrm{CNPq}$ (Comissão Nacional de Desenvolvimento Científico e Tecnológico) pelo apoio burocrático e financeiro.

Ressalto que erros e omissões são de minha inteira responsabilidade. 


\section{RESUMO}

BRITO, T. F. Corpo Docente: Fatores determinantes do desempenho discente no ENADE. 2015. 98 p. Dissertação (Mestrado) - Faculdade de Economia, Administração e Contabilidade; Universidade de São Paulo; 2015.

Os impactos do crescimento quantitativo da educação superior brasileira para a sua qualidade têm sido questionados, visto que a qualidade do ensino é importante preditora do crescimento econômico de um país e que o processo de expansão teria possibilitado o estabelecimento de instituições de ensino e cursos com baixa qualidade. Neste contexto, é fundamental conhecer a influência dos recursos disponibilizados à educação superior para a efetividade do processo de ensino-aprendizagem. No entanto, na literatura acadêmica, há evidente escassez de estudos que exploram as relações entre o desempenho discente e o nível de escolaridade e o regime de trabalho docente. Esta pesquisa aborda o ensino de Administração, que apresentou significativa expansão nos últimos 15 anos, compatível com a tendência mundial de crescimento das escolas de negócio. O objetivo é determinar como as características do corpo docente de uma IES influenciam o desempenho dos concluintes de seus cursos de graduação em Administração no Exame Nacional de Desempenho dos Estudantes (ENADE). Assim, para o desenvolvimento deste estudo, foi criado um banco de dados a partir dos Microdados ENADE 2012 e dos Microdados Censo da Educação Superior 2012, disponibilizados pelo Instituto Nacional de Estudos e Pesquisas Educacionais Anísio Teixeira (INEP). Com base neste, foram desenvolvidos três modelos de regressão múltipla: um modelo geral, contemplando todas as Instituições de Ensino Superior (IES) do banco de dados, um modelo específico para as IES públicas e outro específico para as IES privadas; sendo que a variável dependente empregada nestes modelos foi gerada por meio de uma análise fatorial, que condensou as informações contidas em cinco variáveis que mensuravam objetivamente o desempenho dos concluintes dos cursos de Administração das 1.286 IES do banco de dados no ENADE 2012. Concluiu-se que o nível de escolaridade do corpo docente, a quantidade de docentes por curso e o volume de cursos ofertados pela IES têm impacto significativo para o desempenho discente. Quanto ao regime de dedicação do corpo docente, foram encontradas evidências da capacidade preditiva destas variáveis, especificamente para o desempenho dos concluintes de IES públicas. Espera-se que os resultados alcançados estimulem o desenvolvimento de novos estudos, a fim de consolidar esta linha de pesquisa e ampliar o conhecimento científico, gerando contribuições práticas que promovam a melhoria contínua da qualidade do ensino de Administração no Brasil.

Palavras-chave: Ensino superior; Administração; Avaliação da educação. 


\begin{abstract}
BRITO, T. F. Faculty: determinants of students' performance on ENADE. 2015. 98 p. Dissertation (Master of Science) - Faculdade de Economia, Administração e Contabilidade; Universidade de São Paulo; 2015.

The impacts of Brazilian higher education quantitative growth on its quality have been challenged since educational quality is an important predictor of a country's economic growth. It is also known that this expansion process allowed the establishment of low quality educational institutions and courses. In this context, it is fundamental to know how available educational resources influence learning effectiveness in higher education. However, in academic publishing, there is obvious lack of studies that explored the relationship between students' performance and faculty educational attainment and faculty working arrangements. This research is focused on Management Education in Brazil, which showed substantial expansion over the last 15 years, consistently with the global growth of Management Education. Its main purpose is to investigate the effects of faculty characteristics on graduate students' performance on the Brazilian national exam (Exame Nacional de Desempenho dos Estudantes - ENADE). Therefore, a database was created, using data extracted from 'Microdados ENADE 2012' and from 'Microdados Censo da Educação Superior 2012'. Three multiple regression models were developed: a general model, for all the 1,286 higher education institutions in the database, and two specific models (one for public educational institutions and the other for private educational institutions). The dependent variable was generated through a factor analysis, which compressed the information contained in five variables that objectively measured graduate students' performance on ENADE 2012. The results provide compelling evidence that faculty educational attainment, number of teachers per course and amount of courses offered by an IES have predictive power over students' performance on ENADE 2012. It is expected that these findings encourage the development of new studies in order to reinforce this research area and expand the scientific knowledge, generating practical contributions that could promote ongoing improvement of Management Education quality in Brazil.
\end{abstract}

Keywords: Higher education; Management; Educational assessment. 
LISTA DE TABELAS

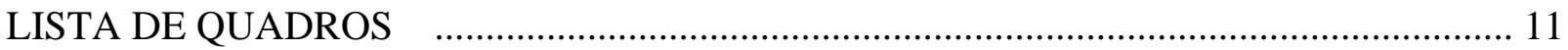

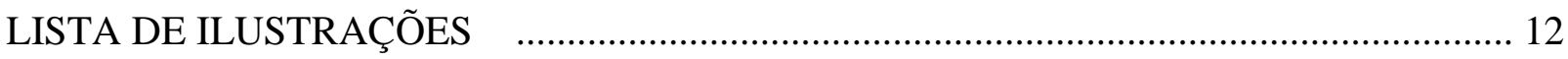

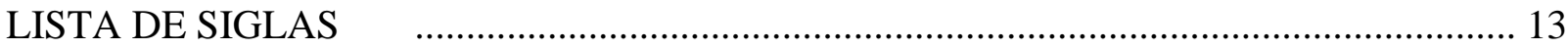

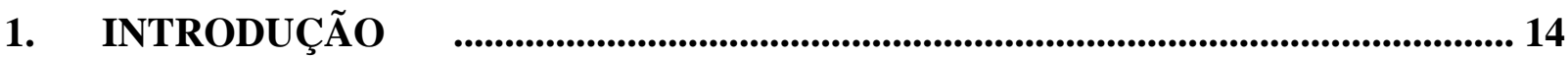

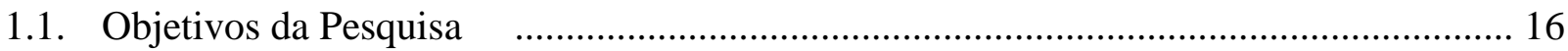

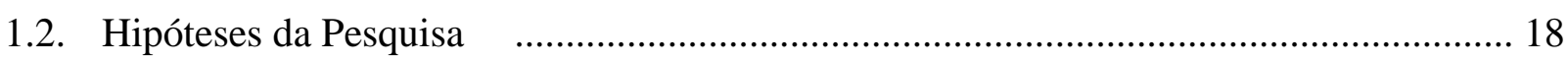

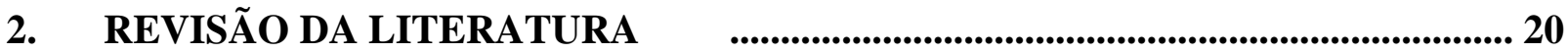

2.1. Ensino de Administração de Empresas .................................................................. 20

2.2. Avaliação da Educação Superior no Brasil …...................................................... 23

2.2.1 Exame Nacional de Desempenho dos Estudantes (ENADE) ................................. 24

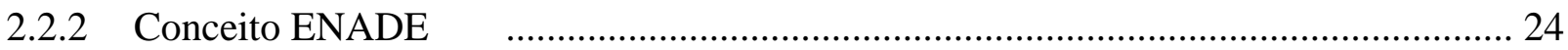

2.2.3 Conceito Preliminar de Curso (CPC) …....................................................... 25

2.2.4 Índice Geral de Cursos Avaliados da Instituição (IGC) ......................................... 27

3. METODOLOGIA $\quad$....................................................................................................................... 29

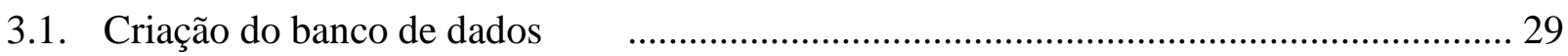

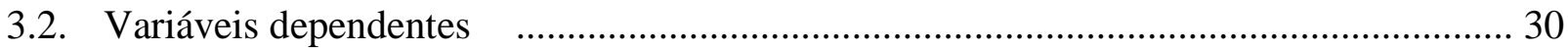

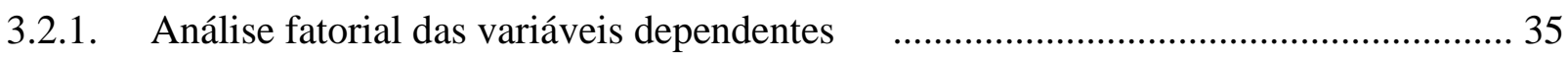

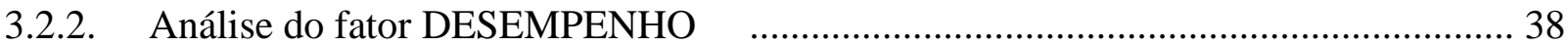

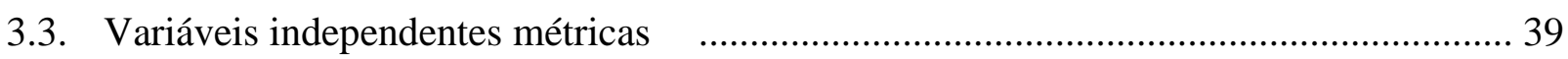

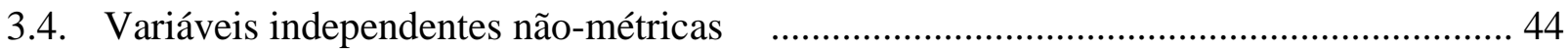

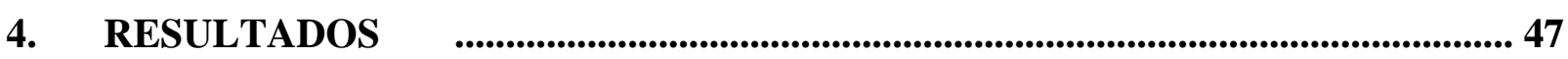

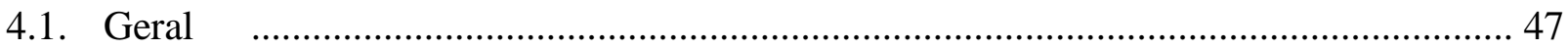

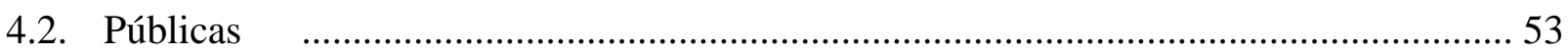

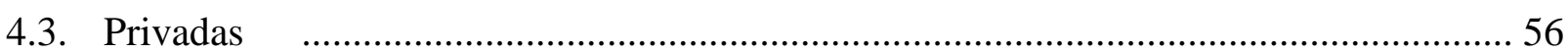

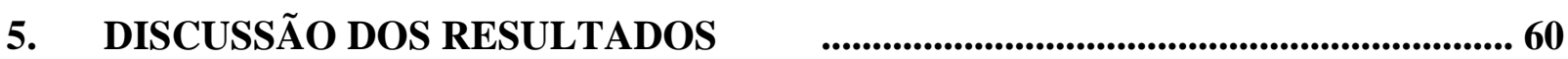

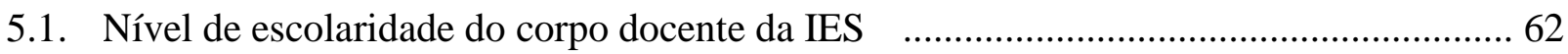

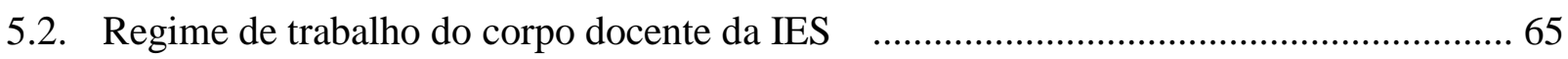

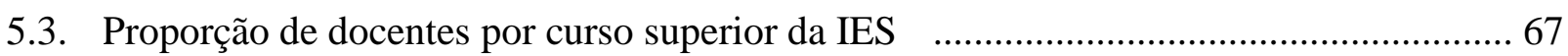

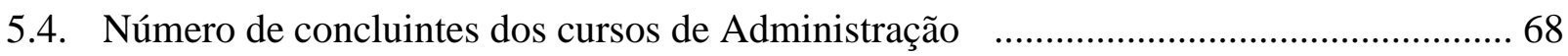

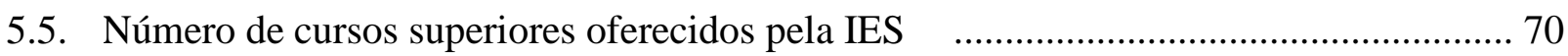

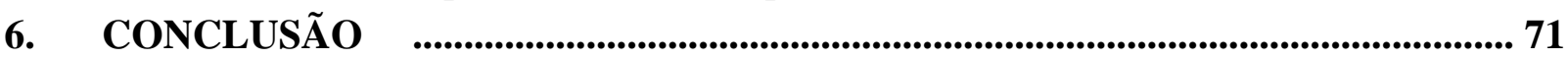

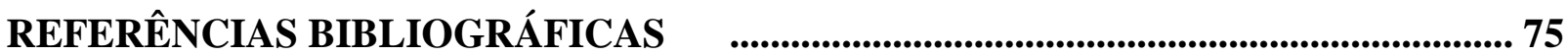

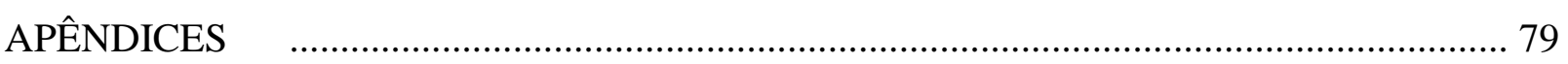




\section{LISTA DE TABELAS}

Tabela 1 - Cursos da categoria 'Gerenciamento e Administração' (2014) .......................... 22

Tabela 2 - Conversão das Notas ENADE em Conceito ENADE ........................................ 25

Tabela 3 - Conversão do $\mathrm{CPC}_{i}$ (contínuo) em CPC (faixa) ................................................. 27

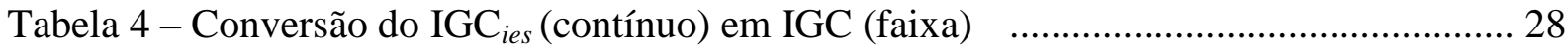

Tabela 5 - Criação de Dummy para Categ_Admin .......................................................... 45

Tabela 6 - Criação de Dummy para Org_Academ ............................................................ 45

Tabela 7 - Criação de Dummy para Regiao_BR ........................................................... 45

Tabela 8 - Criação de Dummy para Capital …................................................................ 45

Tabela 9 - Variâncias únicas das variáveis independentes ('Geral') .................................. 51

Tabela 10 - Variâncias únicas das variáveis independentes ('Públicas') ............................. 55

Tabela 11 - Variâncias únicas das variáveis independentes ('Privadas') ............................. 59

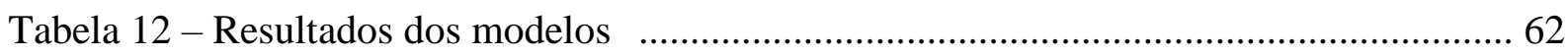

Tabela 13 - Coeficientes das variáveis relacionadas às hipóteses H1 e H2 ......................... 63

Tabela 14 - Coeficientes das variáveis relacionadas às hipóteses H3 e H4 ......................... 65

Tabela 15 - Coeficientes da variável relacionada à hipótese H5 ........................................ 67

Tabela 16 - Coeficientes da variável relacionada à hipótese H6 ........................................ 68

Tabela 17 - Coeficientes da variável relacionada à hipótese $\mathrm{H} 7 \quad$........................................ 70 


\section{LISTA DE QUADROS}

Quadro 1 - As primeiras IES de AE

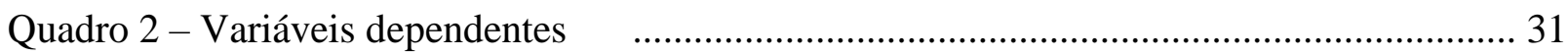

Quadro 3 - Variáveis independentes métricas ................................................................... 40

Quadro 4 - Correlações entre as variáveis independentes $\quad$..................................................... 43

Quadro 5 - Variáveis independentes não-métricas $\quad$................................................................ 45

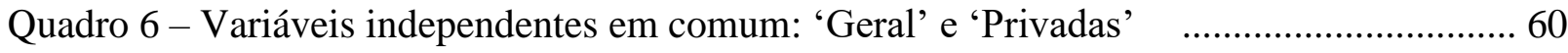

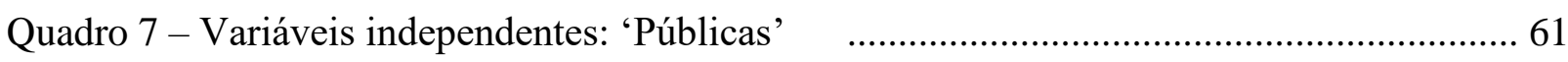

Quadro 8 - Referência para a avaliação das hipóteses de pesquisa $\quad$...................................... 62

Quadro 9 - Resultados das hipóteses de pesquisa ........................................................... 72 


\section{LISTA DE ILUSTRAÇÕES}

Gráfico 1 - IES públicas e privadas (1985-2014) ............................................................... 15

Gráfico 2 - Cursos de graduação em administração (2000-2014) ....................................... 17

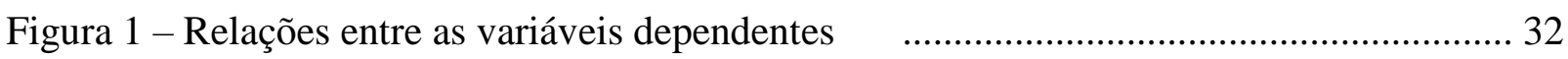

Figura 2 - Diagramas de dispersão das variáveis dependentes .......................................... 34 


\section{LISTA DE SIGLAS}
AE Administração de Empresas
CE Componente Específico do ENADE
CAPES Coordenação de Aperfeiçoamento de Pessoal de Nível Superior
CONAES Comissão Nacional de Avaliação da Educação Superior
CPC Conceito Preliminar de Curso
ENADE Exame Nacional de Desempenho dos Estudantes
FG Formação Geral do ENADE
IDD Indicador da Diferença entre os Desempenhos Esperado e Observado
IES Instituições de Educação Superior
IGC Índice Geral de Cursos Avaliados da Instituição
INEP Instituto Nacional de Estudos e Pesquisas Educacionais Anísio Teixeira
MEC Ministério da Educação
SINAES Sistema Nacional de Avaliação da Educação Superior 


\section{INTRODUÇÃO}

Dados publicados pelo Instituto Nacional de Estudos e Pesquisas Educacionais Anísio Teixeira (INEP) revelam a notável expansão da educação superior no Brasil: o número de Instituições de Educação Superior (IES) ${ }^{1}$ passou de 859 (em 1985) para 2.368 (em 2014), um crescimento de 175,7\%. Em 30 anos, o volume total de cursos de graduação aumentou $738,1 \%$, sendo que, em 2014, as IES ofertavam 31.513 cursos de graduação presenciais e 1.365 cursos de graduação à distância; e, no mesmo período, as matrículas cresceram 472,4\% (com 6.486.171 matrículas nos cursos de graduação presenciais e 1.341.842 matrículas nos cursos à distância, em 2014).

Dentre os fatores que impulsionaram este crescimento, são apontados os movimentos de urbanização, modernização e globalização, o crescimento econômico do país, o aumento do contingente de jovens formados no Ensino Médio, a ascensão das mulheres na sociedade, as crescentes exigências do mercado de trabalho por maior escolaridade e qualificação, as mudanças culturais impulsionadas pela tecnologia de informação e a ênfase recente ao ensino tecnológico e ao ensino à distância pelo Ministério da Educação (MEC) (NUNES, 2007; DIAS SOBRINHO, 2010).

Além disso, modificações nas políticas educacionais flexibilizaram e incentivaram a abertura de cursos superiores em todo o país, principalmente pela iniciativa privada. Dentre elas, o Decreto 2.306 de 1997, que criou novas figuras jurídicas para as IES - o Centro Universitário e as Faculdades Integradas -, promovendo a diversificação de modelos organizacionais no sistema de educação superior.

Um cenário de dispersão se foi constituindo e se alargando, concorrendo instituições
públicas e privadas, de diferentes tamanhos e modalidades de financiamento,
mantidas pela União, pelos estados, por municípios, por grupos religiosos ou
empresários privados, de elites ou de massas, vinculadas aos projetos nacionais,
regionais ou transnacionais, oferecendo serviços educativos presenciais ou a
distância, de larga ou curta duração, em muitas ou em poucas áreas de
conhecimento, valorizando a pesquisa ou, mais comumente, a capacitação para os
empregos, sem fim de lucro ou com o objetivo do lucro sem fim (DIAS
SOBRINHO, 2010, p. 197).

Em consequência do Decreto 2.306 de 1997, o número de IES privadas cresceu 200,4\% entre 1997 e 2014²; ao passo que o crescimento das IES públicas no mesmo período foi de 41,2\%. Em 1997, as IES privadas representavam 76,6\% do total de IES no Brasil; já, em 2014 , estas correspondiam a $87,4 \%$ do total.

\footnotetext{
${ }^{1}$ Apêndice A - Crescimento da educação superior no Brasil (1985-2014).

${ }^{2}$ Apêndice B - Crescimento das IES (1985-2014).
} 


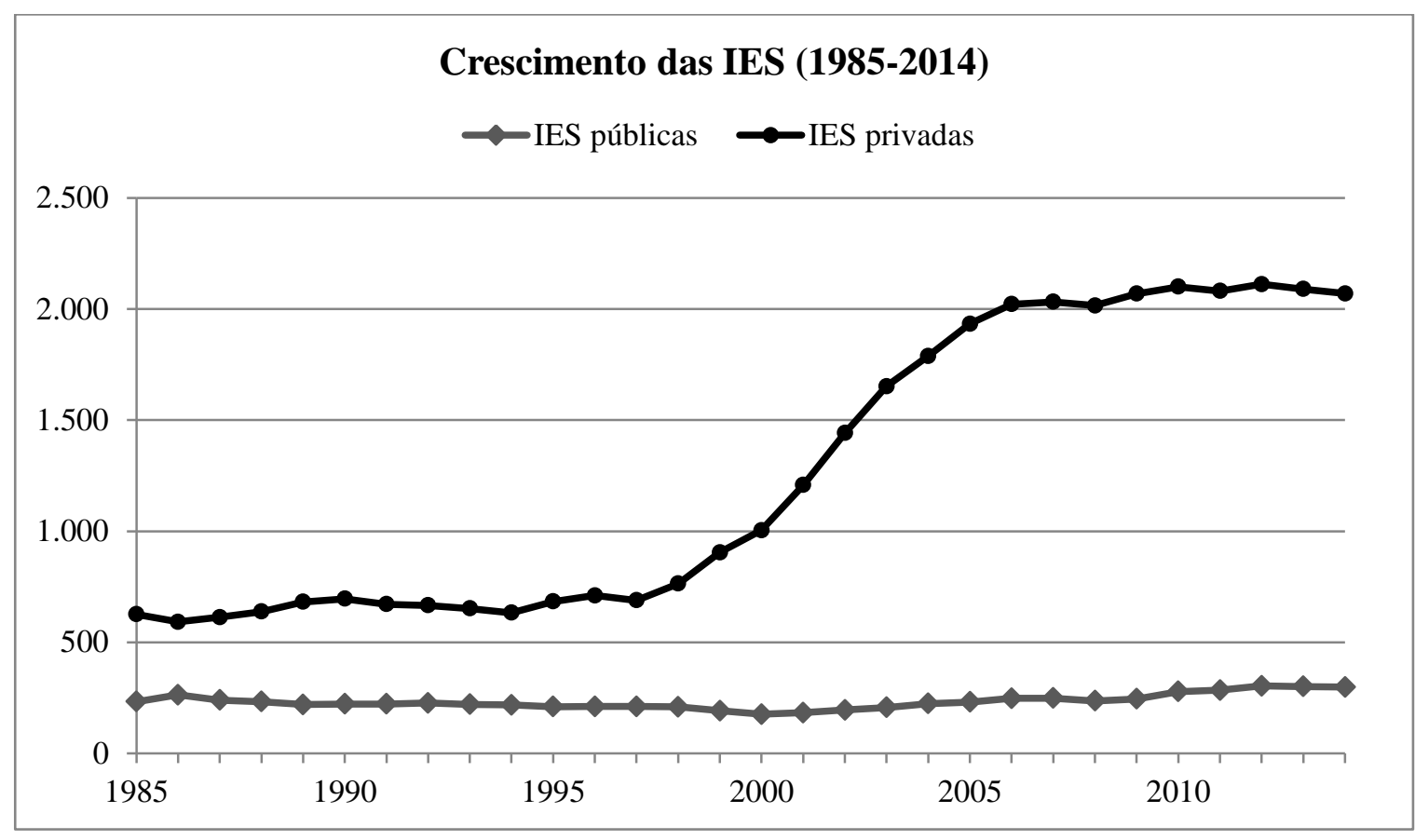

Gráfico 1 - IES públicas e privadas (1985-2014)

Os impactos do crescimento quantitativo da educação superior para a sua qualidade têm sido alvo de questionamentos: o processo de expansão teria possibilitado o estabelecimento de diversas IES e cursos com baixa qualidade (POLIDORI, 2009, p. 443). Assim, o foco da política educacional brasileira se transforma na melhoria da qualidade do ensino, uma vez que a qualidade (e não a quantidade) é importante preditora do crescimento econômico de um país (ANDRADE, 2011).

Diante disso, as políticas e os procedimentos de avaliação da educação superior no Brasil vêm evoluindo de forma constante e consistente (DIAS; HORIGUELA; MARCUELLI, 2006). Desde 2004, o governo federal empreende avaliações educacionais em larga escala através do Sistema Nacional de Avaliação da Educação Superior (SINAES), que compreende avaliações institucionais, avaliações dos cursos e a avaliação dos estudantes (a qual se dá periodicamente por meio da realização do Exame Nacional de Desempenho dos Estudantes, o ENADE).

Processos de avaliação geram evidências empíricas sobre as debilidades e potencialidades das IES, promovendo a transparência nas relações entre as IES e seus diferentes stakeholders: os corpos docente, discente e técnico-administrativo, a sociedade civil e o governo (BRITO, 2008; ANDRADE, 2011). Consequentemente, seus resultados têm forte repercussão na mídia, que cria e divulga rankings (subprodutos das avaliações) que, 
inevitavelmente, estabelecem um estado explícito ou implícito de concorrência, a partir das comparações entre os desempenhos das IES (DAMETTO; ESQUINSANI, 2015).

Tal hierarquização produz diversos efeitos econômicos. Dentre os benefícios por uma posição de destaque, estão: expansão da demanda por vagas nas IES por estudantes nacionais e internacionais de alto de desempenho, maior facilidade na captação de recursos para o financiamento de pesquisas, aumento da procura por parte da indústria para o estabelecimento de parcerias e convênios de pesquisa e inovação e maior destaque para o corpo docente (MOURA; MOURA, 2013; DAMETTO; ESQUINSANI, 2015). Logo, tornouse prática comum a inserção das posições dos cursos em ferramentas de divulgação, particularmente das IES privadas (ANDRADE, 2011).

Neste contexto, o conhecimento sobre a influência dos recursos disponibilizados à educação superior brasileira para o processo de ensino-aprendizagem é uma necessidade imperativa (ARAÚJO et al., 2013). Ademais, na literatura acadêmica, há evidente escassez de pesquisas que exploram, especificamente, as relações entre o desempenho discente e a titulação e o regime de trabalho docente (MIRANDA et al., 2015).

\subsection{Objetivos da Pesquisa}

Compatível com a tendência mundial de crescimento das escolas de negócios, em um ritmo mais acelerado do que as outras partes das universidades (STARKEY; HATCHUEL; TEMPEST, 2004; ENGWALL, 2007), no Brasil, a graduação em Administração apresentou significativa expansão entre os anos 2000 e 2014.

Analisando a categoria 'Gerenciamento e Administração' das Sinopses Estatísticas da Educação Superior, disponibilizadas pelo INEP, constata-se um crescimento de 369,7\% no volume de $\operatorname{cursos}^{3}$ (de 989 cursos em 2000, para 4.645 cursos em 2014 - sendo 4.232 cursos presenciais e 413 cursos à distância) e um crescimento de 298,1\% no volume de matrículas (de 338.789 em 2000, para 1.348.616 em 2014). No entanto, este crescimento "tem ocorrido de forma desordenada, o que implica em dúvidas sobre a qualidade do ensino" (LOURENÇO et al., 2012, p. 6).

\footnotetext{
${ }^{3}$ Apêndice C - Crescimento dos cursos de graduação (Gerenciamento e Administração).
} 


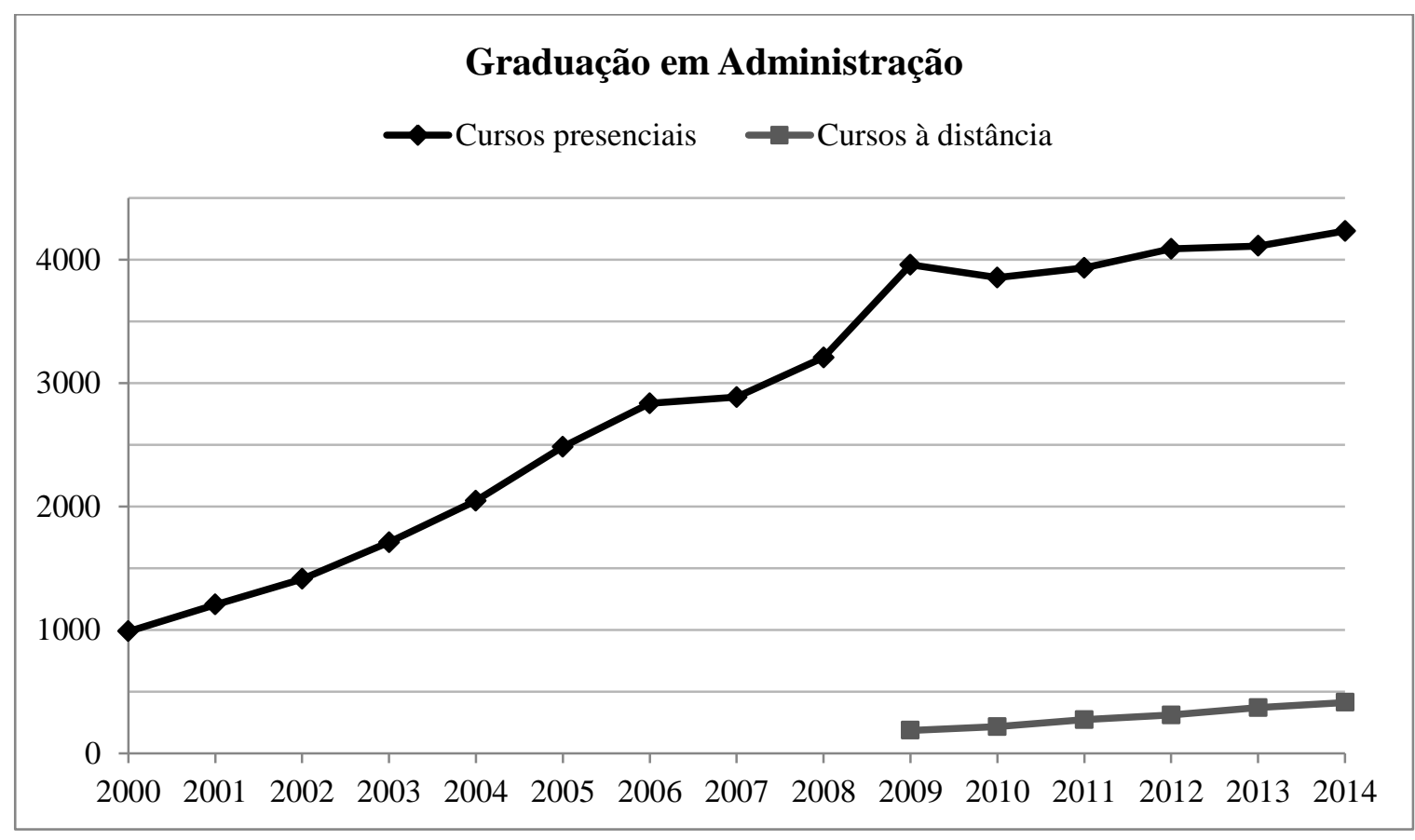

Gráfico 2 - Cursos de graduação em administração (2000-2014)

À vista disso, o objetivo desta pesquisa é determinar como as características do corpo docente de uma IES influenciam o desempenho dos concluintes de seus cursos de graduação em Administração no ENADE.

Para o desenvolvimento deste estudo adotou-se o ENADE 2012, posto que estes eram os dados disponíveis mais recentes de avaliação dos cursos de Administração. Logo, são objetivos específicos deste estudo descritivo transversal:

- Analisar o efeito do nível de escolaridade do corpo docente para o desempenho dos concluintes de cursos de Administração no ENADE 2012;

- Analisar o efeito do regime de dedicação do corpo docente para o desempenho dos concluintes de cursos de Administração no ENADE 2012;

- Analisar o efeito da quantidade de docentes por curso ofertado pela IES para o desempenho dos concluintes de cursos de Administração no ENADE 2012.

Para atingir estes objetivos, os procedimentos metodológicos incluem a criação de um banco de dados, a partir dos Microdados ENADE 2012 e dos Microdados Censo da Educação Superior 2012, e o desenvolvimento de três modelos de regressão múltipla - um que contempla todas as IES do banco de dados ('Geral') e dois específicos ('Públicas' e 'Privadas'). O desenvolvimento de modelos específicos segundo a categoria administrativa das IES (públicas ou privadas) é justificado, uma vez que os processos seletivos das IES 
públicas são mais concorridos, possibilitando uma seleção rigorosa dos candidatos mais bem preparados (BITTENCOURT et al., 2008).

A unidade de análise do estudo é o conjunto de cursos do grupo Administração, oferecidos por cada IES em 2012. Este critério foi adotado por razões práticas e teóricas, já que os cursos oferecidos por determinada IES estão inseridos em um contexto institucional, no qual seus estudantes compartilham da estrutura administrativa e dos procedimentos acadêmicos, e são submetidos a influências comuns; ou seja, a cultura de uma IES a distingue de outras (MORICONI; NASCIMENTO, 2014).

Quanto às limitações de escopo deste estudo, não foram analisados os cursos de pósgraduação e o papel das IES na geração de novos conhecimentos por meio da pesquisa acadêmica - o foco é a sua função educacional (a preparação dos alunos para a carreira). Não foram discutidas a finalidade do ENADE ou a influência de seus resultados sobre o planejamento pedagógico das IES; tampouco foram questionados os objetivos e o conteúdo das provas do ENADE. Este estudo não propõe um novo modelo de avaliação discente.

Outras limitações estão relacionadas à adoção do ENADE por este estudo. Como as universidades públicas estaduais têm participação facultativa no ENADE, a Universidade de São Paulo não faz parte do banco de dados criado. Além disso, o modelo explicativo aqui apresentado foi desenvolvido para um contexto específico (o desempenho dos alunos de Administração no ENADE 2012), não sendo generalizável para outros cursos de graduação ou avaliações do curso de Administração realizadas em outros anos - os resultados alcançados são particulares ao contexto analisado.

Esta pesquisa pode contribuir para a promoção da melhoria da qualidade do ensino de Administração no Brasil, ao prover uma melhor compreensão sobre como as variáveis estudadas (características do corpo docente e da IES) impactam o desempenho discente. Além disso, seus resultados estimulam a geração de hipóteses de pesquisa para estudos futuros.

\subsection{Hipóteses da Pesquisa}

Programas de pós-graduação Stricto Sensu agregam "maior conhecimento profissional ao docente, o que consequentemente poderá refletir em uma melhor aprendizagem dos alunos” (ZONATTO et al., 2013, p. 13). Assim, sugere-se que: 
H1: A proporção de docentes com Doutorado no corpo docente da IES tem relação positiva com o desempenho discente no ENADE.

H2: A proporção de docentes com Especialização no corpo docente da IES tem relação negativa com o desempenho discente no ENADE.

Assumindo que o regime de dedicação integral tem um impacto positivo sobre o desempenho discente, devido à maior disponibilidade de tempo que o professor teria para atender os seus alunos, bem como para desenvolver pesquisas e atualizar seus conhecimentos e materiais didáticos, sugere-se que:

H3: A proporção de regime de dedicação Integral no corpo docente da IES tem relação positiva com o desempenho discente no ENADE.

H4: A proporção de regime de dedicação Parcial no corpo docente da IES tem relação negativa com o desempenho discente no ENADE.

Assumindo que um maior volume de docentes por curso pode prover mais liberdade e flexibilidade aos professores para o desenvolvimento de suas atividades fora da sala de aula (pesquisas, estudos e preparação/atualização de aulas, entre outras), propõe-se que:

H5: O número de docentes por curso da IES tem relação positiva com o desempenho discente no ENADE.

Supondo que uma melhor gestão acadêmica, resultante da experiência acumulada pela equipe administrativa de uma IES com as especificidades de um dado curso, pode impactar positivamente o desempenho discente; e que o volume de concluintes reflete a tradição de uma IES em uma dada área, então:

H6: O total de concluintes dos cursos de Administração da IES tem relação positiva com o desempenho discente no ENADE.

Assumindo que quanto maior o volume de cursos de graduação oferecidos por uma IES, maior deve ser a estrutura disponibilizada aos seus alunos (em termos de salas de aula, bibliotecas e espaços de convívio, entre outros); e que tal estrutura pode impactar o desempenho do seu corpo discente, propõe-se que:

H7: O volume de cursos oferecidos pela IES tem relação positiva com o desempenho discente no ENADE. 


\section{REVISÃO DA LITERATURA}

A revisão da literatura trata, primeiramente, das origens e do crescimento do ensino de Administração de Empresas, bem como do histórico da regulamentação do curso no Brasil até o momento atual. A segunda parte consiste de uma breve exposição do sistema brasileiro de avaliação do ensino superior vigente.

\subsection{Ensino de Administração de Empresas}

No século XIX, o desenvolvimento econômico, decorrente da industrialização e da subsequente emergência de organizações complexas com crescentes necessidades de coordenação eficiente de fluxos físicos e financeiros, impulsionou o advento da educação em Administração (ENGWALL, 2007). Com o aparecimento de diversos novos problemas de gestão, as primeiras escolas de Administração de Empresas (AE) surgiram na década de 1850, nos Estados Unidos da América e na Europa.

Quadro 1 - As primeiras IES de AE

\begin{tabular}{|l|l|}
\hline Ano & Escola de AE \\
\hline 1851 & University of Louisiana, EUA \\
\hline 1852 & $\begin{array}{l}\text { Institut Supérieur de Commerce de l'Etat, Antwerp, Bélgica } \\
\text { Institut Supérieur de Commerce Saint Ignace, Antwerp, Bélgica } \\
\text { University of Wisconsin, EUA }\end{array}$ \\
\hline 1854 & Ecole Supérieure de Commerce, Paris, França \\
\hline 1856 & Wiener Handelsakademie, Áustria \\
\hline
\end{tabular}
Fonte: Adaptado de ENGWALL (2007).

Tal como surgiram estas primeiras escolas, a educação em AE no Brasil teve início em resposta a uma demanda do mercado de trabalho. Na década de 1950, diversas empresas estrangeiras iniciaram suas operações no país (Volkswagen, Mercedes, Ford e General Motors, entre outras), gerando uma necessidade crescente por administradores profissionais que pudessem atuar nestas organizações (OLIVEIRA; LOURENÇO; CASTRO, 2015).

Usando como modelo a Universidade de Harvard, o padre jesuíta Roberto Sabóia de Medeiros criou, em 1941, a primeira escola brasileira de AE: a Escola Superior de 
Administração de Negócios de São Paulo (ESAN/SP) - a qual, atualmente, compõe o Centro Universitário da FEI. Assim, o ensino formal de AE instituiu-se no Brasil sob forte influência do modelo norte-americano (evidenciada pela reprodução dos currículos importados e pela formação de professores no exterior).

Alterações nos marcos legais brasileiros relacionados à regulamentação do ensino de graduação em AE, ao longo dos anos, promoveram a ampliação da autonomia e da flexibilidade das IES na concepção de suas estruturas curriculares (RIBEIRO e SACRAMENTO, 2009).

Em 1965, a profissão de Administrador foi oficializada no Brasil pela Lei no 4.769 e, em 1966, por meio de resolução não-numerada, deu-se a regulamentação do ensino de AE. Foi estabelecido um currículo mínimo, que contemplava as áreas funcionais e os aspectos relativos à formação geral do administrador, legitimando cursos e diplomas e possibilitando a expansão da educação em AE no país (CLOSS; ARAMBURU; ANTUNES, 2009).

Tal legislação de ensino permaneceu vigente por vinte e sete anos, até que, em 1993, o currículo mínimo foi reformulado pela Resolução $n^{\circ}$ 02/93, com o objetivo de estabelecer uma formação mais generalista (que permitisse um melhor acompanhamento dos avanços da ciência e da tecnologia), resultando na oferta de diversas habilitações específicas para os cursos de graduação em AE, por todo o país (OLIVEIRA; LOURENÇO; CASTRO, 2015).

Em 1996, foi decretada a Lei de Diretrizes e Bases da Educação (Lei no 9.394), que desvinculou a necessidade de um currículo mínimo para o exercício profissional e assegurou autonomia às IES para a criação de cursos e para o desenvolvimento dos respectivos projetos e currículos, os quais devem atender às Diretrizes Curriculares Nacionais:

\footnotetext{
Art. 53. No exercício de sua autonomia, são asseguradas às universidades, sem prejuízo de outras, as seguintes atribuições:

I - criar, organizar e extinguir, em sua sede, cursos e programas de educação superior previstos nesta Lei, obedecendo às normas gerais da União e, quando for o caso, do respectivo sistema de ensino;

II - fixar os currículos dos seus cursos e programas, observadas as diretrizes gerais pertinentes [...] (BRASIL, 1996).
}

Atualmente, as diretrizes para os cursos de graduação em $\mathrm{AE}$ correspondem à Resolução $\mathrm{n}^{\circ} 4$, de 13 de julho de 2005, que discorre sobre o projeto pedagógico do curso (Artigo $2^{\circ}$ ), o perfil esperado do egresso (Artigo $3^{\circ}$ ), o estágio curricular supervisionado (Artigo $7^{\circ}$ ), as atividades complementares (Artigo $8^{\circ}$ ) e a adoção opcional do trabalho de conclusão de curso pelas IES (Artigo $9^{\circ}$ ); além de introduzir o desenvolvimento de habilidades e competências como elemento orientador do processo de formulação de projetos pedagógicos e currículos: 
Art. 4. O Curso de Graduação em Administração deve possibilitar a formação profissional que revele, pelo menos, as seguintes competências e habilidades:

I - reconhecer e definir problemas, equacionar soluções, pensar estrategicamente, introduzir modificações no processo produtivo, atuar preventivamente, transferir e generalizar conhecimentos e exercer, em diferentes graus de complexidade, o processo da tomada de decisão;

II - desenvolver expressão e comunicação compatíveis com o exercício profissional, inclusive nos processos de negociação e nas comunicações interpessoais ou intergrupais;

III - refletir e atuar criticamente sobre a esfera da produção, compreendendo sua posição e função na estrutura produtiva sob seu controle e gerenciamento;

IV - desenvolver raciocínio lógico, crítico e analítico para operar com valores e formulações matemáticas presentes nas relações formais e causais entre fenômenos produtivos, administrativos e de controle, bem assim expressando-se de modo crítico e criativo diante dos diferentes contextos organizacionais e sociais;

$\mathrm{V}$ - ter iniciativa, criatividade, determinação, vontade política e administrativa, vontade de aprender, abertura às mudanças e consciência da qualidade e das implicações éticas do seu exercício profissional;

VI - desenvolver capacidade de transferir conhecimentos da vida e da experiência cotidianas para o ambiente de trabalho e do seu campo de atuação profissional, em diferentes modelos organizacionais, revelando-se profissional adaptável;

VII - desenvolver capacidade para elaborar, implementar e consolidar projetos em organizações; e

VIII - desenvolver capacidade para realizar consultoria em gestão e administração, pareceres e perícias administrativas, gerenciais, organizacionais, estratégicos e operacionais (BRASIL, 2005, grifo nosso).

Dados extraídos das Sinopses Estatísticas da Educação Superior, disponibilizadas anualmente pelo INEP, revelam que os cursos de Administração no Brasil têm apresentado crescimento expressivo, compatível com a tendência mundial de crescimento das escolas de negócios, em um ritmo mais acelerado do que as outras partes das universidades (STARKEY; HATCHUEL; TEMPEST, 2004; ENGWALL, 2007). Dentre as possíveis razões para este fenômeno de crescimento, são apontadas: a ampla gama de habilitações possíveis e de oportunidades de trabalho para os egressos dos cursos de AE; e a incorporação de conceitos de AE à linguagem cotidiana, ampliando a necessidade dos cidadãos comuns em conhecê-los para efetivamente entender o que acontece no seu ambiente de trabalho e na sua vida pessoal (ENGWALL, 2007).

Tabela 1 - Cursos da categoria 'Gerenciamento e Administração' (2014)

\begin{tabular}{|l|l|c|c|}
\hline Tipo de Curso & IES & Cursos & Matrículas \\
\hline \multirow{2}{*}{ Presenciais } & Públicas & 561 & 120.405 \\
\cline { 2 - 4 } & Privadas & 3.671 & 773.932 \\
\hline \multirow{2}{*}{ Aistância } & Públicas & 76 & 26.521 \\
\cline { 2 - 4 } & Privadas & 337 & 427.758 \\
\hline
\end{tabular}


No período 2000-2014, o volume de cursos de graduação da categoria 'Gerenciamento e Administração' ${ }^{4}$ cresceu 369,7\%, passando de 989 cursos em 2000 para 4.645 cursos em 2014 (4.232 cursos presenciais e 413 cursos à distância). O número de matrículas também aumentou substancialmente: 298,1\% entre os anos 2000 e 2014.

\title{
2.2. Avaliação da Educação Superior no Brasil
}

Os processos nacionais de avaliação da educação superior são coordenados, atualmente, pelo Sistema Nacional de Avaliação da Educação Superior (SINAES), instituído pela Lei $n^{\circ} 10.861$, de 14 de abril de 2004, e supervisionado pela Comissão Nacional de Avaliação da Educação Superior (CONAES).

\begin{abstract}
$\S 1^{\circ} \mathrm{O}$ SINAES tem por finalidades a melhoria da qualidade da educação superior, a orientação da expansão da sua oferta, o aumento permanente da sua eficácia institucional e efetividade acadêmica e social e, especialmente, a promoção do aprofundamento dos compromissos e responsabilidades sociais das instituições de educação superior, por meio da valorização de sua missão pública, da promoção dos valores democráticos, do respeito à diferença e à diversidade, da afirmação da autonomia e da identidade institucional. (BRASIL, 2004, Art. $1^{\circ}$ ).
\end{abstract}

O SINAES atua em cooperação com os sistemas de ensino dos Estados e do Distrito Federal e consta de três pilares: avaliação institucional, avaliação dos cursos e avaliação dos estudantes. A realização das avaliações é responsabilidade do Instituto Nacional de Estudos e Pesquisas Educacionais Anísio Teixeira (INEP), e cabe ao Ministério da Educação (MEC) tornar público e disponível os resultados das avaliações das IES e de seus cursos.

O desempenho dos estudantes é avaliado mediante a aplicação periódica do Exame Nacional de Desempenho dos Estudantes (ENADE) e cálculo do Conceito ENADE.

Em 2007, por meio da Portaria Normativa $\mathrm{n}^{\circ}$ 40, foram criados: o Conceito Preliminar de Curso (CPC), que subsidia os processos de regulação e supervisão da educação superior, contemplando o credenciamento e a renovação de credenciamento das IES, bem como a autorização, o reconhecimento e a renovação de reconhecimento dos cursos de graduação; e o Índice Geral de Cursos Avaliados da Instituição (IGC), resultado da avaliação institucional, que representa a avaliação dos cursos de graduação e de pós-graduação ofertados pela IES.

\footnotetext{
${ }^{4}$ Apêndice C - Crescimento dos cursos de graduação (Gerenciamento e Administração).
} 


\subsubsection{Exame Nacional de Desempenho dos Estudantes (ENADE)}

Realizado anualmente pelo INEP com o objetivo geral de avaliar "o desempenho dos estudantes em relação aos conteúdos programáticos previstos nas diretrizes curriculares do respectivo curso de graduação, e as habilidades e competências adquiridas em sua formação" (BRASIL, 2007), o ENADE é componente curricular obrigatório dos cursos de educação superior (BRASIL, 2004), sendo responsabilidade da IES a inscrição dos seus alunos.

Embora o ENADE seja componente curricular obrigatório, as universidades públicas estaduais têm participação facultativa. A Universidade Estadual Paulista (UNESP) participa do ENADE desde 2004 e a Universidade Estadual de Campinas (UNICAMP), desde 2010. Em 2013, a Universidade de São Paulo (USP) firmou um acordo de cooperação técnica com o INEP com duração de três anos, que prevê a adesão voluntária de seus alunos ao exame sendo que os resultados serão utilizados exclusivamente pelo INEP e pela USP para estudos internos (UNIVERSIDADE DE SÃO PAULO, 2013).

A periodicidade da avaliação do desempenho de cada área pelo ENADE é trienal. Assim, foi definido o calendário de referência para as áreas (BRASIL, 2007):

- Ano I: saúde, ciências agrárias e áreas afins;

- Ano II: ciências exatas, licenciaturas e áreas afins;

- Ano III: ciências sociais aplicadas, ciências humanas e áreas afins.

O exame é composto por 10 questões de Formação Geral (FG), elaboradas com base na matriz de referência do Exame Nacional do Ensino Médio (ENEM) e comum a todos os cursos das áreas avaliadas, e por 30 questões específicas de cada área (Componente Específico - CE), direcionadas à verificação dos conteúdos, habilidades e competências desenvolvidos durante a graduação. Além da prova, o Questionário do Estudante e o Questionário de Percepção da Prova compõem os instrumentos básicos do ENADE.

Em relação à proposta original do ENADE, houve duas mudanças relevantes: em 2009, o exame tornou-se populacional (originalmente, este era amostral) e, em 2011, os ingressantes foram dispensados da prova.

\subsubsection{Conceito ENADE}


A unidade de cálculo do Conceito ENADE é a 'Unidade de Observação', que consiste de um conjunto de cursos de determinada área, oferecidos por uma IES em um município específico.

Desde 2008, no cálculo do Conceito ENADE são considerados apenas os desempenhos médios dos concluintes, em termos dos seus resultados nas questões de Formação Geral (FG) e nas questões do Componente Específico (CE). Uma vez que a média orienta este processo, as Unidades de Observação com menos de dois concluintes participantes da edição do exame não obtém Conceito ENADE (ficam “Sem Conceito - SC").

As medidas originais de FG e de CE são padronizadas e transformadas em notas que variam de 0 (zero) a 5 (cinco), dando origem às Notas Padronizadas de Formação Geral $\left(\mathrm{NPFG}_{i}\right)$ e do Componente Específico $\left(\mathrm{NPCE}_{i}\right)$. A média ponderada destas notas padronizadas (onde $\mathrm{NPFG}_{i}$ tem peso 0,25 e NPCE $_{i}$ tem peso 0,75) resulta na Nota ENADE da Unidade de Observação $i\left(\mathrm{NC}_{i}\right)$ - uma variável contínua no intervalo entre 0 (zero) e 5 (cinco):

$$
\mathrm{NC}_{i}=\left(0,25 \cdot \mathrm{NP}_{F G i}\right)+\left(0,75 \cdot \mathrm{NP}_{C E i}\right)
$$

Para a obtenção do Conceito ENADE da Unidade de Observação, representado por um valor inteiro entre 1 (um - o resultado mais baixo) e 5 (cinco - o melhor resultado possível), é realizada a conversão das Notas ENADE $\left(\mathrm{NC}_{i}\right)$ :

Tabela 2 - Conversão das Notas ENADE em Conceito ENADE

\begin{tabular}{|c|c|}
\hline $\mathbf{N C}_{i}$ & Conceito ENADE \\
\hline $0 \leq \mathrm{NC}_{i}<0,945$ & 1 \\
\hline $0,945 \leq \mathrm{NC}_{i}<1,945$ & 2 \\
\hline $1,945 \leq \mathrm{NC}_{i}<2,945$ & 3 \\
\hline $2,945 \leq \mathrm{NC}_{i}<3,945$ & 4 \\
\hline $3,945 \leq \mathrm{NC}_{i} \leq 5$ & 5 \\
\hline
\end{tabular}

Fonte: INEP, 2013, p. 13.

\subsubsection{Conceito Preliminar de Curso (CPC)}

A partir do Conceito ENADE e das informações que constam das bases de dados do MEC, os cursos superiores são avaliados pelo indicador Conceito Preliminar de Curso (CPC), 
instituído pela Portaria Normativa $\mathrm{n}^{\circ} 4$, de 5 de agosto de 2008. Assim como para o Conceito ENADE, a unidade de cálculo do CPC é a 'Unidade de Observação'.

O CPC é calculado no ano seguinte à aplicação do ENADE, combinando as modalidades presencial e à distância e divulgando os conceitos para cada Unidade de Observação de maneira unificada (BRASIL, 2007). Em seu cálculo, diversos componentes são avaliados, além do Conceito ENADE:

- A proporção de professores vinculados à Unidade de Observação cuja titulação é igual ou superior ao Doutorado;

- A proporção de professores vinculados à Unidade de Observação cuja titulação é igual ou superior ao Mestrado;

- A proporção de professores vinculados à Unidade de Observação cujo regime de dedicação seja integral ou parcial;

- A proporção de alunos que avaliaram positivamente a infraestrutura (equipamentos e/ou materiais disponíveis);

- A proporção de alunos que avaliaram positivamente a organização didático-pedagógica (a composição dos planos de ensino apresentados pelos professores); e

- O Indicador da Diferença entre os Desempenhos Esperado e Observado (IDD).

O IDD fornece informações comparativas do desempenho médio no ENADE para cada Unidade de Observação. Resulta da diferença entre o resultado médio obtido pelos concluintes de uma Unidade de Observação $i$ e os resultados médios das demais Unidades de Observação que possuem estudantes de perfil semelhante (resultado médio esperado), com base em dados disponíveis sobre o perfil dos estudantes.

Os dados sobre o corpo docente são coletados do Sistema de Cadastro de Docentes, e os dados referentes à percepção discente são extraídos do Questionário Socioeconômico do ENADE. Os valores de cada componente são padronizados e transformados em valores entre 0 (zero) e 5 (cinco), dando origem às notas padronizadas. Uma ponderação destas notas padronizadas dos componentes gera um valor contínuo:

$$
\begin{aligned}
& \mathrm{CPC}_{i}=\left(0,35 . \mathrm{NIDD}_{i}\right)+\left(0,20 . \mathrm{NC}_{i}\right)+\left(0,15 . \mathrm{NPD}_{i}\right)+ \\
& \left(0,075 . \mathrm{NPM}_{i}\right)+\left(0,075 . \mathrm{NPR}_{i}\right)+\left(0,075 . \mathrm{NF}_{i}\right)+(0,075 . \mathrm{NO} i)
\end{aligned}
$$

Onde:

$\mathrm{CPC}_{i}$ : valor contínuo do CPC para a Unidade de Observação $i$; $\mathrm{NIDD}_{i}$ : nota padronizada do IDD para a Unidade de Observação $i$; 
$\mathrm{NC}_{i}$ : nota padronizada do IDD para a Unidade de Observação $i$;

$\mathrm{NPD}_{i}$ : nota padronizada da proporção de professores doutores para a Unidade de

Observação $i$;

$\mathrm{NPM}_{i}$ : nota padronizada da proporção de professores mestres para a Unidade de

Observação $i$;

$\mathrm{NPR}_{i}$ : nota padronizada da proporção de professores com regime de dedicação integral ou parcial para a Unidade de Observação $i$;

$\mathrm{NF}_{i}$ : nota padronizada da percepção discente sobre a infraestrutura para a Unidade de Observação $i$;

$\mathrm{NO}_{i}$ : nota padronizada percepção discente sobre a organização didático-pedagógica para a Unidade de Observação $i$;

Tabela 3 - Conversão do $\mathrm{CPC}_{i}$ (contínuo) em CPC (faixa)

\begin{tabular}{|c|c|}
\hline $\mathbf{C P C}_{\boldsymbol{i}}$ (contínuo) & $\mathbf{C P C}$ (faixa) \\
\hline $0 \leq \mathrm{CPC}_{i}<0,945$ & 1 \\
\hline $0,945 \leq \mathrm{CPC}_{i}<1,945$ & 2 \\
\hline $1,945 \leq \mathrm{CPC}_{i}<2,945$ & 3 \\
\hline $2,945 \leq \mathrm{CPC}_{i}<3,945$ & 4 \\
\hline $3,945 \leq \mathrm{CPC}_{i} \leq 5$ & 5 \\
\hline
\end{tabular}

Fonte: INEP, 2013, p. 23.

O valor de $\mathrm{CPC}_{i}$ obtido é, então, convertido em faixas que vão de 1 (um) a 5 (cinco), resultando no CPC da Unidade de Observação. Os cursos com CPC igual a 1 (um) ou 2 (dois) recebem visitas de comissões de avaliação e devem se comprometer a realizar as alterações necessárias. Por sua vez, o reconhecimento dos cursos que obtém CPC igual ou superior a 3 (três) é renovado automaticamente.

\subsection{4. Índice Geral de Cursos Avaliados da Instituição (IGC)}

O IGC é calculado para cada IES pela média ponderada dos CPCs do triênio e uma conversão dos conceitos fixados pela Coordenação de Aperfeiçoamento de Pessoal de Nível Superior (CAPES) referentes à avaliação trienal da pós-graduação stricto sensu. Os pesos de tal ponderação correspondem ao volume de matrículas da IES nos cursos de graduação e de 
pós-graduação, sendo que para as IES sem cursos de pós-graduação o IGC é a média ponderada dos cursos de graduação (INEP, 2013).

Assim como nos cálculos do Conceito ENADE e do CPC, o valor contínuo obtido $\left(\mathrm{IGC}_{\text {ies }}\right)$ varia entre 0 e 5 e é transformado em faixas com valores inteiros entre 1 (um) e 5 (cinco):

Tabela 4 - Conversão do $\operatorname{IGC}_{i e s}$ (contínuo) em IGC (faixa)

\begin{tabular}{|c|c|}
\hline $\mathbf{I G C}_{\text {ies }}$ (contínuo) & IGC (faixa) \\
\hline $0 \leq \mathrm{IGC}_{\text {ies }}<0,945$ & 1 \\
\hline $0,945 \leq \mathrm{IGC}_{i e s}<1,945$ & 2 \\
\hline $1,945 \leq \mathrm{IGC}_{i e s}<2,945$ & 3 \\
\hline $2,945 \leq \mathrm{IGC}_{i e s}<3,945$ & 4 \\
\hline $3,945 \leq \mathrm{IGC}_{i e s} \leq 5$ & 5 \\
\hline
\end{tabular}

Fonte: INEP, 2013, p. 27. 


\section{METODOLOGIA}

No Brasil, o desempenho dos estudantes dos cursos de graduação em Administração foi avaliado, até o momento, pelo ENADE 2006, pelo ENADE 2009, pelo ENADE 2012 e pelo ENADE 2015. Para o desenvolvimento deste estudo, foram adotados os resultados do ENADE 2012, pois estes eram os dados disponíveis mais recentes.

Para o ENADE 2012, foi convocada a população de alunos concluintes, regularmente inscritos pelas IES: “aqueles que tenham expectativa de conclusão do curso até julho de 2013, assim como aqueles que tiverem concluído mais de $80 \%$ (oitenta por cento) da carga horária mínima do currículo do curso da IES até o término do período de inscrições" (BRASIL, 2012). Portanto, foram dispensados os concluintes que colaram grau até 31 de agosto de 2012 e os alunos ingressantes.

O exame era composto por 10 questões de Formação Geral (8 questões objetivas e 2 discursivas) e 30 questões do Componente Específico (27 questões objetivas e 3 discursivas).

Neste capítulo, primeiramente, será descrito o processo de criação do banco de dados utilizado por este estudo. Em seguida, serão apresentadas as cinco variáveis dependentes originais, que representam objetivamente os resultados obtidos pelos concluintes dos cursos de Administração no ENADE 2012; e, será pormenorizada a análise fatorial que combinou estas para a criação de uma única variável estatística, nomeada DESEMPENHO. Por fim, são apresentadas as variáveis independentes do banco de dados.

\subsection{Criação do banco de dados}

A partir dos Microdados ENADE 2012 e dos Microdados Censo da Educação Superior 2012 (disponibilizados pelo INEP ${ }^{6}$ ), foi criado o banco de dados, cuja unidade de observação é a IES que ofereceu cursos de graduação em Administração em 2012, representada por dois ou mais concluintes com participação válida ${ }^{7}$ no ENADE 2012.

\footnotetext{
${ }^{5}$ Período de inscrições do ENADE 2012: 16 de julho a 17 de agosto de 2012 (BRASIL, 2012).

${ }^{6}$ Microdados disponíveis em: <http://portal.inep.gov.br/basica-levantamentos-acessar〉.

${ }^{7}$ Para este estudo, os critérios definidos para 'participação válida' são: a presença efetiva e a resposta a pelo menos um conjunto de questões objetivas (Formação Geral ou Componente Específico).
} 
Os Microdados ENADE 2012 indicam a inscrição de 176.254 concluintes de cursos de graduação em Administração, de 1.308 IES. No entanto, destes:

- 36.074 alunos não compareceram ao exame;

- 90 alunos estavam presentes, porém tiveram seus resultados desconsiderados devido a problemas administrativos;

- 318 alunos presentes entregaram toda a prova em branco;

- 13 alunos presentes não responderam nenhum dos conjuntos de questões objetivas (Formação Geral ou Componente Específico).

Assim, os dados dos alunos de Administração com 'participação válida' foram agregados segundo o código único de identificação da IES (padronizado pelo MEC). Em seguida, foram excluídas ${ }^{8}$ do banco de dados: as IES sem concluintes com participação válida; as IES que tiveram um único concluinte com participação válida (exclusão justificada, dado que as variáveis dependentes do banco de dados são médias); e, as IES que não constavam nos Microdados do Censo da Educação Superior 2012. Como resultado, o banco de dados criado para este estudo contempla 139.620 concluintes de cursos de graduação em Administração (79,21\% do total de alunos inscritos), de 1.290 IES.

Este banco de dados foi utilizado para a criação dos modelos de regressão múltipla “técnica estatística multivariada usada para examinar a relação entre uma única variável dependente e um conjunto de variáveis independentes" (HAIR Jr. et al., 2009, p. 163) -, conforme os objetivos desta pesquisa. Portanto, as suas variáveis foram divididas entre:

- Variáveis dependentes, que representam os resultados obtidos pelos concluintes dos cursos de Administração no ENADE 2012; e

- Variáveis independentes, que retratam as características dos corpos docentes e das IES.

\subsection{Variáveis dependentes}

A partir dos Microdados ENADE 2012, foram criadas cinco variáveis dependentes, que representam o efetivo desempenho dos concluintes de Administração de cada IES que compõe o banco de dados: Nota_Obj_FG, Nota_FG, Nota_Obj_CE, Nota_CE e Nota_Geral.

\footnotetext{
${ }^{8}$ As IES excluídas do banco de dados estão descritas no Apêndice D.
} 
Quadro 2 - Variáveis dependentes

\begin{tabular}{|l|l|l|}
\hline Variável & Escala & Descrição \\
\hline Nota_Obj_FG & Razão & $\begin{array}{l}\text { Média da nota dos concluintes de Administração na prova objetiva de } \\
\text { Formação Geral }\end{array}$ \\
\hline Nota_FG & Razão & $\begin{array}{l}\text { Média ponderada da nota dos concluintes de Administração na prova } \\
\text { objetiva (60\%) e na prova discursiva (40\%) de Formação Geral }\end{array}$ \\
\hline Nota_Obj_CE & Razão & $\begin{array}{l}\text { Média da nota dos concluintes de Administração na prova objetiva do } \\
\text { Componente Específico }\end{array}$ \\
\hline Nota_CE & Razão & $\begin{array}{l}\text { Média ponderada da nota dos concluintes de Administração na prova } \\
\text { objetiva (85\%) e na prova discursiva (15\%) do Componente Específico }\end{array}$ \\
\hline Nota_Geral & Razão & $\begin{array}{l}\text { Média ponderada da nota dos concluintes de Administração nas provas } \\
\text { objetivas e discursivas de Formação Geral (25\%) e do Componente } \\
\text { Específico (75\%) }\end{array}$ \\
\hline
\end{tabular}

As variáveis Nota_Obj_FG e Nota_Obj_CE representam, para cada IES, a média da nota dos concluintes dos cursos de Administração nas 8 questões objetivas de Formação Geral e nas 27 questões objetivas do Componente Específico, respectivamente.

As variáveis Nota_FG e Nota_CE são médias ponderadas das questões objetivas e discursivas de cada prova - em Nota_FG, as 8 questões objetivas de Formação Geral (Nota_Obj_FG) têm peso 60\%, enquanto as 2 questões discursivas têm peso $40 \%$; já, em Nota_CE, as 27 questões objetivas do Componente Específico (Nota_Obj_CE) têm peso 85\% e as 3 questões discursivas têm peso $15 \%$.

O cálculo das variáveis Nota_Obj_FG e Nota_FG para cada IES considerou apenas os resultados dos concluintes que efetivamente responderam as questões objetivas de Formação Geral; de maneira similar, o cálculo de Nota_Obj_CE e Nota_CE considerou somente os resultados dos concluintes que efetivamente responderam as questões objetivas do Componente Específico.

Para o cálculo de Nota_Geral, foram admitidos apenas os resultados dos concluintes que efetivamente responderam as questões objetivas de Formação Geral e as questões objetivas do Componente Específico. O valor desta variável para cada IES resulta da média ponderada entre Nota_CE (peso 75\%) e Nota_FG (peso 25\%) obtidas pelos concluintes que cumpriram os requisitos de participação citados.

Logo, é possível afirmar que existe alguma estrutura subjacente neste conjunto de variáveis dependentes - suposição conceitual básica para o desenvolvimento de uma análise fatorial (HAIR Jr. et al., 2005, p. 109) - uma vez que existem relações intrínsecas entre elas. 


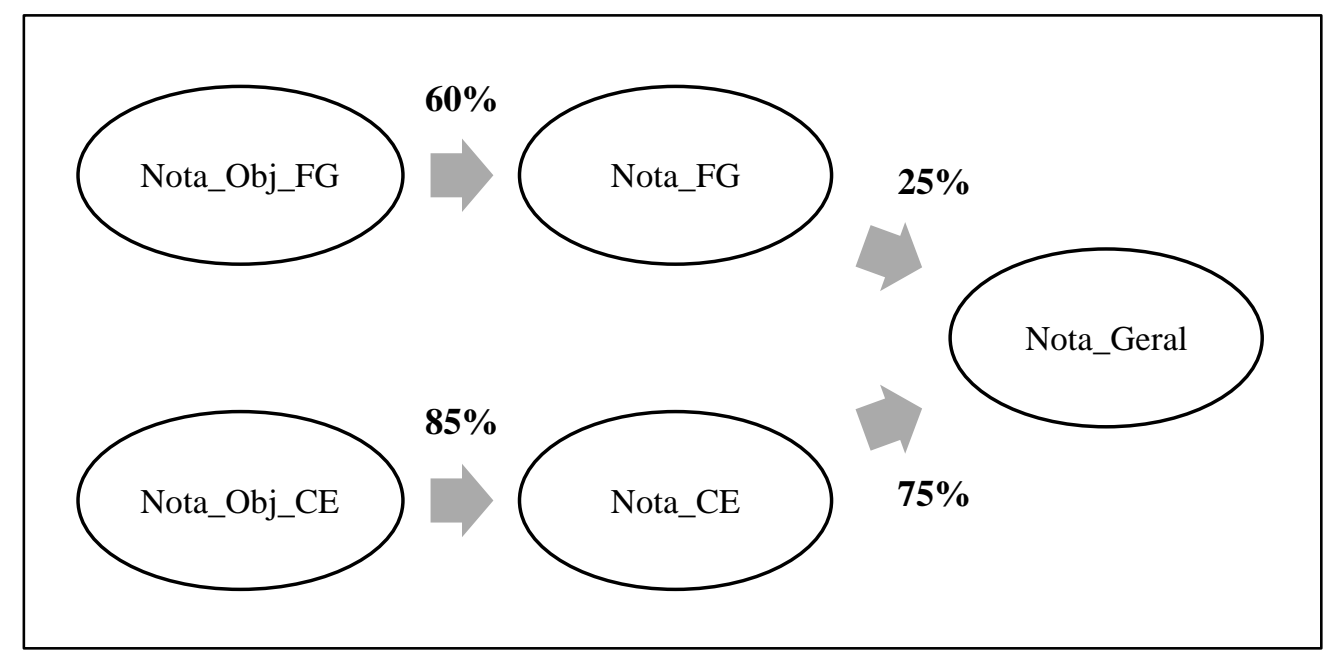

Figura 1 - Relações entre as variáveis dependentes

As cinco variáveis dependentes têm 100\% dos valores válidos (nenhum dado ausente), e desvios padrão aparentemente semelhantes. Analisando os valores de assimetria e curtose ${ }^{9}$, nenhuma das variáveis dependentes parece ter distribuição normal. O teste não paramétrico de adesão à normal Kolmogorov-Smirnov corrobora tal característica ao rejeitar H0 ('H0: A distribuição da variável é normal') para as cinco variáveis dependentes.

\section{Estatísticas}

\begin{tabular}{|c|c|c|c|c|c|c|}
\hline & & Nota_Obj_FG & Nota_FG & Nota_Obj_CE & Nota_CE & Nota_Geral \\
\hline \multirow[t]{2}{*}{$N$} & Válido & 1290 & 1290 & 1290 & 1290 & 1290 \\
\hline & Ausente & 0 & 0 & 0 & 0 & 0 \\
\hline \multicolumn{2}{|c|}{ Média } & 45,984446 & 43,330370 & 35,312839 & 32,293370 & 35,066547 \\
\hline \multicolumn{2}{|c|}{ Modelo padrão } & 5,2791257 & 4,8196189 & 6,3769407 & 6,0555046 & 5,5101732 \\
\hline \multicolumn{2}{|c|}{ Assimetria } &, 284 &, 051 & 1,172 & 1,176 & ,994 \\
\hline \multicolumn{2}{|c|}{ Kurtosis } & 1,468 & 1,397 & 1,896 & 2,036 & 1,612 \\
\hline
\end{tabular}

Tests of Normality

\begin{tabular}{|l|r|r|r|r|r|r|}
\hline & \multicolumn{3}{|c|}{ Kolmogorov-Smirnov $^{\text {a }}$} & \multicolumn{3}{|c|}{ Shapiro-Wilk } \\
\cline { 2 - 7 } & Estatistica & \multicolumn{1}{|c|}{ df } & \multicolumn{1}{c|}{ Sig. } & Estatistica & \multicolumn{1}{c|}{ df } & \multicolumn{1}{c|}{ Sig. } \\
\hline Nota_Obj_FG &, 044 & 1290 &, 000 &, 986 & 1290 &, 000 \\
Nota_FG &, 034 & 1290 &, 002 &, 988 & 1290 &, 000 \\
Nota_Obj_CE &, 097 & 1290 &, 000 &, 928 & 1290 &, 000 \\
Nota_CE &, 093 & 1290 &, 000 &, 929 & 1290 &, 000 \\
Nota_Geral &, 086 & 1290 &, 000 &, 946 & 1290 &, 000 \\
\hline
\end{tabular}

a. Lilliefors Significance Correction

\footnotetext{
${ }^{9} \mathrm{O}$ Apêndice E contém os histogramas que representam a distribuição destas variáveis.
} 
Como as variáveis dependentes não são normalmente distribuídas, o coeficiente de correlação de ordem de ranqueamento de Spearman, uma estatística mais conservadora (HAIR Jr. et al., 2005, p. 317), foi empregado na análise de correlações entre estas variáveis:

\section{Correlações}

\begin{tabular}{|c|c|c|c|c|c|c|}
\hline & \multicolumn{5}{|c|}{ Rô de Spearman } \\
\hline & & $\begin{array}{c}\text { Nota_Obj } \\
\text { FG }\end{array}$ & Nota_FG & $\begin{array}{c}\text { Nota_Obj } \\
\text { _CE }\end{array}$ & Nota_CE & Nota_Geral \\
\hline \multirow[t]{3}{*}{ Nota_Obj_FG } & $\begin{array}{l}\text { Correlações de } \\
\text { coeficiente }\end{array}$ & 1,000 & $859^{n x}$ &, $676^{\mathrm{N}}$ &, $674^{x \times}$ &, $748^{\star x}$ \\
\hline & Sig. (2 extremidades) & &, 000 &, 000 &, 000 &, 000 \\
\hline & N & 1290 & 1290 & 1290 & 1290 & 1290 \\
\hline \multirow[t]{3}{*}{ Nota_FG } & $\begin{array}{l}\text { Correlações de } \\
\text { coeficiente }\end{array}$ & $859^{\mathrm{k}}$ & 1,000 &, $722^{\star \pi}$ &, $754^{\pi x}$ & $846^{\star \pi}$ \\
\hline & Sig. (2 extremidades) &, 000 & &, 000 &, 000 &, 000 \\
\hline & $N$ & 1290 & 1290 & 1290 & 1290 & 1290 \\
\hline \multirow[t]{3}{*}{ Nota_Obj_CE } & $\begin{array}{l}\text { Correlações de } \\
\text { coeficiente }\end{array}$ &, $676^{\mathrm{x}}$ &, $722^{\mathrm{n}}$ & 1,000 &, $992^{\times \star}$ &, $971^{\star \star}$ \\
\hline & Sig. (2 extremidades) &, 000 &, 000 & &, 000 &, 000 \\
\hline & N & 1290 & 1290 & 1290 & 1290 & 1290 \\
\hline \multirow[t]{3}{*}{ Nota_CE } & $\begin{array}{l}\text { Correlações de } \\
\text { coeficiente }\end{array}$ & $674^{\mathrm{n}}$ &, $754^{\pi x}$ &, $992^{\star x}$ & 1,000 &, $986^{* \pi}$ \\
\hline & Sig. (2 extremidades) &, 000 & .000 &, 000 & &, 000 \\
\hline & $\mathrm{N}$ & 1290 & 1290 & 1290 & 1290 & 1290 \\
\hline \multirow[t]{3}{*}{ Nota_Geral } & $\begin{array}{l}\text { Correlações de } \\
\text { coeficiente }\end{array}$ &, $748^{* \times}$ & $846^{\mathrm{N}}$ &, $971^{\kappa \times}$ &, $986^{\pi x}$ & 1,000 \\
\hline & Sig. (2 extremidades) &, 000 &, 000 &, 000 & .000 & \\
\hline & $\mathrm{N}$ & 1290 & 1290 & 1290 & 1290 & 1290 \\
\hline
\end{tabular}

**. A correlação é significativa no nivel 0,01 (2 extremidades)

Todas as correlações são estatisticamente significantes, positivas e, no mínimo, moderadas; sendo que as três correlações bivariadas entre Nota_Geral, Nota_CE e Nota_Obj_CE são 'muito fortes' e a variável Nota_FG tem correlações 'altas' com todas as outras variáveis dependentes.

Apesar da variável Nota_Obj_FG não se relacionar conceitualmente (Figura 1) com as variáveis Nota_Obj_CE e Nota_CE, existem correlações moderadas entre elas $(0,676$ e 0,674, respectivamente). Desta forma, é possível inferir que alunos com bom desempenho nas questões objetivas de Formação Geral também têm bom desempenho nas questões objetivas do Componente Específico ${ }^{10}$ (e vice-versa).

\footnotetext{
${ }^{10}$ Questões objetivas do Componente Específico representam 85\% de Nota_CE.
} 


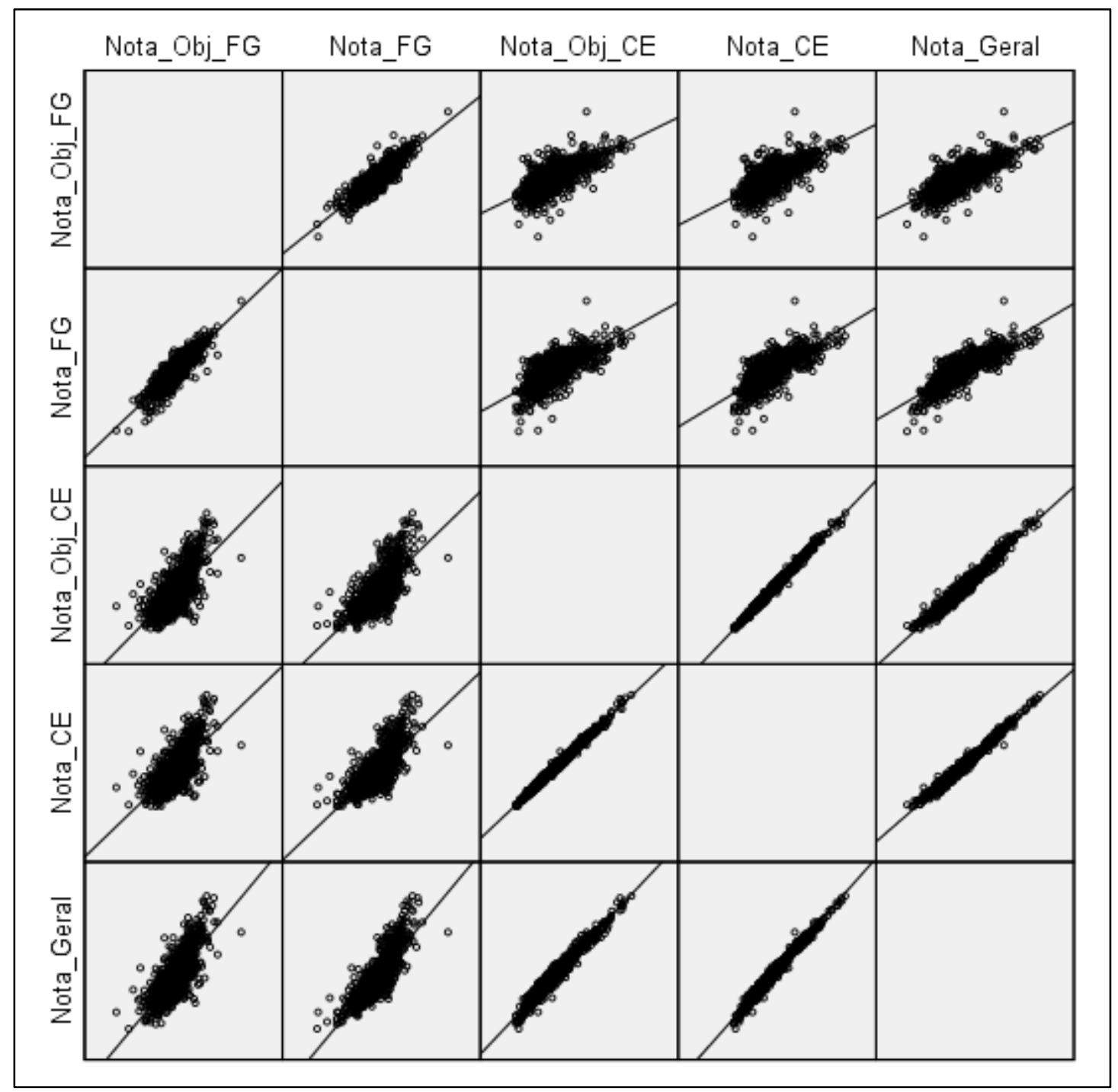

Figura 2 - Diagramas de dispersão das variáveis dependentes

Uma destas cinco variáveis dependentes poderia ser simplesmente adotada para o desenvolvimento dos modelos de regressão múltipla que compõem este estudo. Ao invés disso, considerando todos estes indicadores de desempenho igualmente importantes, uma análise fatorial foi desenvolvida com o objetivo de criar uma nova medida composta que reduza, de forma objetiva e imparcial, os dados das cinco variáveis dependentes originais.

As observações atípicas não foram eliminadas, com o objetivo de garantir generalidade. Quanto à violação das suposições de normalidade, “[...] em análise fatorial as preocupações que se impõem se centram muito mais no caráter e na composição das variáveis incluídas na análise do que em suas qualidades estatísticas" (HAIR Jr. et al., 2005, p. 109). Além disso, o tamanho da amostra (1.290 IES) permite aproximar as distribuições das variáveis à distribuição normal, segundo o teorema do limite central (ANDERSON; SWEENEY; WILLIAMS, 2011, p. 355). 


\subsubsection{Análise fatorial das variáveis dependentes}

O objetivo desta análise fatorial é condensar a informação contida nas cinco variáveis dependentes originais em uma única variável estatística (um único fator), a partir da identificação da estrutura subjacente dos dados, a fim de representar o desempenho discente dos concluintes dos cursos de graduação em Administração no ENADE 2012.

Quanto ao tamanho da amostra, a recomendação da proporção de dez observações para cada variável (HAIR Jr. et al., 2005, p. 108) é atendida, com uma proporção casos-porvariável igual a 258. Tal valor também minimiza as chances de superajustamento dos dados.

Tendo atestado, anteriormente, que as cinco variáveis dependentes apresentam um número substancial de correlações significantes e maiores que 0,3 , serão analisadas outras medidas de adequação da análise fatorial: o teste de esfericidade de Bartlett e a medida de adequação da amostra (MSA). O teste de esfericidade de Bartlett "fornece a significância estatística de que a matriz de correlação tem correlações significantes entre pelo menos algumas das variáveis" (HAIR Jr. et al., 2005, p. 110); enquanto a MSA quantifica o grau de intercorrelações entre as variáveis.

Teste de KMO e Bartlett

\begin{tabular}{|c|c|c|}
\hline \multicolumn{2}{|c|}{$\begin{array}{l}\text { Medida Kaiser-Meyer-Olkin de adequação de } \\
\text { amostragem. }\end{array}$} & ,687 \\
\hline \multirow{3}{*}{$\begin{array}{l}\text { Teste de esfericidade de } \\
\text { Bartlett }\end{array}$} & Qui-quadrado aprox. & 24732,552 \\
\hline & & 10 \\
\hline & Sig. &, 000 \\
\hline
\end{tabular}

Matrizes anti-imagem

\begin{tabular}{|l|r|r|r|r|r|}
\hline & \multicolumn{6}{|c|}{ Correlação anti-imagem } \\
\cline { 2 - 6 } & Nota_Obj_FG & Nota_FG & Nota_Obj_CE & Nota_CE & Nota_Geral \\
\hline Nota_Obj_FG &, $911^{\mathrm{a}}$ &, 038 &,- 468 &, 073 &,- 059 \\
Nota_FG &, 038 &, $564^{\mathrm{a}}$ &,- 009 &, 999 & $-1,000$ \\
Nota_Obj_CE &,- 468 &,- 009 &, $931^{\mathrm{a}}$ &,- 053 &, 023 \\
Nota_CE &, 073 &, 999 &,- 053 &, $602^{\mathrm{a}}$ & $-1,000$ \\
Nota_Geral &,- 059 & $-1,000$ &, 023 & $-1,000$ &, $618^{\text {a }}$ \\
\hline
\end{tabular}

a. Medidas de adequação de amostragem (MSA) 
O resultado significante do teste de esfericidade de Bartlett $(0,000)$ indica que existem correlações suficientes entre as variáveis. O valor da medida Kaiser-Meyer-Olkin (KMO) de adequação de amostra $(0,687)$ é superior a 0,5 , como recomendado (HAIR Jr. et al., 2005, p. 110). Os valores de MSA para cada variável (presentes na diagonal da matriz de correlação anti-imagem) são todos superiores a 0,5. Assim, não é necessária a exclusão de nenhuma variável e é permitido proceder com a análise fatorial.

O método de análise de componentes principais, que foca "[...] o número mínimo de fatores necessários para explicar a porção máxima da variância total representada no conjunto original de variáveis" (HAIR Jr. et al., 2005, p. 112), foi adotado para o desenvolvimento desta análise fatorial, dado o seu objetivo de buscar uma solução que resulte em um único fator para representar adequadamente o conjunto de variáveis dependentes.

Logo, é realizada a extração dos fatores iniciais não-rotacionados, que explora as possibilidades de redução dos dados e explicita uma estimativa preliminar do número de fatores a extrair.

Variância total explicada

\begin{tabular}{|l|r|r|r|r|r|r|}
\hline \multirow{2}{*}{ Componente } & \multicolumn{4}{|c|}{ Valores próprios iniciais } & \multicolumn{3}{c|}{$\begin{array}{c}\text { Somas de extração de } \\
\text { carregamentos ao quadrado }\end{array}$} \\
\cline { 2 - 7 } & Total & $\begin{array}{c}\text { \% de } \\
\text { variância }\end{array}$ & $\begin{array}{c}\% \\
\text { cumulativa }\end{array}$ & Total & $\begin{array}{c}\% \text { de } \\
\text { variância }\end{array}$ & $\begin{array}{c}\% \\
\text { cumulativa }\end{array}$ \\
\hline 1 & 4,346 & 86,928 & 86,928 & 4,346 & 86,928 & 86,928 \\
2 &, 519 & 10,386 & 97,314 & & & \\
3 &, 129 & 2,582 & 99,896 & & & \\
4 &, 005 &, 104 & 100,000 & & & \\
5 &, 000 &, 000 & 100,000 & & & \\
\hline
\end{tabular}

Método de extração: análise do componente principal.

Segundo o critério de raiz latente, somente os fatores que apresentam autovalor maior que 1,0 são significantes. O modelo resultou em um único fator, o qual conquistou um percentual da variância total extraída de aproximadamente $86,93 \%$. Tal solução é satisfatória, considerando o valor de referência de 60\% (HAIR Jr. et al., 2005, p. 114).

A matriz não-rotacionada apresenta as cargas fatoriais (o grau de associação de cada variável com o fator). Neste modelo, todas as cargas apresentam valores maiores que $\pm 0,50$ e, portanto, são significantes. 
Matriz de componente ${ }^{\mathrm{a}}$

\begin{tabular}{|l|r|}
\hline & Componente \\
\cline { 2 - 2 } & 1 \\
\hline Nota_Obj_FG &, 862 \\
Nota_FG &, 898 \\
Nota_Obj_CE &, 952 \\
Nota_CE &, 958 \\
Nota_Geral &, 986 \\
\hline \multicolumn{2}{|c|}{ Método de extração: Análise } \\
do Componente principal.
\end{tabular}

a. 1 componentes extraídos.

As comunalidades representam a quantia de variância explicada pela solução fatorial para cada variável. Como todos os valores expostos são maiores que 0,50 , nenhuma ação corretiva é necessária (HAIR Jr. et al., 2005, p. 121), pois as variáveis dependentes originais têm níveis de explicação suficientes.

\section{Comunalidades}

\begin{tabular}{|l|c|r|}
\hline & Inicial & Extração \\
\hline Nota_Obj_FG & 1,000 &, 744 \\
Nota_FG & 1,000 &, 807 \\
Nota_Obj_CE & 1,000 &, 906 \\
Nota_CE & 1,000 &, 918 \\
Nota_Geral & 1,000 &, 972 \\
\hline
\end{tabular}

Finalmente, para a redução de dados foi escolhido o método de escores fatoriais, computado com base nas cargas fatoriais de todas as variáveis no fator e calculados pelo método da regressão. As cargas dos fatores são divididas pelos coeficientes de correlação, controlando a variância das variáveis originais, o que resulta em valores de ponderação menores. "Essa técnica de produzir escores de fatores assegura que os resultados tenham uma média de 0 e uma variância igual ao quadrado do coeficiente de correlação múltipla entre os escores dos fatores estimados e os verdadeiros valores dos fatores" (FIELD, 2009, p. 560) 


Matriz de coeficiente de
pontuação de componente
\begin{tabular}{|l|r|}
\hline \multicolumn{1}{|c|}{} & Componente \\
\cline { 2 - 2 } & 1 \\
\hline Nota_Obj_FG &, 198 \\
Nota_FG &, 207 \\
Nota_Obj_CE &, 219 \\
Nota_CE &, 220 \\
Nota_Geral &, 227 \\
\hline
\end{tabular}
Método de extração: Análise
do Componente principal.

Os escores dos fatores representam um escore múltiplo para cada indivíduo em um fator particular. Assim, o objetivo de redução dos dados das cinco variáveis dependentes originais foi alcançado, e as análises multivariadas subsequentes utilizarão os escores do fator criado, denominado DESEMPENHO.

\subsubsection{Análise do fator DESEMPENHO}

Uma vez que o fator foi criado pelo método de regressão, são verificadas a média 0 (zero) e a variância 1 (um). A distribuição é leptocúrtica (pontiaguda, dado que o valor de curtose é positivo) e deslocada à esquerda (dado que o valor de assimetria também é positivo).

Estatísticas

\begin{tabular}{|c|c|c|}
\hline \multicolumn{3}{|c|}{ DESEMPENHO } \\
\hline N & Válido & 1290 \\
\hline & Ausente & 0 \\
\hline Mé & &, 0000000 \\
\hline Mo & padrão & 1,00000000 \\
\hline As: & & 839 \\
\hline Ku & & 1,326 \\
\hline Mír & & $-3,13838$ \\
\hline Má & & 4,02469 \\
\hline
\end{tabular}

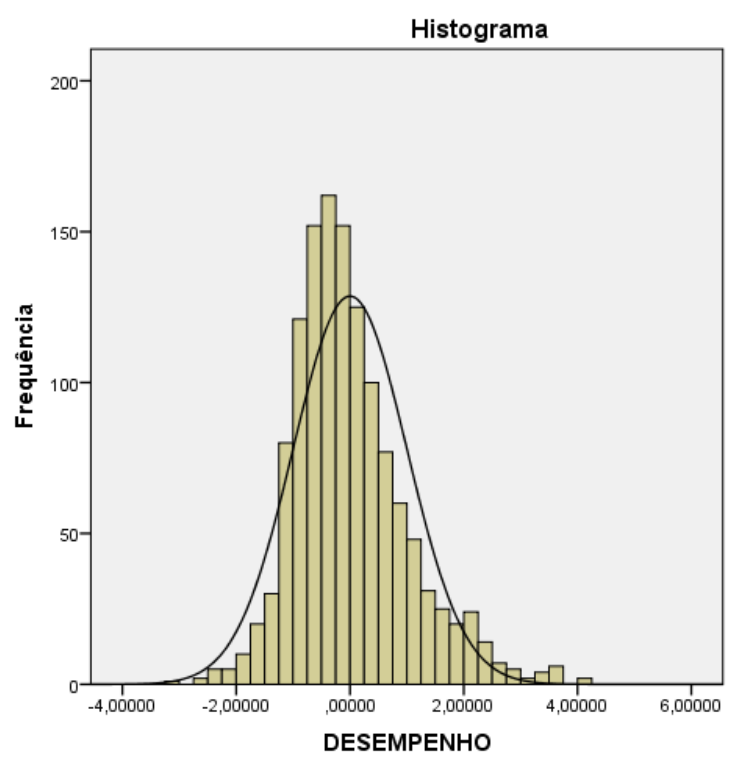


O teste de Komogorov-Smirnov e a análise visual do gráfico de probabilidade normal $^{11}$ atestam que a distribuição da variável DESEMPENHO difere da normal.

Tests of Normality

\begin{tabular}{|c|r|c|c|c|c|c|}
\hline & \multicolumn{3}{|c|}{ Kolmogorov-Smirnov $^{\text {a }}$} & \multicolumn{3}{|c|}{ Shapiro-Wilk } \\
\cline { 2 - 7 } & Estatística & \multicolumn{1}{|c|}{ df } & \multicolumn{1}{c|}{ Sig. } & Estatística & df & Sig. \\
\hline DESEMPENHO &, 080 & 1290 &, 000 &, 959 & 1290 &, 000 \\
\hline
\end{tabular}

a. Lilliefors Significance Correction

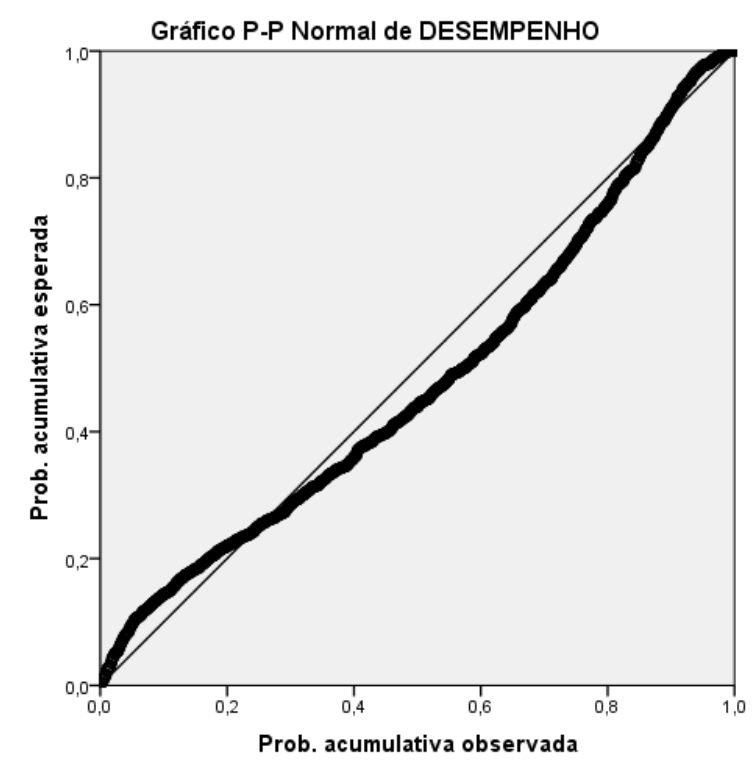

\subsection{Variáveis independentes métricas}

As 12 (doze) variáveis independentes métricas do banco de dados, criadas a partir dos Microdados Censo da Educação Superior 2012, representam as características da IES (N_Cursos e N_Concl) e do corpo docente das IES (Doc_EmEx_Curso, Doc_Espec, Doc_Mest, Doc_Dout, Doc_MestDout, Doc_Hor, Doc_Parc, Doc_Integ_excl, Doc_Integ_sem_excl e Doc_Integral).

\footnotetext{
${ }^{11}$ Gráfico de probabilidade normal: "Na representação gráfica da probabilidade normal, a distribuição é representada por uma reta inclinada em 45 graus. A distribuição real é comparada com essa reta de maneira que diferenças são mostradas como desvios da reta, tornando a identificação de diferenças bastante visível e interpretável." (HAIR Jt. et al., 2009, p. 51).
} 
Quadro 3 - Variáveis independentes métricas

\begin{tabular}{|c|c|c|}
\hline Variável & Escala & Descrição \\
\hline N_Cursos & Razão & Total de cursos oferecidos pela IES \\
\hline N_Concl & Razão & Concluintes de Administração inscritos no ENADE 2012 \\
\hline Doc_EmEx_Curso & Razão & $\begin{array}{l}\text { Proporção de docentes da IES ‘em exercício' pelo total de } \\
\text { cursos ofertados pela IES }\end{array}$ \\
\hline Doc_Espec & Razão & $\begin{array}{l}\text { Proporção de docentes da IES 'em exercício' com nível de } \\
\text { escolaridade correspondente à 'Especialização' }\end{array}$ \\
\hline Doc_Mest & Razão & $\begin{array}{l}\text { Proporção de docentes da IES 'em exercício' com nível de } \\
\text { escolaridade correspondente a 'Mestrado' }\end{array}$ \\
\hline Doc_Dout & Razão & $\begin{array}{l}\text { Proporção de docentes da IES 'em exercício' com nível de } \\
\text { escolaridade correspondente a 'Doutorado' }\end{array}$ \\
\hline Doc_MestDout & Razão & $\begin{array}{l}\text { Proporção de docentes da IES ‘em exercício' com nível de } \\
\text { escolaridade correspondente à 'Stricto Sensu' } \\
\text { Escala múltipla, criada a partir da soma das variáveis originais: } \\
\text { - Doc_Mest (Proporção de docentes da IES ‘em exercício' com } \\
\text { nível de escolaridade correspondente a 'Mestrado'); e } \\
\text { - Doc_Dout (Proporção de docentes da IES ‘em exercício' com } \\
\text { nível de escolaridade correspondente a 'Doutorado'). }\end{array}$ \\
\hline Doc_Hor & Razão & $\begin{array}{l}\text { Proporção de docentes da IES 'em exercício' com regime } \\
\text { de trabalho 'Horista' }\end{array}$ \\
\hline Doc_Parc & Razão & $\begin{array}{l}\text { Proporção de docentes da IES 'em exercício' com regime } \\
\text { de trabalho 'Parcial' }\end{array}$ \\
\hline Doc_Integ_excl & Razão & $\begin{array}{l}\text { Proporção de docentes da IES 'em exercício' com regime } \\
\text { de trabalho 'Integral com dedicação exclusiva' }\end{array}$ \\
\hline Doc_Integ_sem_excl & Razão & $\begin{array}{l}\text { Proporção de docentes da IES ‘em exercício’ com regime } \\
\text { de trabalho ‘Integral sem dedicação exclusiva' }\end{array}$ \\
\hline Doc_Integral & Razão & $\begin{array}{l}\text { Proporção de docentes da IES ‘em exercício' com regime } \\
\text { de trabalho 'Integral' } \\
\text { Escala múltipla, criada a partir da soma das variáveis originais: } \\
\text { - Doc_Integ_excl (Proporção de docentes da IES 'em exercício' } \\
\text { com regime de trabalho 'Integral com dedicação exclusiva'); e } \\
\text { - Doc_Integ_sem_excl (Proporção de docentes da IES 'em } \\
\text { exercício' com regime de trabalho 'Integral sem dedicação } \\
\text { exclusiva'). }\end{array}$ \\
\hline
\end{tabular}

Assim, tem-se: duas variáveis relacionadas ao "tamanho" da IES (N_Cursos e N_Concl); uma variável relacionada à quantidade relativa de docentes em exercício (Doc_EmEx_Curso); quatro variáveis relacionadas ao nível de escolaridade do corpo docente (Doc_Espec, Doc_Mest, Doc_Dout e Doc_MestDout); e, cinco variáveis relacionadas ao regime de trabalho do corpo docente (Doc_Hor, Doc_Parc, Doc_Integ_excl, Doc_Integ_sem_excl e Doc_Integral)

A variável Doc_EmEx_Curso denota a razão, para cada IES, entre o número total de docentes 'em exercício' no ano de 2012 e o número total de cursos de graduação oferecidos 
no ano de 2012 (independente da área do conhecimento). Estes dados foram extraídos dos Microdados Censo da Educação Superior 2012 (tabelas Docentes e Cursos), não sendo possível vincular, com precisão, cada docente a um curso específico. Assim, esta variável é uma proxy do número de docentes 'em exercício' dos cursos de Administração da IES.

Estatísticas

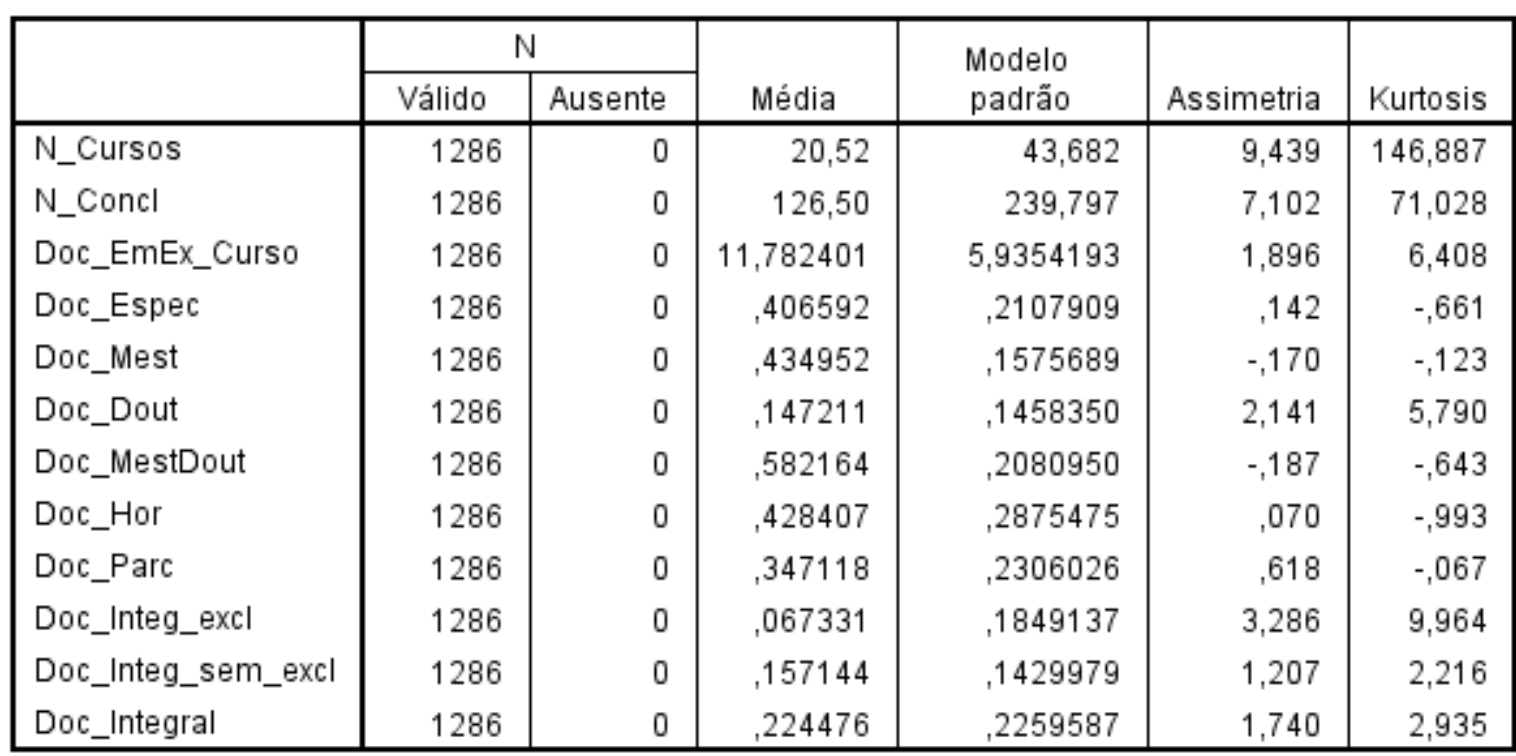

Com o objetivo de garantir a generalidade do estudo, foi realizada uma análise de observações atípicas (outliers) bastante conservadora, uma vez que os dados refletem a realidade das IES que oferecem cursos de graduação em Administração. Após a padronização das variáveis foram encontradas 4 IES com valores extremos para N_Concl (18,278 e 17,785) e para Doc_EmEx_Curso $\left(18,510\right.$ e 9,739). Assim, estas IES foram removidas ${ }^{12}$ do banco de dados, pois distorceriam as análises estatísticas.

Sendo o tamanho da amostra (1.286 IES) suficientemente grande, o teorema do limite central permite concluir que as distribuições das variáveis ${ }^{13}$ podem ser aproximadas a distribuições normais (ANDERSON; SWEENEY; WILLIAMS, 2011, p. 355), apesar da nãosignificância do teste não paramétrico de aderência à normal Kolmogorov-Smirnov.

\footnotetext{
${ }^{12}$ As quatro IES excluídas estão descritas no Apêndice D.

${ }^{13}$ Histogramas e gráficos de probabilidade normal das variáveis independentes estão disponíveis no Apêndice F.
} 
Tests of Normality

\begin{tabular}{|l|r|r|r|r|r|r|}
\hline \multirow{2}{*}{} & \multicolumn{3}{|c|}{ Kolmogorov-Smirnov $^{\text {a }}$} & \multicolumn{3}{c|}{ Shapiro-Wilk } \\
\cline { 2 - 7 } & Estatística & df & \multicolumn{1}{c|}{ Sig. } & Estatística & df & Sig. \\
\hline N_Cursos &, 328 & 1286 &, 000 &, 387 & 1286 &, 000 \\
N_Concl &, 302 & 1286 &, 000 &, 403 & 1286 &, 000 \\
Doc_EmEx_Curso &, 107 & 1286 &, 000 &, 868 & 1286 &, 000 \\
Doc_Espec &, 038 & 1286 &, 000 &, 987 & 1286 &, 000 \\
Doc_Mest &, 034 & 1286 &, 001 &, 995 & 1286 &, 000 \\
Doc_Dout &, 156 & 1286 &, 000 &, 796 & 1286 &, 000 \\
Doc_MestDout &, 039 & 1286 &, 000 &, 987 & 1286 &, 000 \\
Doc_Hor &, 072 & 1286 &, 000 &, 956 & 1286 &, 000 \\
Doc_Parc &, 066 & 1286 &, 000 &, 962 & 1286 &, 000 \\
Doc_Integ_excl &, 358 & 1286 &, 000 &, 414 & 1286 &, 000 \\
Doc_Integ_sem_excl &, 136 & 1286 &, 000 &, 898 & 1286 &, 000 \\
Doc_Integral &, 160 & 1286 &, 000 &, 811 & 1286 &, 000 \\
\hline
\end{tabular}

a. Lilliefors Significance Correction

O coeficiente de correlação de ordem de ranqueamento de Spearman foi utilizado para a análise de correlações entre as variáveis métricas independentes e a variável dependente (DESEMPENHO) ${ }^{14}$.

Correlações

\begin{tabular}{|l|r|r|}
\hline \multirow{2}{*}{} & \multicolumn{2}{|c|}{ Rô de Spearman } \\
\cline { 2 - 3 } & \multicolumn{2}{|c|}{ DESEMPENHO } \\
\cline { 2 - 3 } & $\begin{array}{c}\text { Correlações } \\
\text { de coeficiente }\end{array}$ & $\begin{array}{c}\text { Sig. (2 } \\
\text { extremidades) }\end{array}$ \\
\hline DESEMPENHO & 1,000 & $\cdot$ \\
N_Cursos &, 228 &, 000 \\
N_Concl &, 016 &, 558 \\
Doc_EmEx_Curso &, 146 &, 000 \\
Doc_Espec &,- 325 &, 000 \\
Doc_Mest &, 091 &, 001 \\
Doc_Dout &, 277 &, 000 \\
Doc_MestDout &, 308 &, 000 \\
Doc_Hor &,- 132 &, 000 \\
Doc_Parc &,- 128 &, 000 \\
Doc_Integ_excl &, 151 &, 000 \\
Doc_Integ_sem_excl &, 090 &, 001 \\
Doc_Integral &, 208 &, 000 \\
\hline
\end{tabular}

\footnotetext{
${ }^{14}$ Diagramas de dispersão disponíveis no Apêndice G.
} 
Das doze variáveis independentes, apenas N_Concl não tem correlação significante com a variável dependente. Foram identificadas cinco correlações pequenas (com Doc_Espec, Doc_MestDout, Doc_Dout, N_Cursos e Doc_Integral) e sete correlações leves (Doc_Integ_excl, Doc_EmEx_Curso, Doc_Hor, Doc_Parc, Doc_Mest, Doc_Integ_sem_excl e N_Concl).

Dentre as correlações significantes entre as variáveis independentes e a variável DESEMPENHO, somente três são negativas: Doc_Espec $(-0,325)$, Doc_Hor $(-0,132)$ e Doc_Parc $(-0,128)$.

Quadro 4 - Correlações entre as variáveis independentes

\begin{tabular}{|c|c|c|c|}
\hline Variável & Variável & Coeficiente & $\begin{array}{c}\text { Força de } \\
\text { associação }\end{array}$ \\
\hline Doc_MestDout & Doc_Espec & $-0,990$ & Muito forte \\
\hline Doc_Integral & Doc_Integ_sem_excl & 0,805 & Alta \\
\hline Doc_Espec & Doc_Dout & $-0,729$ & Alta \\
\hline Doc_MestDout & Doc_Dout & 0,724 & Alta \\
\hline Doc_MestDout & Doc_Mest & 0,717 & Alta \\
\hline Doc_Espec & Doc_Mest & $-0,689$ & Moderada \\
\hline Doc_Hor & Doc_Integral & $-0,639$ & Moderada \\
\hline Doc_Hor & Doc_Parc & $-0,621$ & Moderada \\
\hline N_Cursos & N_Concl & 0,568 & Moderada \\
\hline N_Cursos & Doc_Integral & 0,492 & Moderada \\
\hline Doc_Hor & Doc_Integ_sem_excl & $-0,477$ & Moderada \\
\hline N_Cursos & Doc_Dout & 0,470 & Moderada \\
\hline N_Cursos & Doc_Integ_sem_excl & 0,427 & Moderada \\
\hline Doc_Dout & Doc_Integral & 0,401 & Moderada \\
\hline
\end{tabular}

Dentre as 56 correlações significantes entre as variáveis independentes, foram identificadas: uma correlação muito forte, quatro correlações fortes, nove correlações moderadas, 20 correlações pequenas e 21 correlações leves.

As correlações altas entre as variáveis Doc_MestDout, Doc_Mest e Doc_Dout já eram esperadas, uma vez que Doc_MestDout é uma escala múltipla, criada a partir da soma destas outras duas variáveis independentes. De maneira semelhante, a correlação alta e positiva entre Doc_Integral e Doc_Integ_sem_excl também era esperada, pois Doc_Integral é uma escala múltipla, que representa a soma dos valores das variáveis Doc_Integ_excl e Doc_Integ_sem_excl - também há correlação positiva entre Doc_Integral e Doc_Integ_excl, porém esta é pequena $(0,359)$. 
A correlação muito forte e negativa $(-0,990)$ entre Doc_Espec e Doc_MestDout revela uma oposição quase-perfeita entre estas variáveis, pois a primeira mede a proporção de docentes com escolaridade Lato Sensu, enquanto a última mede a proporção de docentes com escolaridade Stricto Sensu. Neste sentido, também há associação alta e negativa entre Doc_Espec e Doc_Dout $(-0,729)$ e associação moderada e negativa entre Doc_Espec e Doc_Mest $(-0,689)$.

Entre as variáveis que representam o regime de trabalho do corpo docente, Doc_Hor (que representa o regime de dedicação 'Horista') destaca-se por estabelecer relações negativas com todas as outras: com Doc_Integral (-0,639), com Doc_Parc $(-0,621)$, com Doc_Integ_sem_excl $(-0,477)$ e com Doc_Integ_excl $(-0,287)$.

Há correlação moderada positiva entre as variáveis N_Concl e N_Cursos $(0,568)$, reforçando a ideia de que IES maiores (que oferecem diversos cursos) têm um número maior de concluintes destes cursos (inclusive, concluintes de Administração, que podem advir de múltiplos cursos oferecidos por uma mesma IES).

A correlação moderada e positiva entre Doc_Integral e Doc_Dout $(0,401)$ sugere que uma maior proporção de professores doutores está relacionada com uma maior proporção do regime de trabalho 'Integral'. Além disso, as correlações positivas estabelecidas entre estas variáveis e N_Cursos $(0,492$ e 0,470, respectivamente) implicam que a oferta de um número maior de cursos de graduação por uma IES está relacionada com proporções superiores de professores doutores e de docentes trabalhando em tempo Integral.

\subsection{Variáveis independentes não-métricas}

As quatro variáveis não-métricas do banco de dados (Categ_Admin, Org_Academ, Regiao_BR e Capital) foram criadas a partir dos Microdados Censo da Educação Superior 2012 (tabela Instituições).

Para posterior inclusão destas variáveis independentes em modelos de regressão múltipla, foram criadas dummys, segundo a abordagem de codificação indicadora. Para a variável Categ_Admin, a categoria de referência foi 'Pública'; para Org_Academ, 'Universidade'; para Regiao_BR, 'Centro-Oeste'; e, para Capital, 'Não'. 
Quadro 5 - Variáveis independentes não-métricas

\begin{tabular}{|l|c|l|}
\hline Variável & Escala & Descrição \\
\hline Categ_Admin & Nominal & $\begin{array}{l}\text { Categoria Administrativa da IES } \\
\text { (Pública; Privada) }\end{array}$ \\
\hline Org_Academ & Nominal & $\begin{array}{l}\text { Organização Acadêmica da IES } \\
\text { (Universidade; Centro Universitário; Faculdade) }\end{array}$ \\
\hline Regiao_BR & Nominal & $\begin{array}{l}\text { Região do Brasil onde são ofertados os cursos da IES } \\
\text { (Centro-Oeste; Nordeste; Norte; Sudeste; Sul) }\end{array}$ \\
\hline Capital & Nominal & $\begin{array}{l}\text { Localização da reitoria / sede administrativa da IES em } \\
\text { capital estadual } \\
\text { (Sim; Não) }\end{array}$ \\
\hline
\end{tabular}

Tabela 5-Dummy de Categ_Admin

\begin{tabular}{|l|c|}
\hline Categ_Admin & DummyCA \\
\hline Pública & 0 \\
\hline Privada & 1 \\
\hline
\end{tabular}

Tabela 6-Dummy de Org_Academ

\begin{tabular}{|l|c|c|}
\hline Org_Academ & DummyOA1 & DummyOA2 \\
\hline Universidade & 0 & 0 \\
\hline Centro Universitário & 1 & 0 \\
\hline Faculdade & 0 & 1 \\
\hline
\end{tabular}

Tabela 7 - Dummy de Regiao_BR

\begin{tabular}{|l|c|c|c|c|}
\hline Regiao_BR & DummyRB1 & DummyRB2 & DummyRB3 & DummyRB4 \\
\hline Centro-Oeste & 0 & 0 & 0 & 0 \\
\hline Nordeste & 1 & 0 & 0 & 0 \\
\hline Norte & 0 & 1 & 0 & 0 \\
\hline Sudeste & 0 & 0 & 1 & 0 \\
\hline Sul & 0 & 0 & 0 & 1 \\
\hline
\end{tabular}

Tabela 8-Dummy de Capital

\begin{tabular}{|l|c|}
\hline Capital & DummyCapital \\
\hline Não & 0 \\
\hline Sim & 1 \\
\hline
\end{tabular}

No banco de dados: 90,4\% das IES são privadas; 76,8\% são faculdades; 45,9\% das IES estão localizadas na região Sudeste; e 66,2\% não têm reitoria ou sede administrativa localizada em capitais dos Estados brasileiros. 
Categ_Admin

\begin{tabular}{|c|c|c|c|c|c|}
\hline & & Frequência & Porcentual & $\begin{array}{c}\text { Porcentagem } \\
\text { válida }\end{array}$ & $\begin{array}{c}\text { Porcentagem } \\
\text { acumulativa }\end{array}$ \\
\hline \multirow[t]{3}{*}{ Válido } & Pública & 123 & 9,6 & 9,6 & 9,6 \\
\hline & Privada & 1163 & 90,4 & 90,4 & 100,0 \\
\hline & Total & 1286 & 100,0 & 100,0 & \\
\hline
\end{tabular}

Org_Academ

\begin{tabular}{|ll|r|r|r|r|}
\hline & & & $\begin{array}{c}\text { Porcentagem } \\
\text { válida }\end{array}$ & $\begin{array}{c}\text { Porcentagem } \\
\text { acumulativa }\end{array}$ \\
\hline Válido & Universidade & 176 & 13,7 & 13,7 & 13,7 \\
& Centro Universitário & 123 & 9,5 & 9,5 & 23,2 \\
& Faculdade & 989 & 76,8 & 76,8 & 100,0 \\
Total & 1288 & 100,0 & 100,0 & \\
\hline
\end{tabular}

Regiao_BR

\begin{tabular}{|ll|r|r|r|r|}
\hline & Frequência & Porcentual & \multicolumn{1}{c|}{$\begin{array}{c}\text { Porcentagem } \\
\text { válida }\end{array}$} & $\begin{array}{c}\text { Porcentagem } \\
\text { acumulativa }\end{array}$ \\
\hline Válido & Centro-Oeste & 144 & 11,2 & 11,2 & 11,2 \\
& Nordeste & 230 & 17,9 & 17,9 & 29,0 \\
Norte & 82 & 6,4 & 6,4 & 35,4 \\
Sudeste & 591 & 45,9 & 45,9 & 81,3 \\
Sul & 241 & 18,7 & 18,7 & 100,0 \\
Total & 1288 & 100,0 & 100,0 & \\
\hline
\end{tabular}

\section{Capital}

\begin{tabular}{|rl|r|r|r|r|}
\hline & Frequência & Porcentual & $\begin{array}{c}\text { Porcentagem } \\
\text { válida }\end{array}$ & $\begin{array}{c}\text { Porcentagem } \\
\text { acumulativa }\end{array}$ \\
\hline Válido & Sim & 436 & 33,8 & 33,8 & 33,8 \\
& Não & 854 & 66,2 & 66,2 & 100,0 \\
& Total & 1290 & 100,0 & 100,0 & \\
\hline
\end{tabular}




\section{RESULTADOS}

Segundo os objetivos desta pesquisa, foram desenvolvidos três modelos de regressão múltipla: o primeiro, denominado 'Geral', contempla todas as IES do banco de dados (1.286 casos); o segundo é um modelo específico, criado a partir dos dados de 123 IES públicas ('Públicas'); e, o terceiro corresponde às 1.163 IES privadas ('Privadas').

Para o desenvolvimento de cada um dos três modelos, foram analisadas as correlações entre a variável dependente (DESEMPENHO) e as variáveis independentes do banco de dados e testados modelos de regressão alternativos com a abordagem por etapas (stepwise).

Neste capítulo, são apresentados, para cada modelo: outputs do software estatístico (SPSS), análise dos coeficientes e das variâncias únicas das variáveis independentes, testes das hipóteses da pesquisa e análise das suposições estatísticas da regressão múltipla.

\subsection{Geral}

O modelo 'Geral' é composto por oito variáveis independentes: Doc_Dout, Doc_Integ_excl, Doc_Espec, Doc_EmEx_Curso, N_Concl, N_Cursos, DummyCapital e Doc_Parc. Com um valor de $\mathrm{R}^{2}$ de 0,239, é possível afirmar que o modelo explica 23,9\% da variância total de DESEMPENHO; e, sendo o valor de $\mathrm{R}^{2}$ ajustado muito próximo do valor de $\mathrm{R}^{2}$ (uma diferença de 0,004), é possível afirmar que o modelo é generalizável à população.

A estatística de Durbin-Watson, que informa sobre a independência dos erros, "pode variar entre 0 e 4, com 2 significando que os resíduos não são correlacionados” (FIELD, 2009, p. 179). Assim, com o valor de 1,911 (próximo de 2), a hipótese de independência dos erros é satisfeita.

Os valores de Fator de Inflação da Variância (VIF) são baixos (a média é de 1,612), e nenhum dos valores de Tolerância é inferior a 0,20. De tal modo, como proposto por FIELD (2009, p. 202), podemos afirmar que não há problemas de multicolinearidade para estes dados. 
Resumo do modelo ${ }^{\mathrm{b}}$

\begin{tabular}{|l|l|r|r|r|r|}
\hline Modelo & $\mathrm{R}$ & $\mathrm{R}$ quadrado & $\begin{array}{c}\text { R quadrado } \\
\text { ajustado }\end{array}$ & $\begin{array}{c}\text { Erro padrão } \\
\text { da estimativa }\end{array}$ & $\begin{array}{c}\text { Durbin- } \\
\text { Watson }\end{array}$ \\
\hline 1 &, $489^{\mathrm{a}}$ &, 239 &, 235 &, 8753197 & 1,911 \\
\hline
\end{tabular}

a. Preditores: (Constante), Doc_Parc, Doc_Espec, Doc_EmEx_Curso, N_Concl, DummyCapital, Doc_Integ_excl, N_Cursos, Doc_Dout

b. Variável dependente: DESEMPENHO

ANOVA $^{\mathrm{a}}$

\begin{tabular}{|c|c|c|c|c|c|c|}
\hline & & $\begin{array}{l}\text { Soma dos } \\
\text { Quadrados }\end{array}$ & df & $\begin{array}{l}\text { Quadrado } \\
\text { Médio }\end{array}$ & $\mathrm{F}$ & Sig. \\
\hline \multirow[t]{3}{*}{1} & Regressão & 307,909 & 8 & 38,489 & 50,234 &, $000^{\mathrm{b}}$ \\
\hline & Resíduos & 978,418 & 1277 & ,766 & & \\
\hline & Total & 1286,327 & 1285 & & & \\
\hline
\end{tabular}

Coeficientes $^{\mathrm{a}}$

\begin{tabular}{|c|c|c|c|c|c|c|c|c|}
\hline & & \multicolumn{2}{|c|}{$\begin{array}{l}\text { Coeficientes não } \\
\text { padronizados }\end{array}$} & \multirow{2}{*}{$\begin{array}{c}\text { Coeficientes } \\
\text { padronizados } \\
\text { Beta }\end{array}$} & \multirow[b]{2}{*}{$t$} & \multirow[b]{2}{*}{ Sig. } & \multicolumn{2}{|c|}{$\begin{array}{l}\text { Estatísticas de } \\
\text { colinearidade }\end{array}$} \\
\hline \multicolumn{2}{|c|}{ Modelo } & B & $\begin{array}{l}\text { Modelo } \\
\text { padrão }\end{array}$ & & & & $\begin{array}{l}\text { Toler } \\
\text { ância }\end{array}$ & VIF \\
\hline \multirow[t]{9}{*}{1} & (Constante) & .032 &, 119 & & 266 & .791 & & \\
\hline & Doc_Dout & 1,143 &, 278 & 167 & 4,114 & ,000 & ,363 & 2,752 \\
\hline & Doc_Integ_excl &, 588 &, 176 &, 109 & 3,344 &, 001 &, 565 & 1,770 \\
\hline & Doc_Espec &,- 848 & 161 &,- 179 & $-5,278$ & ,000 &, 520 & 1,923 \\
\hline & Doc_EmEx_Curso &, 023 &, 004 & , 134 & 5,216 &, 000 &, 900 & 1,111 \\
\hline & N_Concl &,- 001 &, 000 &,- 161 & $-5,478$ &, 000 & 690 & 1,449 \\
\hline & N_Cursos &, 004 & 001 &, 162 & 5,128 &, 000 &, 595 & 1,681 \\
\hline & DummyCapital &,- 160 & 054 &,- 075 & $-2,930$ &, 003 &, 898 & 1,113 \\
\hline & Doc_Parc &,- 283 & 111 &,- 065 & $-2,548$ & ,011 & ,909 & 1,100 \\
\hline
\end{tabular}

a. Variável dependente: DESEMPENHO

Todos os coeficientes do modelo, exceto o intercepto, têm significância estatística. Em termos relativos, a variável independente mais importante neste modelo é Doc_Espec (a proporção de docentes da IES 'em exercício' com nível de escolaridade correspondente à 'Especialização').

Apesar de não possuir correlação significante com a variável dependente (DESEMPENHO), a variável N_Concl foi incluída neste modelo de regressão com um coeficiente não-padronizado de sinal negativo $(-0,001)$. No entanto, a hipótese correspondente a esta variável (H6: o total de concluintes dos cursos de Administração da IES tem relação positiva com o desempenho discente no ENADE) não foi rejeitada, uma vez que, analisando 
as correlações significantes estabelecidas entre N_Concl e as outras variáveis independentes do modelo, verifica-se uma associação moderada com N_Cursos - que explica a inversão do sinal (em relação ao esperado). Assim, com base na especificação do modelo original (e não sobre a variável estatística estimada), não rejeitamos $\mathbf{H 6}$.

Correlações

\begin{tabular}{|l|r|r|c|}
\hline \multirow{2}{*}{} & \multicolumn{3}{|c|}{ Rô de Spearman } \\
\cline { 2 - 4 } & \multicolumn{3}{|c|}{ DESEMPENHO } \\
\cline { 2 - 4 } & $\begin{array}{c}\text { Correlações } \\
\text { de coeficiente }\end{array}$ & $\begin{array}{c}\text { Sig. (2 } \\
\text { extremidades) }\end{array}$ & $\mathrm{N}$ \\
\hline N_Concl &, 016 &, 558 & 1286 \\
\hline
\end{tabular}

Correlações

\begin{tabular}{|l|r|c|c|}
\hline \multirow{2}{*}{} & \multicolumn{3}{|c|}{ Rô de Spearman } \\
\cline { 2 - 4 } & \multicolumn{3}{|c|}{ N_Concl } \\
\cline { 2 - 4 } & $\begin{array}{c}\text { Correlações } \\
\text { de coeficiente }\end{array}$ & $\begin{array}{c}\text { Sig. (2 } \\
\text { extremidades) }\end{array}$ & N \\
\hline N_Cursos &, 568 &, 000 & 1286 \\
\hline
\end{tabular}

Comparando os coeficientes de correlação entre as outras variáveis independentes do modelo e a variável dependente (DESEMPENHO) com os coeficientes não padronizados do modelo, é atestada a coerência dos sinais para todas estas variáveis.

Correlações

\begin{tabular}{|l|r|r|c|}
\hline \multirow{2}{*}{} & \multicolumn{3}{|c|}{ Rô de Spearman } \\
\cline { 2 - 4 } & \multicolumn{3}{|c|}{ DESEMPENHO } \\
\cline { 2 - 4 } & $\begin{array}{c}\text { Correlações } \\
\text { de coeficiente }\end{array}$ & $\begin{array}{c}\text { Sig. (2 } \\
\text { extremidades) }\end{array}$ & N \\
\hline Doc_Dout &, 277 &, 000 & 1286 \\
Doc_Integ_excl &, 151 &, 000 & 1286 \\
Doc_Espec &,- 325 &, 000 & 1286 \\
Doc_EmEx_Curso &, 146 &, 000 & 1286 \\
N_Cursos &, 228 &, 000 & 1286 \\
Doc_Parc &,- 128 &, 000 & 1286 \\
\hline
\end{tabular}

Assim, quanto às outras hipóteses da pesquisa:

- A significância estatística e o sinal positivo do coeficiente de Doc_Dout no modelo justifica a não rejeição de H1; 
- A significância estatística e o sinal negativo do coeficiente de Doc_Espec no modelo justifica a não rejeição de $\mathbf{H 2}$;

- A significância estatística e o sinal positivo do coeficiente de Doc_Integ_excl no modelo justifica a não rejeição de $\mathbf{H 3}$;

- A significância estatística e o sinal negativo do coeficiente de Doc_Parc no modelo justifica a não rejeição de H4;

- A significância estatística e o sinal positivo do coeficiente de Doc_EmEx_Curso no modelo justifica a não rejeição de H5;

- A significância estatística e o sinal positivo do coeficiente da variável independente N_Cursos no modelo justifica a não rejeição de H7.

Portanto, todas as sete hipóteses propostas por este estudo não foram rejeitadas no modelo 'Geral'.

Além disso, a inclusão da variável independente DummyCapital, que indica se a reitoria ou sede administrativa da IES está localizada na capital de uma UF brasileira ou não (adotando "Não" como categoria de referência), no modelo 'Geral' com coeficiente negativo sugere que as IES localizadas em capitais têm valor de DESEMPENHO inferior às IES localizadas em outras cidades.

\begin{tabular}{|c|c|c|c|c|}
\hline \multicolumn{5}{|c|}{ Coeficientes $^{a}$} \\
\hline \multirow{2}{*}{\multicolumn{2}{|c|}{ Modelo }} & \multicolumn{3}{|c|}{ Correlaçőes } \\
\hline & & Ordem zero & Parcial & Parte \\
\hline \multirow[t]{8}{*}{1} & Doc_Dout &, 410 &, 114 & 100 \\
\hline & Doc_Integ_excl &, 354 &, 093 &, 082 \\
\hline & Doc_Espec &,- 348 &,- 146 &,- 129 \\
\hline & Doc_EmEx_Curso & ,181 & 144 &, 127 \\
\hline & N_Concl &,- 017 &,- 152 &,- 134 \\
\hline & N_Cursos &, 216 &, 142 & ,125 \\
\hline & DummyCapital & ,016 &,- 082 &,- 072 \\
\hline & Doc_Parc &,- 148 &,- 071 &,- 062 \\
\hline
\end{tabular}

a. Variável dependente: DESEMPENHO

Com o objetivo de analisar a distribuição da variância explicada pelo modelo entre as variáveis independentes, foi realizada a análise de correlações semiparciais (que correspondem aos valores da coluna 'Parte' na tabela 'Coeficientes', saída do SPSS). Elevando-as ao quadrado, foi obtida a variância única explicada por cada variável independente (HAIR Jr. et al., 2009, p.194). 
Tabela 9 - Variâncias únicas das variáveis independentes ('Geral')

\begin{tabular}{|l|c|c|}
\hline Variável independente & $\begin{array}{c}\text { Correlação } \\
\text { semiparcial }\end{array}$ & $\begin{array}{c}\text { Variância única } \\
\text { explicada }\end{array}$ \\
\hline Doc_Dout & 0,100 & $1,0 \%$ \\
\hline Doc_Integ_excl & 0,082 & $0,7 \%$ \\
\hline Doc_Espec & $-0,129$ & $1,7 \%$ \\
\hline Doc_EmEx_Curso & 0,127 & $1,6 \%$ \\
\hline N_Concl & $-0,134$ & $1,8 \%$ \\
\hline N_Cursos & 0,125 & $1,6 \%$ \\
\hline DummyCapital & $-0,072$ & $0,5 \%$ \\
\hline Doc_Parc & $-0,062$ & $0,4 \%$ \\
\hline
\end{tabular}

As variâncias únicas das variáveis independentes do modelo 'Geral' somam 9,3\%, o que indica que grande parte da variância total de DESEMPENHO explicada $(23,9 \%)$ é atribuída às variâncias compartilhadas pelas suas variáveis independentes.
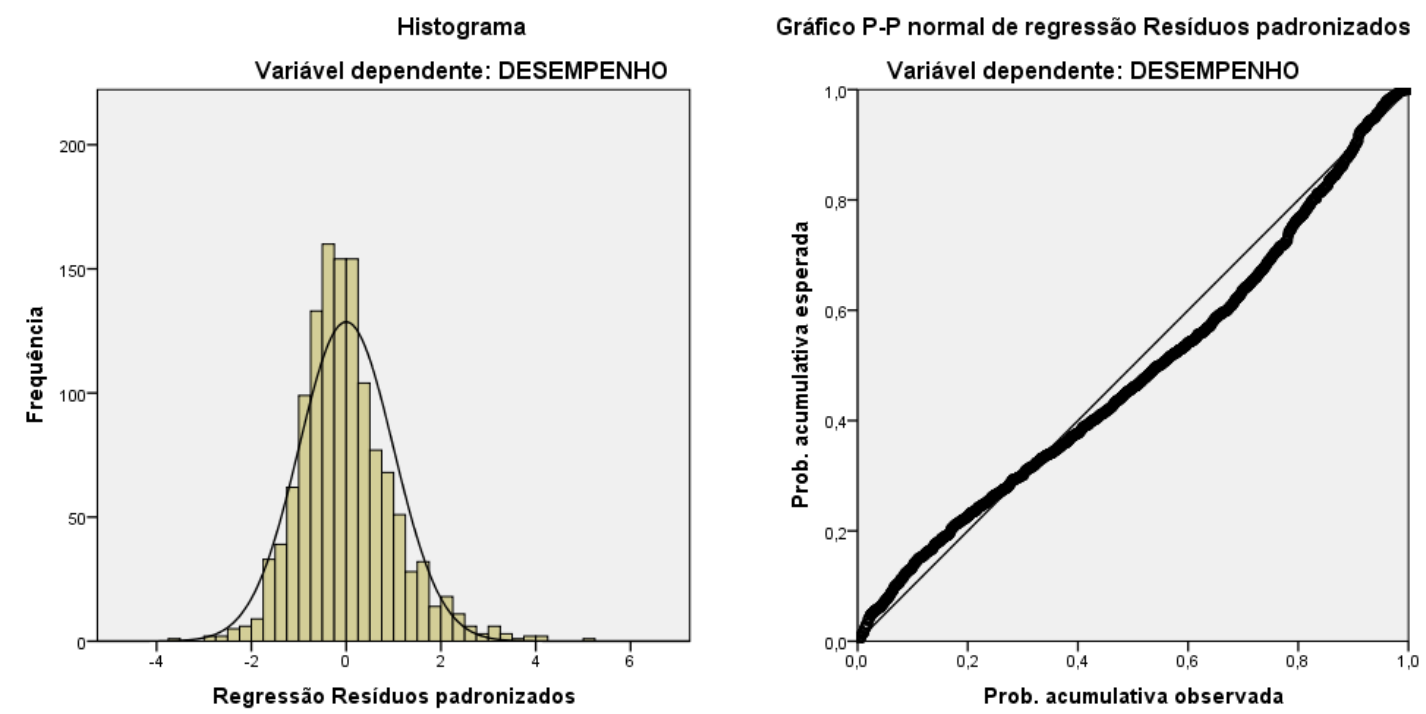

A análise visual da "representação gráfica dos resíduos versus as variáveis independentes ou previstas é um método básico para identificar violações de suposições para a relação geral” (HAIR Jr., p. 174). Segundo os gráficos de resíduos do modelo 'Geral', aparentemente, os resíduos ocorrem aleatoriamente em torno de zero, atestando variância constante do termo de erro. 

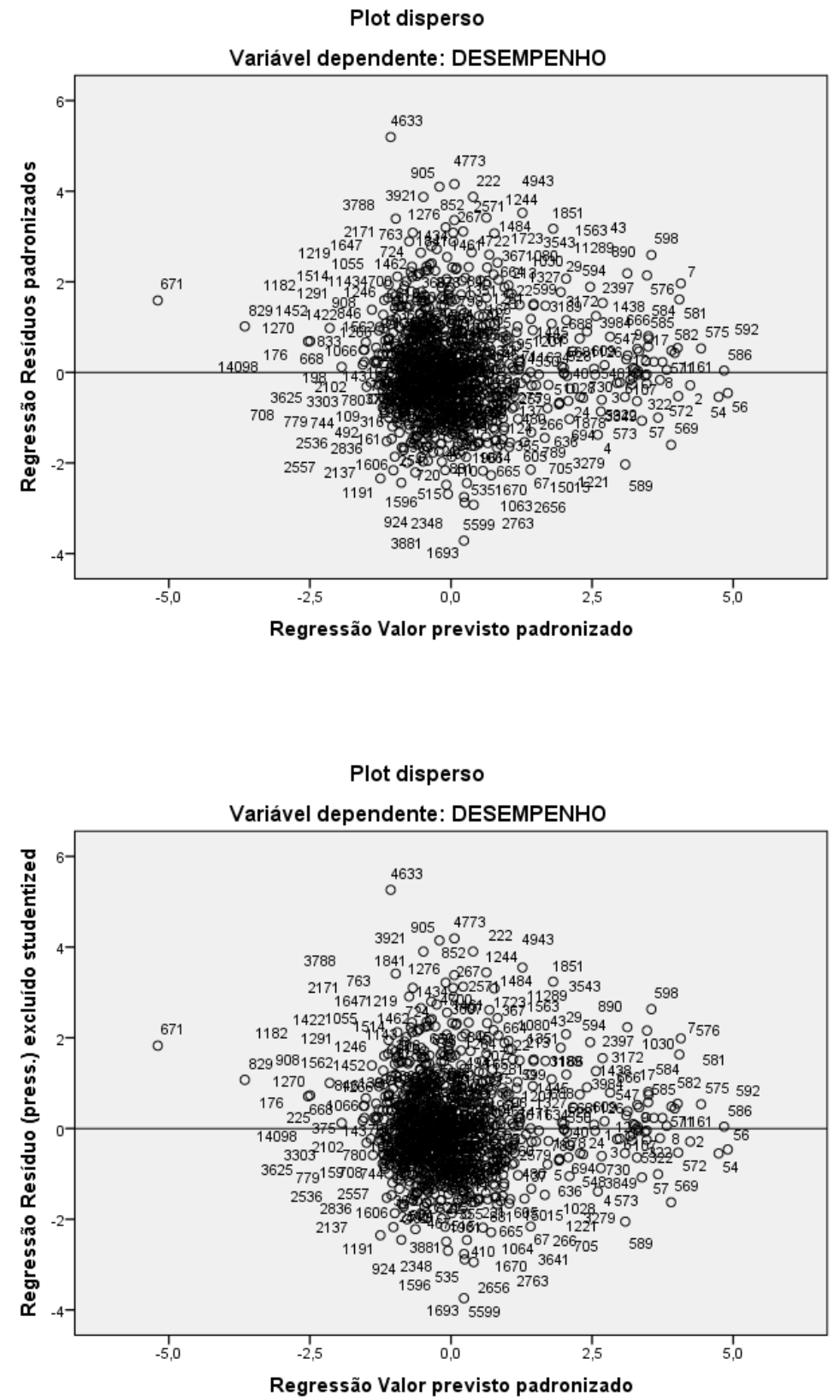

Em síntese, assume-se que a variável estatística satisfaz as suposições de regressão. Analisando os diagnósticos por caso, foram identificados 9 (nove) casos com resíduos padronizados menores que -2 ou maiores que 2 , que representam $0,69 \%$ da amostra. Além disso, a análise de casos influentes revelou que nenhum caso da amostra (ou, nenhuma IES) tem valor de distância de Cook superior a 1, não existindo motivos reais para a exclusão de nenhum caso. 


\subsection{Públicas}

Com cinco variáveis independentes (N_Cursos, Doc_EmEx_Curso, Doc_Integral, DummyRB3 e DummyRB4), o modelo 'Públicas' explica 60,6\% da variância total de DESEMPENHO das IES públicas $\left(\mathrm{R}^{2}=0,606\right)$. Os erros da regressão são independentes (Durbin-Watson $=1,830$ ) e pode-se afirmar que o modelo é generalizável para a população das IES públicas (com uma diferença de apenas 0,017 entre $\mathrm{R}^{2}$ e $\mathrm{R}^{2}$ ajustado).

Todas as variáveis independentes do modelo têm significância estatística, apresentam baixos valores de VIF (média: 1,241) e valores de Tolerância superiores a 0,20 - portanto, não há problemas de multicolinearidade.

Resumo do modelo ${ }^{b}$

\begin{tabular}{|l|c|r|r|r|r|}
\hline Modelo & $\mathrm{R}$ & R quadrado & $\begin{array}{c}\text { R quadrado } \\
\text { ajustado }\end{array}$ & $\begin{array}{c}\text { Erro padrão } \\
\text { da estimativa }\end{array}$ & $\begin{array}{c}\text { Durbin- } \\
\text { Watson }\end{array}$ \\
\hline 1 &, $778^{\mathrm{a}}$ &, 606 &, 589 &, 8031588 & 1,830 \\
\hline
\end{tabular}

a. Preditores: (Constante), DummyRB4, Doc_Integral, Doc_EmEx_Curso, N_Cursos, DummyRB3

b. Variável dependente: DESEMPENHO

ANOVA $^{a}$

\begin{tabular}{|rl|r|r|r|r|r|}
\hline \multicolumn{2}{|c|}{} & \multicolumn{1}{|c|}{$\begin{array}{c}\text { Soma dos } \\
\text { Quadrados }\end{array}$} & \multicolumn{1}{c|}{ df } & \multicolumn{1}{c|}{$\begin{array}{c}\text { Quadrado } \\
\text { Médio }\end{array}$} & \multicolumn{1}{c|}{ F } & \multicolumn{1}{c|}{ Sig. } \\
\hline 1 & Regressão & 116,076 & 5 & 23,215 & 35,989 &, $000^{\mathrm{b}}$ \\
& Residuos & 75,472 & 117 &, 645 & & \\
& Total & 191,549 & 122 & & & \\
\hline
\end{tabular}

Coeficientes $^{a}$

\begin{tabular}{|c|c|c|c|c|c|c|c|c|}
\hline & & \multicolumn{2}{|c|}{$\begin{array}{c}\text { Coeficientes não } \\
\text { padronizados }\end{array}$} & \multirow{2}{*}{$\begin{array}{c}\begin{array}{c}\text { Coeficientes } \\
\text { padronizados }\end{array} \\
\text { Beta }\end{array}$} & \multirow[b]{2}{*}{$t$} & \multirow[b]{2}{*}{ Sig. } & \multicolumn{2}{|c|}{$\begin{array}{r}\text { Estatísticas de } \\
\text { colinearidade }\end{array}$} \\
\hline & & $\mathrm{B}$ & $\begin{array}{l}\text { Modelo } \\
\text { padrão }\end{array}$ & & & & $\begin{array}{l}\text { Toler } \\
\text { ância }\end{array}$ & VIF \\
\hline 1 & (Constante) & $-1,939$ & .238 & & $-8,136$ &, 000 & & \\
\hline & N_Cursos &, 005 &, 001 &, 279 & 4,300 &, 000 &, 800 & 1,250 \\
\hline & Doc_EmEx_Curso &, 075 & ,012 &, 384 & 6,160 &, 000 & ,868 & 1,152 \\
\hline & Doc_Integral & 1,669 &, 245 & 451 & 6,816 &, 000 &, 769 & 1,301 \\
\hline & DummyRB3 &, 722 &, 174 &, 271 & 4,155 &, 000 &, 791 & 1,264 \\
\hline & DummyRB4 & ,449 & ,185 &, 156 & 2,419 &, 017 & ,809 & 1,237 \\
\hline
\end{tabular}

a. Variável dependente: DESEMPENHO 
No modelo 'Públicas', a variável independente de maior importância relativa (segundo os coeficientes padronizados) é Doc_Integral, que representa a proporção de docentes da IES 'em exercício' com regime de trabalho 'Integral'.

\section{Correlações}

\begin{tabular}{|l|r|r|r|}
\hline \multirow{2}{*}{} & \multicolumn{3}{|c|}{ Rô de Spearman } \\
\cline { 2 - 4 } & \multicolumn{3}{|c|}{ DESEMPENHO } \\
\cline { 2 - 4 } & $\begin{array}{c}\text { Correlações } \\
\text { de coeficiente }\end{array}$ & $\begin{array}{c}\text { Sig. (2 } \\
\text { extremidades) }\end{array}$ & $\mathrm{N}$ \\
\hline N_Cursos &, 461 &, 000 & 123 \\
Doc_EmEx_Curso &, 546 &, 000 & 123 \\
Doc_Integral &, 553 &, 000 & 123 \\
\hline
\end{tabular}

A análise das correlações bivariadas (específicas para este conjunto de dados) e dos coeficientes das variáveis independentes do modelo atestou coerência nos sinais dos coeficientes da variável estatística de regressão. Assim, quanto às hipóteses da pesquisa, no modelo 'Públicas':

- A não inclusão da variável independente Doc_Dout justifica a rejeição de H1;

- A não inclusão da variável independente Doc_Espec justifica a rejeição de H2;

- A significância estatística e o sinal positivo do coeficiente de Doc_Integral justifica a não rejeição de $\mathrm{H3}$;

- A não inclusão da variável independente Doc_Parc justifica a rejeição de H4;

- A significância estatística e o sinal positivo do coeficiente de Doc_EmEx_Curso justifica a não rejeição de $\mathbf{H 5}$;

- A não inclusão da variável independente N_Concl justifica a rejeição de H6;

- A significância estatística e o sinal positivo do coeficiente de N_Cursos justifica a não rejeição de $\mathrm{H} 7$.

Presentes na composição da variável estatística do modelo 'Públicas', as variáveis independentes DummyRB3 e DummyRB4 fazem parte do grupo de dummys criadas para representar a variável não-métrica Regiao_BR (relacionada à região do Brasil onde são ofertados os cursos de graduação da IES) - sendo que DummyRB3 corresponde à região Sudeste e DummyRB4 corresponde à região Sul.

Os coeficientes positivos de DummyRB3 e DummyRB4 implicam em acréscimos no valor de DESEMPENHO das IES públicas que atuam na região Sudeste $(0,722)$ ou na região Sul $(0,449)$, sugerindo relativa superioridade destas sobre as demais. 


\begin{tabular}{|c|c|c|c|c|}
\hline \multicolumn{5}{|c|}{ Coeficientes $^{a}$} \\
\hline \multirow{2}{*}{\multicolumn{2}{|c|}{ Modelo }} & \multicolumn{3}{|c|}{ Correlações } \\
\hline & & Ordem zero & Parcial & Parte \\
\hline \multirow[t]{5}{*}{1} & N_Cursos & ,352 &, 369 &, 250 \\
\hline & Doc_EmEx_Curso & ,494 & ,495 &, 357 \\
\hline & Doc_Integral &, 621 &, 533 &, 396 \\
\hline & DummyRB3 &, 156 &, 359 &, 241 \\
\hline & DummyRB4 &,- 028 & 218 &, 140 \\
\hline
\end{tabular}

a. Variável dependente: DESEMPENHO

Analisando a distribuição da variância explicada pelas variáveis independentes do modelo 'Públicas', identificou-se a relevância de Doc_Integral e Doc_EmEx_Curso, cujas variâncias únicas somadas representam 28,4\% da variância total de DESEMPENHO.

Tabela 10 - Variâncias únicas das variáveis independentes ('Públicas')

\begin{tabular}{|l|c|c|}
\hline Variável independente & $\begin{array}{c}\text { Correlação } \\
\text { semiparcial }\end{array}$ & $\begin{array}{c}\text { Variância única } \\
\text { explicada }\end{array}$ \\
\hline N_Cursos & 0,250 & $6,3 \%$ \\
\hline Doc_EmEx_Curso & 0,357 & $12,7 \%$ \\
\hline Doc_Integral & 0,396 & $15,7 \%$ \\
\hline DummyRB3 & 0,241 & $5,8 \%$ \\
\hline DummyRB4 & 0,140 & $2,0 \%$ \\
\hline
\end{tabular}

Os gráficos de distribuição dos resíduos revelam que, no modelo 'Públicas', estes ocorrem aleatoriamente - não houve violação das suposições da análise de regressão.
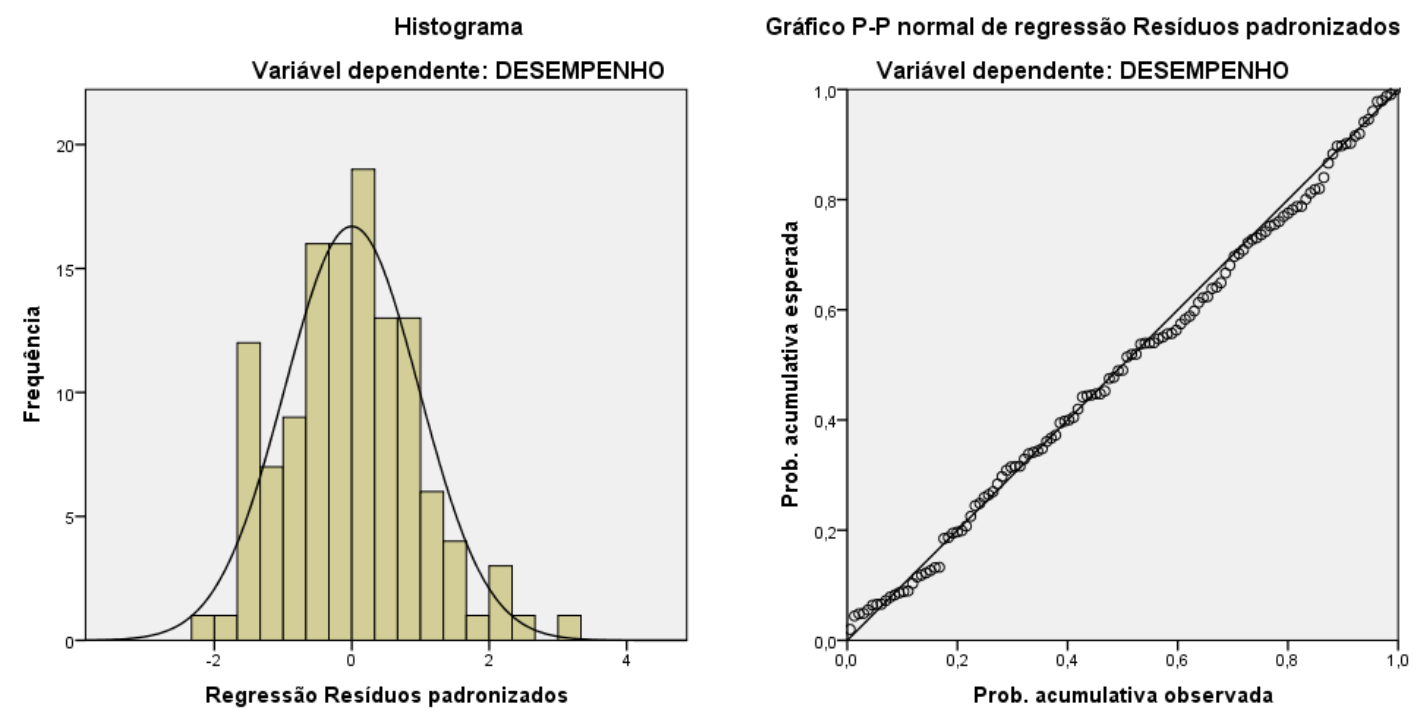

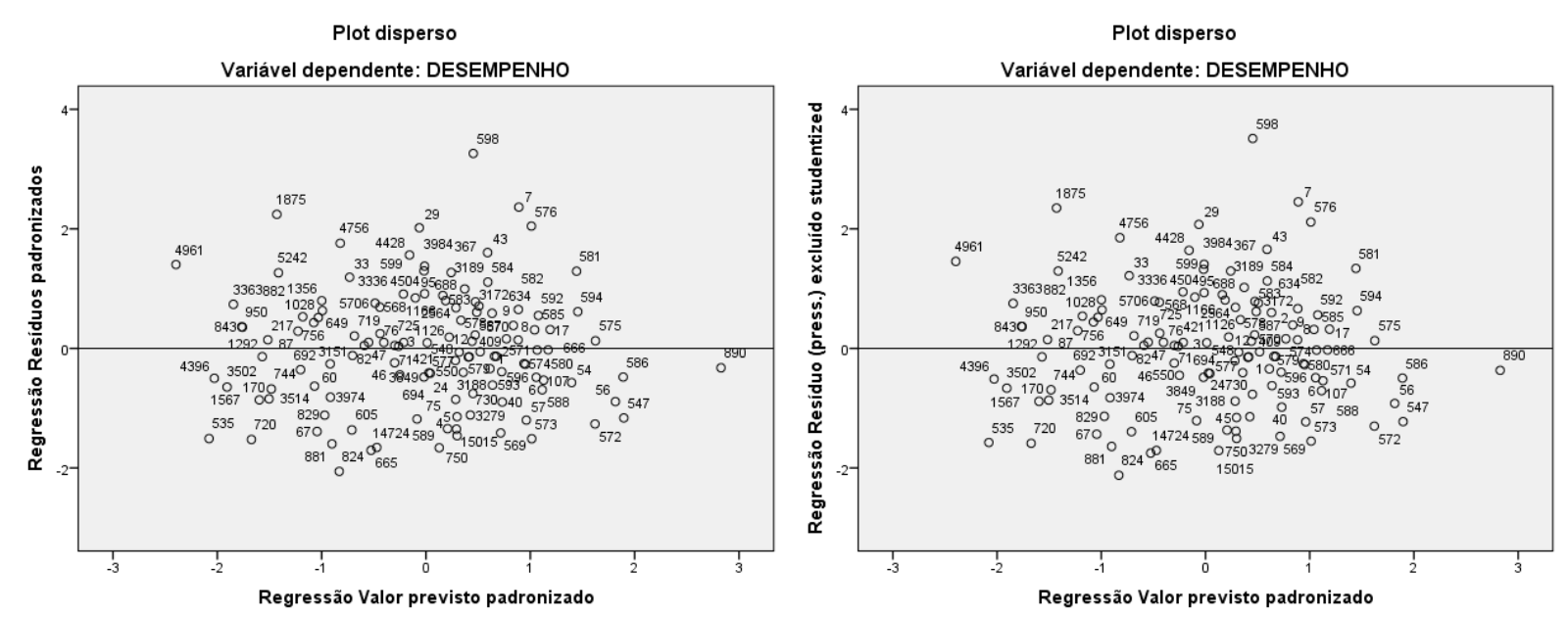

Nenhum caso da amostra apresentou distância de Cook superior a 1, ou seja, nenhum caso deveria ser excluído do modelo 'Públicas'; e apenas 6 IES (4,9\%) têm resíduos padronizados menores que -2 ou maiores que 2 .

\subsection{Privadas}

O modelo 'Privadas' tem seis variáveis independentes (Doc_Espec, Doc_Dout, Doc_EmEx_Curso, N_Concl, N_Cursos e DummyCapital), que explicam apenas 9,0\% da variância total de DESEMPENHO das 1.163 IES privadas.

\begin{tabular}{|c|c|c|c|c|c|}
\hline \multicolumn{6}{|c|}{ Resumo do modelo $^{\mathrm{b}}$} \\
\hline Modelo & $\mathrm{R}$ & $\mathrm{R}$ quadrado & $\begin{array}{c}\text { R quadrado } \\
\text { ajustado }\end{array}$ & $\begin{array}{l}\text { Erro padrão } \\
\text { da estimativa }\end{array}$ & $\begin{array}{l}\text { Durbin- } \\
\text { Watson }\end{array}$ \\
\hline 1 & $301^{\mathrm{a}}$ &, 090 & ,086 & ,8750356 & 1,928 \\
\hline
\end{tabular}

O valor da estatística de Durbin-Watson $(1,928)$ atesta a independência dos erros e não há problema de multicolinearidade - os valores de Tolerância são todos maiores que 0,20 e a média dos valores de Fator de Inflação da Variância (VIF) é 1,485. 
ANOVA $^{\mathrm{a}}$

\begin{tabular}{|rl|r|r|r|r|c|}
\hline \multicolumn{2}{|c|}{} & \multicolumn{1}{|c|}{$\begin{array}{c}\text { Soma dos } \\
\text { Quadrados }\end{array}$} & \multicolumn{1}{c|}{ df } & \multicolumn{1}{c|}{$\begin{array}{c}\text { Quadrado } \\
\text { Médio }\end{array}$} & \multicolumn{1}{c|}{ F } & Sig. \\
\hline 1 & Regressão & 88,012 & 6 & 14,669 & 19,157 &, $000^{\mathrm{b}}$ \\
& Resíduos & 885,135 & 1156 &, 766 & & \\
& Total & 973,146 & 1162 & & & \\
\hline
\end{tabular}

a. Variável dependente: DESEMPENHO

b. Preditores: (Constante), DummyCapital, N_Cursos, Doc_Dout, Doc_EmEx_Curso, N_Concl, Doc_Espec

Coeficientes $^{a}$

\begin{tabular}{|c|c|c|c|c|c|c|c|c|}
\hline & & \multicolumn{2}{|c|}{$\begin{array}{c}\text { Coeficientes não } \\
\text { padronizados }\end{array}$} & \multirow{2}{*}{$\begin{array}{c}\begin{array}{l}\text { Coeficientes } \\
\text { padronizados }\end{array} \\
\text { Beta }\end{array}$} & \multirow[b]{2}{*}{$t$} & \multirow[b]{2}{*}{ Sig. } & \multicolumn{2}{|c|}{$\begin{array}{l}\text { Estatísticas de } \\
\text { colinearidade }\end{array}$} \\
\hline \multicolumn{2}{|c|}{ Modelo } & $B$ & $\begin{array}{l}\text { Modelo } \\
\text { padrão }\end{array}$ & & & & $\begin{array}{l}\text { Toler } \\
\text { ância }\end{array}$ & VIF \\
\hline \multirow[t]{7}{*}{1} & (Constante) &, 062 &, 118 & &, 523 & 601 & & \\
\hline & Doc_Espec &,- 879 & , 168 &,- 192 & $-5,225$ & ,000 &, 583 & 1,716 \\
\hline & Doc_Dout & ,816 &, 325 &, 093 & 2,513 &, 012 &, 575 & 1,738 \\
\hline & Doc_EmEx_Curso &, 017 &, 005 &, 110 & 3,781 &, 000 &, 931 & 1,074 \\
\hline & N_Concl &,- 001 &, 000 &,- 164 & $-4,556$ &, 000 & ,608 & 1,644 \\
\hline & N_Cursos &, 003 &, 001 &, 136 & 3,781 & ,000 &, 611 & 1,637 \\
\hline & DummyCapital &,- 178 &, 057 &,- 092 & $-3,123$ &, 002 &, 910 & 1,099 \\
\hline
\end{tabular}

a. Variável dependente: DESEMPENHO

Assim como no modelo 'Geral', todos os coeficientes do modelo são estatisticamente significantes, com exceção do intercepto; e, em termos de importância relativa, tem destaque a variável independente Doc_Espec, que representa a proporção de docentes da IES 'em exercício' com nível de escolaridade correspondente à 'Especialização'.

Os sinais de todos os coeficientes das variáveis independentes do modelo 'Privadas' têm conformidade com os sinais das correlações bivariadas (particulares a este conjunto de dados) entre estas e a variável dependente (DESEMPENHO).

Correlações

\begin{tabular}{|l|r|r|r|}
\hline \multirow{2}{*}{} & \multicolumn{3}{|c|}{ Rô de Spearman } \\
\cline { 2 - 4 } & \multicolumn{3}{|c|}{ DESEMPENHO } \\
\cline { 2 - 4 } & $\begin{array}{c}\text { Correlações } \\
\text { de coeficiente }\end{array}$ & $\begin{array}{c}\text { Sig. (2 } \\
\text { extremidades) }\end{array}$ & N \\
\hline Doc_Espec &,- 228 &, 000 & 1163 \\
Doc_Dout &, 167 &, 000 & 1163 \\
Doc_EmEx_Curso &, 071 &, 015 & 1163 \\
N_Concl &,- 061 &, 039 & 1163 \\
N_Cursos &, 124 &, 000 & 1163 \\
\hline
\end{tabular}


Quanto às hipóteses da pesquisa, no modelo 'Privadas':

- A significância estatística e o sinal positivo do coeficiente de Doc_Dout justifica a não rejeição de H1;

- A significância estatística e o sinal negativo do coeficiente de Doc_Espec justifica a não rejeição de $\mathbf{H} 2$;

- A não inclusão das variáveis independentes Doc_Integ_excl, Doc_Integ_sem_excl ou Doc_Integral justifica a rejeição de H3;

- A não inclusão da variável independente Doc_Parc justifica a rejeição de H4;

- A significância estatística e o sinal positivo do coeficiente de Doc_EmEx_Curso justifica a não rejeição de H5;

- O sinal negativo do coeficiente de N_Concl justifica a rejeição de H6;

- A significância estatística e o sinal positivo do coeficiente de N_Cursos justifica a não rejeição de $\mathbf{H 7}$.

Assim como no modelo 'Geral', a variável independente DummyCapital (que indica se a reitoria ou sede administrativa da IES está localizada na capital de uma UF brasileira ou não) apresenta coeficiente negativo no modelo 'Privadas'. Como a categoria de referência para a criação desta dummy foi "Não", o valor de DESEMPENHO de IES privadas com reitoria ou sede administrativa localizada em capitais é inferior, sofrendo uma redução de 0,178 .

\begin{tabular}{|c|c|c|c|c|}
\hline \multicolumn{5}{|c|}{ Coeficientes $^{a}$} \\
\hline \multirow{2}{*}{\multicolumn{2}{|c|}{ Modelo }} & \multicolumn{3}{|c|}{ Correlações } \\
\hline & & Ordem zero & Parcial & Parte \\
\hline \multirow[t]{6}{*}{1} & Doc_Espec &,- 230 &,- 152 &,- 147 \\
\hline & Doc_Dout &, 199 &, 074 &, 070 \\
\hline & Doc_EmEx_Curso &, 094 & , 111 & , 106 \\
\hline & N_Concl &,- 039 &,- 133 &,- 128 \\
\hline & N_Cursos &, 059 & ,111 & , 106 \\
\hline & DummyCapital &,- 033 &,- 091 &,- 088 \\
\hline
\end{tabular}

a. Variável dependente: DESEMPENHO

Considerando o percentual da variância de DESEMPENHO explicada pelo modelo de regressão $(9,0 \%)$, a variância única de suas variáveis independentes representa grande parte do resultado alcançado, uma vez que estas somam 7,3\%. 
Tabela 11 - Variâncias únicas das variáveis independentes ('Privadas')

\begin{tabular}{|l|c|c|}
\hline Variável independente & $\begin{array}{c}\text { Correlação } \\
\text { semiparcial }\end{array}$ & $\begin{array}{c}\text { Variância única } \\
\text { explicada }\end{array}$ \\
\hline Doc_Espec & $-0,147$ & $2,2 \%$ \\
\hline Doc_Dout & 0,070 & $0,5 \%$ \\
\hline Doc_EmEx_Curso & 0,106 & $1,1 \%$ \\
\hline N_Concl & $-0,128$ & $1,6 \%$ \\
\hline N_Cursos & 0,106 & $1,1 \%$ \\
\hline DummyCapital & $-0,088$ & $0,8 \%$ \\
\hline
\end{tabular}

Os gráficos de resíduos comprovam a aleatoriedade destes e evidenciam que não houve violação das suposições da análise de regressão.

Os diagnósticos por caso apontaram 61 IES (5,2\%) com resíduos padronizados menores que -2 ou maiores que 2; e nenhum caso da amostra tem distância de Cook superior a 1, ou seja, nenhum caso do modelo deve ser excluído.
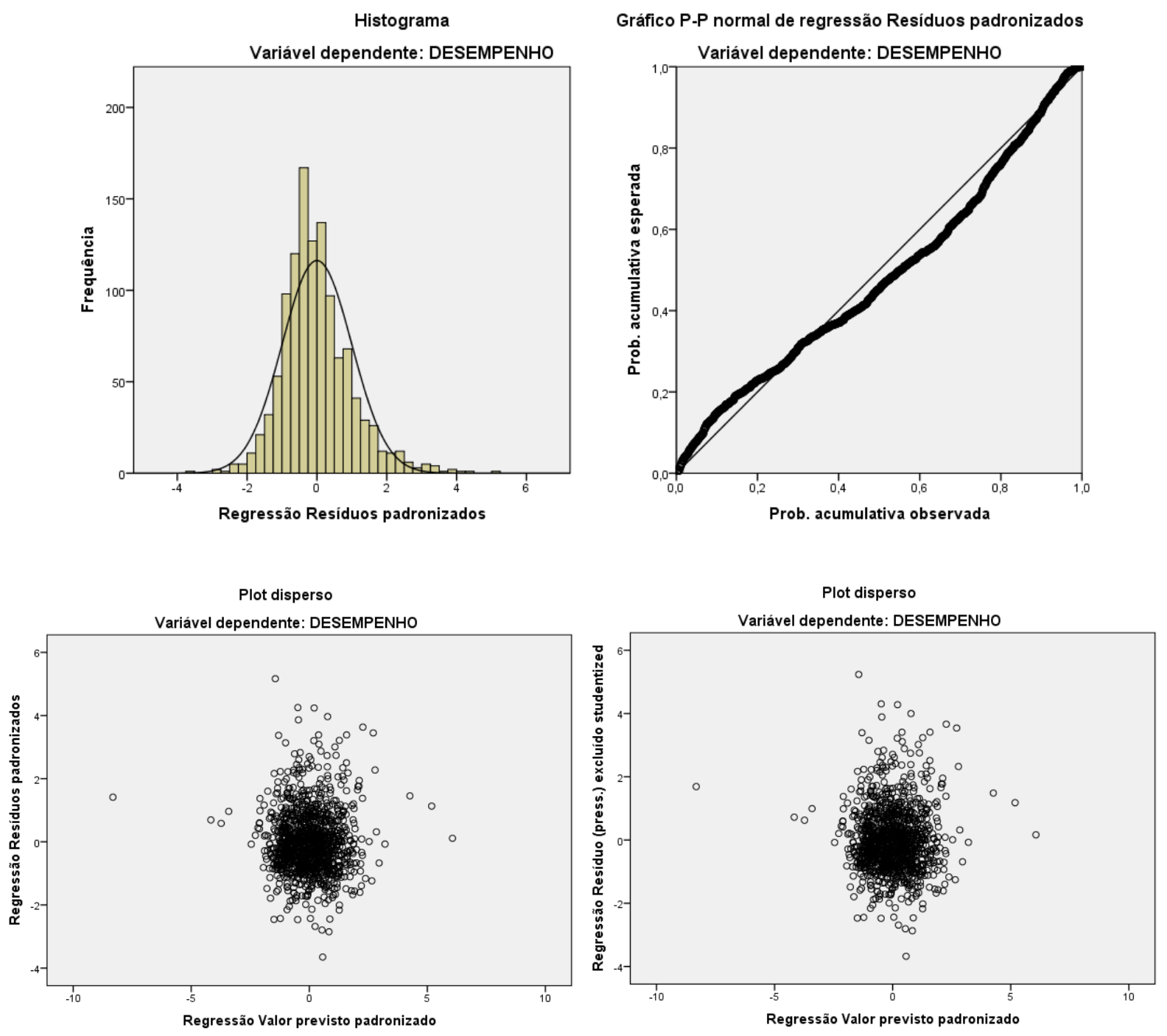


\section{DISCUSSÃO DOS RESULTADOS}

Uma vez que as IES privadas representam 90,4\% do banco de dados, os modelos 'Geral' e 'Privadas' guardam expressiva semelhança: seis variáveis independentes em comum (N_Cursos, N_Concl, Doc_EmEx_Curso, Doc_Espec, Doc_Dout e DummyCapital), sendo a variável Doc_Espec a mais importante em ambos os modelos.

Quadro 6 - Variáveis independentes em comum: 'Geral' e 'Privadas'

\begin{tabular}{|l|l|}
\hline Variável & Descrição \\
\hline N_Cursos & Total de cursos oferecidos pela IES \\
\hline N_Concl & Concluintes de Administração inscritos no ENADE 2012 \\
\hline Doc_EmEx_Curso & $\begin{array}{l}\text { Proporção de docentes da IES 'em exercício' pelo total de } \\
\text { cursos ofertados pela IES }\end{array}$ \\
\hline Doc_Espec & $\begin{array}{l}\text { Proporção de docentes da IES 'em exercício' com nível de } \\
\text { escolaridade correspondente à 'Especialização' }\end{array}$ \\
\hline Doc_Dout & $\begin{array}{l}\text { Proporção de docentes da IES 'em exercício' com nível de } \\
\text { escolaridade correspondente a 'Doutorado' }\end{array}$ \\
\hline DummyCapital & $\begin{array}{l}\text { Localização da reitoria / sede administrativa da IES em } \\
\text { capital estadual } \\
\text { (Sim = 1; Não }=0)\end{array}$ \\
\hline
\end{tabular}

No entanto, estes modelos diferem quanto à quantidade explicada de variância na variável dependente - o modelo 'Geral' explica 23,9\% da variância total de DESEMPENHO das 1.286 IES que constituem o banco de dados deste estudo, enquanto o modelo 'Privadas', criado a partir dos dados de 1.163 IES privadas, explica apenas 9,0\% da variância total de DESEMPENHO.

A abundante variância não-explicada no modelo de regressão 'Privadas' pode resultar tanto de uma limitação não-identificada da variável dependente (DESEMPENHO), quanto do baixo impacto das variáveis independentes do banco de dados (relacionadas às características do corpo docente, à quantidade de docentes por curso, ao número de cursos ofertados e ao número de concluintes) para o desempenho dos alunos de IES privadas no ENADE 2012.

A variável independente DummyCapital está presente nos modelos 'Geral' (coeficiente: -0,160) e 'Privadas' (coeficiente: -0,178). Os valores negativos de seus coeficientes indicam resultados inferiores das IES cuja reitoria ou sede administrativa está localizada em uma capital estadual brasileira, suscitando uma presumível pouca importância 
conferida pelos concluintes dos cursos de Administração destas IES (que correspondem a $33,7 \%$ das 1.286 IES do banco de dados e a 33,5\% das 1.1.63 IES privadas) aos resultados do ENADE, em oposição à importância atribuída à atuação no mercado de trabalho.

O modelo 'Públicas', por sua vez, explicou 60,6\% da variância total de DESEMPENHO das 123 IES públicas do banco de dados (9,6\% do total de IES) a partir de sua variável estatística de regressão, sendo que as variâncias únicas explicadas pelas variáveis independentes deste modelo somam 42,5\% (com destaque para as variáveis Doc_EmEx_Curso e Doc_Integral, cujas variâncias únicas somam 28,4\%).

Quadro 7 - Variáveis independentes: 'Públicas'

\begin{tabular}{|l|l|}
\hline Variável & Descrição \\
\hline N_Cursos & Total de cursos oferecidos pela IES \\
\hline Doc_EmEx_Curso & $\begin{array}{l}\text { Proporção de docentes da IES 'em exercício' pelo total de } \\
\text { cursos ofertados pela IES }\end{array}$ \\
\hline Doc_Integral & $\begin{array}{l}\text { Proporção de docentes da IES 'em exercício' com regime } \\
\text { de trabalho 'Integral' } \\
\text { Escala múltipla, criada a partir da soma das variáveis originais: } \\
\text { - Doc_Integ_excl (Proporção de docentes da IES 'em exercício' } \\
\text { com regime de trabalho 'Integral com dedicação exclusiva'); e } \\
\text { - Doc_Integ_sem_excl (Proporção de docentes da IES 'em } \\
\text { exercício' com regime de trabalho 'Integral sem dedicação } \\
\text { exclusiva'). }\end{array}$ \\
\hline DummyRB3 & $\begin{array}{l}\text { Região do Brasil onde são ofertados os cursos da IES } \\
\text { (Sudeste = 1; Outra região = 0) }\end{array}$ \\
\hline DummyRB4 & $\begin{array}{l}\text { Região do Brasil onde são ofertados os cursos da IES } \\
\text { (Sul = 1; Outra região = 0) }\end{array}$ \\
\hline
\end{tabular}

Das cinco variáveis independentes que compõem o modelo 'Públicas', duas eram dummys que representavam a região do Brasil onde eram ofertados os cursos da IES, indicando resultados superiores dos concluintes de cursos de Administração das IES públicas das regiões Sudeste $(32,5 \%$ das IES públicas) e Sul $(25,2 \%)$. Quanto às razões pelas quais estas duas variáveis foram incluídas no modelo com coeficientes positivos (Sudeste: 0,722; Sul: 0,449), diversas possibilidades emergem: a atração de docentes mais capacitados, dada a reputação das IES públicas destas regiões e a estrutura destes Estados; a estratégia de alocação da verba pública na educação pelas esferas governamentais; ou, ainda, a concentração dos programas de pós-graduação Stricto Sensu nestes Estados (segundo informações disponibilizadas pela CAPES: em 2012, 76,7\% dos programas de Mestrado Acadêmico e Doutorado eram oferecidos por IES das regiões Sudeste e Sul). 
Visto que os três modelos ('Geral', 'Privadas' e 'Públicas') são compostos por diferentes números de variáveis independentes e diferentes tamanhos de amostra, é possível a comparação do poder explicativo por meio da análise do R² ajustado (HAIR Jr. et al., 2009, p. 196). Portanto, pode-se afirmar que o melhor modelo de regressão desenvolvido neste estudo é o modelo 'Públicas' (com $\mathrm{R}^{2}$ ajustado $=0,589$ ), que também apresenta o melhor ajuste geral (com Erro Padrão da estimativa = 0,8031).

Tabela 12 - Resultados dos modelos

\begin{tabular}{|l|c|c|c|}
\hline Modelo & $\mathbf{R}^{\mathbf{2}}$ & $\mathbf{R}^{\mathbf{2}}$ ajustado & Erro Padrão \\
\hline Geral & 0,239 & 0,235 & 0,8753 \\
\hline Públicas & 0,606 & 0,589 & 0,8031 \\
\hline Privadas & 0,090 & 0,086 & 0,8750 \\
\hline
\end{tabular}

As sete hipóteses de pesquisa, criadas a partir dos objetivos específicos deste estudo, foram avaliadas a partir da composição das variáveis estatísticas de regressão dos três modelos desenvolvidos ('Geral', 'Privadas' e 'Públicas'), sendo que, para cada hipótese, foram definidos uma variável independente do banco de dados correspondente e o sinal esperado para o valor de seu coeficiente na variável estatística de regressão.

Quadro 8 - Referência para a avaliação das hipóteses de pesquisa

\begin{tabular}{|c|c|c|c|}
\hline & Escopo & Variável independente & Sinal esperado \\
\hline H1 & \multirow{2}{*}{$\begin{array}{c}\text { Nível de escolaridade do corpo } \\
\text { docente }\end{array}$} & Doc_Dout & Positivo \\
\cline { 3 - 4 } H2 & \multirow{2}{*}{ H3 } & Regime de trabalho do corpo \\
docente & $\begin{array}{c}\text { Doc_Integral; Doc_Integral_excl; } \\
\text { Doc_Integral_sem_excl }\end{array}$ & Pegativo \\
\cline { 3 - 4 } & H4 & Dositivo & Negativo \\
\hline H5 & Docentes por curso superior & Doc_EmEx_Curso & Positivo \\
\hline H6 & Número de concluintes & N_Concl & Positivo \\
\hline H7 & Número de cursos superiores & N_Cursos & Positivo \\
\hline
\end{tabular}

\subsection{Nível de escolaridade do corpo docente da IES}

As hipóteses $\mathrm{H1}$ e $\mathbf{H 2}$ correspondem ao objetivo específico da pesquisa de analisar o efeito do nível de escolaridade do corpo docente para o desempenho dos concluintes de cursos de Administração no ENADE 2012: 
H1: A proporção de docentes com Doutorado no corpo docente da IES tem relação positiva com o desempenho discente no ENADE.

H2: A proporção de docentes com Especialização no corpo docente da IES tem relação negativa com o desempenho discente no ENADE.

Tabela 13 - Coeficientes das variáveis relacionadas às hipóteses H1 e H2

\begin{tabular}{|l|c|c|}
\hline Modelo & Doc_Dout & Doc_Espec \\
\hline Geral & 1,143 & $-0,848$ \\
\hline Públicas & - & - \\
\hline Privadas & 0,816 & $-0,879$ \\
\hline
\end{tabular}

As hipóteses H1 e H2 não foram rejeitadas nos modelos 'Geral' e 'Privadas', uma vez que as variáveis correspondentes à estas hipóteses (Doc_Dout e Doc_Espec) fazem parte de ambos os modelos, com os sinais esperados para seus coeficientes (positivo e negativo, respectivamente).

Por outro lado, as duas hipóteses (H1 e H2) foram rejeitadas no modelo 'Públicas', já que as variáveis independentes Doc_Dout e Doc_Espec não foram incluídas neste modelo, apesar de possuírem correlação significante com a variável dependente e associações moderadas com todas as variáveis independentes métricas do modelo (N_Cursos, Doc_EmEx_Curso e Doc_Integral). As duas variáveis também possuem uma correlação muito forte e negativa entre si $(-0,933)$.

Correlaçöes

\begin{tabular}{|l|r|r|r|}
\hline \multirow{4}{*}{} & \multicolumn{3}{|c|}{ Rô de Spearman } \\
\cline { 2 - 4 } & \multicolumn{3}{|c|}{ DESEMPENHO } \\
\cline { 2 - 4 } & $\begin{array}{c}\text { Correlações } \\
\text { de coeficiente }\end{array}$ & $\begin{array}{c}\text { Sig. (2 } \\
\text { extremidades) }\end{array}$ & N \\
\hline Doc_Dout &, 682 &, 000 & 123 \\
Doc_Espec &,- 662 &, 000 & 123 \\
\hline
\end{tabular}

Correlaçōes

\begin{tabular}{|ll|r|}
\hline & \multicolumn{1}{|c|}{$\begin{array}{c}\text { Rô de } \\
\text { Spearman }\end{array}$} \\
\cline { 3 - 3 } & & Doc_Espec \\
\hline Doc_Dout & Correlações de coeficiente &,- 933 \\
& Sig. (2 extremidades) &, 000 \\
& $N$ & 123 \\
\hline
\end{tabular}




\section{Correlações}

\begin{tabular}{|ll|r|r|r|}
\hline & & \multicolumn{3}{|c|}{ Rô de Spearman } \\
\cline { 3 - 5 } & & N_Cursos & Doc_EmEx_Curso & Doc_Integral \\
\hline Doc_Dout & Correlações de coeficiente &, 612 &, 455 &, 687 \\
& Sig. (2 extremidades) &, 000 &, 000 &, 000 \\
& N & 123 & 123 & 123 \\
\hline Doc_Espec & Correlações de coeficiente &,- 470 &,- 451 &,- 655 \\
& Sig. (2 extremidades) &, 000 &, 000 &, 000 \\
& N & 123 & 123 & 123 \\
\hline
\end{tabular}

Considerando a inclusão de duas dummys relacionadas às regiões do Brasil onde são ofertados os cursos pelas IES (que representam as regiões Sudeste e Sul) no modelo 'Públicas', decidiu-se analisar as estatísticas descritivas de Doc_Dout e de Doc_Espec destes subconjuntos de dados (Sudeste, Sul e Outras regiões).

\section{Estatísticas}

\begin{tabular}{|c|c|c|c|c|c|}
\hline & \multicolumn{3}{|c|}{ Região do Brasil } \\
\hline & & & Sudeste & Sul & $\begin{array}{l}\text { Outras } \\
\text { Regiōes }\end{array}$ \\
\hline \multirow[t]{4}{*}{ Doc_Dout } & \multirow[t]{2}{*}{$\mathrm{N}$} & Válido & 40 & 31 & 52 \\
\hline & & Ausente & 0 & 0 & 0 \\
\hline & \multicolumn{2}{|c|}{ Média } & 449635 & ,362697 & ,331294 \\
\hline & \multicolumn{2}{|c|}{ Modelo padrão } & 2711044 &, 2499894 &, 2172302 \\
\hline \multirow[t]{4}{*}{ Doc_Espec } & \multirow[t]{2}{*}{$N$} & Válido & 40 & 31 & 52 \\
\hline & & Ausente & 0 & 0 & 0 \\
\hline & \multicolumn{2}{|c|}{ Média } & , 138465 & 197019 & 266119 \\
\hline & \multicolumn{2}{|c|}{ Modelo padrão } & ,1518528 & 1813449 & ,2429892 \\
\hline
\end{tabular}

Quanto à proporção de docentes com Doutorado (Doc_Dout), nota-se que as IES públicas do Sudeste têm média $(0,449)$ e desvio-padrão $(0,271)$ superiores às outras regiões do Brasil. Quanto à proporção de docentes com Especialização (Doc_Espec): o Sudeste têm média inferior à região Sul; e, ambas as regiões têm médias e desvios-padrão inferiores às demais regiões do país. Dadas estas diferenças, conclui-se que as duas dummys presentes no modelo 'Públicas' poderiam representar os níveis de escolaridade do corpo docente, não sendo necessária a inclusão das variáveis independentes Doc_Dout e Doc_Espec no modelo 'Públicas'.

Ainda sobre o nível de escolaridade do corpo docente de IES públicas, vale ressaltar que as seleções dos docentes são realizadas por meio de concursos públicos, que estabelecem 
requisitos mínimos para a participação (em termos de formação e produção acadêmica), atraindo grupos homogêneos de candidatos.

\subsection{Regime de trabalho do corpo docente da IES}

As hipóteses $\mathbf{H 3}$ e $\mathbf{H 4}$ correspondem ao objetivo específico da pesquisa de analisar o efeito do regime de dedicação do corpo docente para o desempenho dos concluintes de cursos de Administração no ENADE 2012:

H3: A proporção de regime de dedicação Integral no corpo docente da IES tem relação positiva com o desempenho discente no ENADE.

H4: A proporção de regime de dedicação Parcial no corpo docente da IES tem relação negativa com o desempenho discente no ENADE.

Tabela 14 - Coeficientes das variáveis relacionadas às hipóteses H3 e H4

\begin{tabular}{|l|c|c|}
\hline Modelo & $\begin{array}{c}\text { Doc_Integral, } \\
\text { Doc_Integ_excl ou } \\
\text { Doc_Integ_sem_excl }\end{array}$ & Doc_Parc \\
\hline Geral & 0,588 & $-0,283$ \\
\hline Públicas & 1,669 & - \\
\hline Privadas & - & - \\
\hline
\end{tabular}

No modelo 'Geral', as hipóteses $\mathbf{H 3}$ e $\mathbf{H 4}$ não foram rejeitadas, uma vez que as variáveis Doc_Integ_excl e Doc_Parc fazem parte da sua variável estatística de regressão, com os sinais esperados (positivo e negativo, respectivamente).

Em 'Públicas', H3 não foi rejeitada, dada a presença de Doc_Integral, com coeficiente positivo, na variável estatística. A variável independente Doc_Parc, no entanto, não faz parte do modelo, levando à rejeição de $\mathbf{H 4}$.

Apesar de sua correlação significante com a variável dependente (DESEMPENHO), a força de associação de Doc_Parc com a variável dependente $(-0,228)$ é inferior às forças de associação das variáveis independentes que compõem o modelo 'Públicas'. Além disso, a análise descritiva revela média $(0,667)$ e desvio-padrão $(0,339)$ superiores da proporção de regime de dedicação Integral nos corpos docentes das IES públicas, representada pela variável 
independente Doc_Integral, que compõe a variável estatística de regressão do modelo 'Públicas'.

\section{Correlações}

\begin{tabular}{|l|r|r|r|}
\hline \multirow{2}{*}{} & \multicolumn{3}{|c|}{ Rô de Spearman } \\
\cline { 2 - 4 } & \multicolumn{3}{|c|}{ DESEMPENHO } \\
\cline { 2 - 4 } & $\begin{array}{c}\text { Correlações } \\
\text { de coeficiente }\end{array}$ & $\begin{array}{c}\text { Sig. (2 } \\
\text { extremidades) }\end{array}$ & $\mathrm{N}$ \\
\hline Doc_Parc &,- 228 &, 011 & 123 \\
N_Cursos &, 461 &, 000 & 123 \\
Doc_EmEx_Curso &, 546 &, 000 & 123 \\
Doc_Integral &, 553 &, 000 & 123 \\
\hline
\end{tabular}

\section{Estatísticas}

\begin{tabular}{|ll|r|r|}
\hline & & Doc_Parc & Doc_Integral \\
\hline $\mathrm{N}$ & Válido & 123 & 123 \\
& Ausente & 0 & 0 \\
Média &, 172855 &, 667146 \\
Mediana &, 099600 &, 854700 \\
Modelo padrão &, 1996673 &, 3388136 \\
\hline
\end{tabular}

No modelo 'Privadas', ambas as hipóteses H3 e $\mathbf{H 4}$ foram rejeitadas dada a supressão das três variáveis independentes do banco de dados que poderiam representar o a proporção de docentes atuando em regime de dedicação 'Integral' (Doc_Integral, Doc_Integ_excl e Doc_Integ_sem_excl), bem como de Doc_Parc, que representava a proporção de docentes trabalhando em regime de dedicação 'Parcial'.

Correlações

\begin{tabular}{|l|r|r|r|}
\hline \multirow{2}{*}{} & \multicolumn{3}{|c|}{ Rô de Spearman } \\
\cline { 2 - 4 } & \multicolumn{3}{|c|}{ DESEMPENHO } \\
\cline { 2 - 4 } & $\begin{array}{c}\text { Correlações } \\
\text { de coeficiente }\end{array}$ & $\begin{array}{c}\text { Sig. (2 } \\
\text { extremidades) }\end{array}$ & N \\
\hline Doc_Integral &, 074 &, 012 & 1163 \\
Doc_Integ_excl &,- 032 &, 279 & 1163 \\
Doc_Integ_sem_excl &, 071 &, 015 & 1163 \\
Doc_Parc &,- 035 &, 228 & 1163 \\
\hline
\end{tabular}

As variáveis Doc_Parc e Doc_Integ_excl não têm correlações significantes com a variável dependente (DESEMPENHO). Apesar de Doc_Integral e Doc_Integ_sem_excl terem 
associações significantes com a variável dependente, estas são apenas correlações leves (0,074 e 0,071, respectivamente).

Estatísticas

\begin{tabular}{|lr|r|r|r|r|}
\hline & & Doc_Integral & Doc_Integ_sem_excl & Doc_Parc & Doc_Hor \\
\hline $\mathrm{N}$ & Válido & 1163 & 1163 & 1163 & 1163 \\
& Ausente & 0 & 0 & 0 & 0 \\
Média &, 177658 &, 153212 &, 365548 &, 456794 \\
Mediana &, 156800 &, 121600 &, 342900 &, 468200 \\
Modelo padrão &, 1465375 &, 1384542 &, 2259787 &, 2720087 \\
\hline
\end{tabular}

Uma análise descritiva destas variáveis independentes revela que a contratação de docentes em regime Integral não é prioridade para as IES privadas. A predominância do regime de dedicação Horista, seguido pelo regime Parcial, é constatada pelas médias e desvios-padrão das variáveis do banco de dados relacionadas a tais regimes (Doc_Hor e Doc_Parc, respectivamente).

\subsection{Proporção de docentes por curso superior da IES}

A hipótese $\mathbf{H 5}$ corresponde ao objetivo específico da pesquisa de analisar o efeito da quantidade de docentes por curso ofertado pela IES para o desempenho dos concluintes de cursos de Administração no ENADE 2012:

H5: O número de docentes por curso da IES tem relação positiva com o desempenho discente no ENADE.

Tabela 15 - Coeficientes da variável relacionada à hipótese H5

\begin{tabular}{|l|c|}
\hline Modelo & Doc_EmEx_Curso \\
\hline Geral & 0,023 \\
\hline Públicas & 0,075 \\
\hline Privadas & 0,017 \\
\hline
\end{tabular}

Visto que a variável Doc_EmEx_Curso faz parte dos três modelos criados por este estudo, a hipótese $\mathbf{H 5}$ não foi rejeitada por nenhum deles - afirmando a relação positiva entre 
o número de docentes a serviço de um curso e o desempenho dos concluintes dos cursos de graduação em Administração.

Um número maior de docentes por curso poderia, assim, prover-lhes mais liberdade e flexibilidade para o desenvolvimento de suas atividades fora da sala de aula (pesquisas, estudos, preparação e atualização de materiais didáticos, entre outros), como proposto no Capítulo 1.2. Além disso, sendo cada docente responsável por um número menor de disciplinas (maior distribuição do trabalho), é possível que seja reduzida a pressão, a fadiga e o stress destes profissionais.

A criação da variável Doc_EmEx_Curso, no entanto, carregou consigo uma limitação conceitual (já exposta no Capítulo 3.3): a partir dos Microdados do Censo da Educação Superior 2012, fora possível calcular tanto o número de docentes, quanto o número de cursos oferecidos por cada IES - e, da divisão daquele valor por este, resultaram os valores de Doc_EmEx_Curso. Isto é, não foi possível identificar, com precisão, os docentes dos cursos de administração. A variável Doc_EmEx_Curso é, portanto, uma proxy do número de docentes ‘em exercício’ dos cursos de Administração de uma IES, em 2012.

\subsection{Número de concluintes dos cursos de Administração}

H6: O total de concluintes dos cursos de Administração da IES tem relação positiva com o desempenho discente no ENADE.

Tabela 16 - Coeficientes da variável relacionada à hipótese H6

\begin{tabular}{|l|c|}
\hline Modelo & N_Concl \\
\hline Geral & $-0,001$ \\
\hline Públicas & - \\
\hline Privadas & $-0,001$ \\
\hline
\end{tabular}

Como exposto no Capítulo 4.1, a hipótese H6 não foi rejeitada pelo modelo 'Geral', apesar do sinal negativo do coeficiente de N_Concl (-0,001). Houve uma inversão do sinal (em relação ao esperado), explicada pela associação moderada $(0,568)$ entre esta variável independente e N_Cursos (também presente no modelo 'Geral'). Desta forma, H6 não foi rejeitada com base na especificação do modelo 'Geral'. 


\section{Correlaçōes}

\begin{tabular}{|ll|r|}
\hline & \multicolumn{1}{|c|}{$\begin{array}{c}\text { Rô de } \\
\text { Spearman }\end{array}$} \\
\cline { 3 - 3 } & N_Concl \\
\hline N_Cursos & Correlações de coeficiente &, 568 \\
& Sig. (2 extremidades) &, 000 \\
& N & 1286 \\
\hline
\end{tabular}

No modelo 'Públicas', a variável independente N_Concl têm correlação significante $(0,217)$ com a variável dependente (DESEMPENHO). No entanto, esta variável não foi incluída no modelo, uma vez que o valor dessa associação é visivelmente inferior às correlações que as variáveis independentes do modelo possuem com DESEMPENHO.

Correlaçōes

\begin{tabular}{|l|r|r|r|}
\hline \multirow{2}{*}{} & \multicolumn{3}{|c|}{ Rô de Spearman } \\
\cline { 2 - 4 } & \multicolumn{3}{|c|}{ DESEMPENHO } \\
\cline { 2 - 4 } & $\begin{array}{c}\text { Correlações } \\
\text { de coeficiente }\end{array}$ & $\begin{array}{c}\text { Sig. (2 } \\
\text { extremidades) }\end{array}$ & N \\
\hline N_Concl &, 217 &, 016 & 123 \\
N_Cursos &, 461 &, 000 & 123 \\
Doc_EmEx_Curso &, 546 &, 000 & 123 \\
Doc_Integral &, 553 &, 000 & 123 \\
\hline
\end{tabular}

Estatísticas

\begin{tabular}{|c|c|c|c|c|}
\hline & & \multicolumn{3}{|c|}{ Região do Brasil } \\
\hline & & Sudeste & Sul & $\begin{array}{l}\text { Outras } \\
\text { Regiöes }\end{array}$ \\
\hline \multirow[t]{2}{*}{ N } & Válido & 40 & 31 & 52 \\
\hline & Ausente & 0 & 0 & 0 \\
\hline \multicolumn{2}{|c|}{ Média } & 120,38 & 143,94 & 214,00 \\
\hline \multicolumn{2}{|c|}{ Mediana } & 73,50 & 115,00 & 126,00 \\
\hline \multicolumn{2}{|c|}{ Modelo padrão } & 101,617 & 116,842 & 347,966 \\
\hline
\end{tabular}

Além disso, uma análise das estatísticas descritivas desta variável independente, segundo as regiões do Brasil (dada a inclusão das dummys que representam o Sudeste e o Sul), nota-se que a média e o desvio-padrão do número de concluintes dos cursos de Administração de IES públicas são muito maiores para as demais regiões (Centro-Oeste, Nordeste e Norte, combinados). Dessa forma, as possíveis contribuições que a variável 
independente N_Concl traria ao modelo 'Públicas' são representadas pelas duas dummys relacionadas à região do Brasil onde são ofertados os cursos da IES.

Já, no modelo 'Privadas', a rejeição de H6 é justificada pelo sinal negativo do coeficiente de N_Concl em sua variável estatística de regressão (como determina a hipótese, era esperado sinal positivo).

\subsection{Número de cursos superiores oferecidos pela IES}

H7: O volume de cursos oferecidos pela IES tem relação positiva com o desempenho discente no ENADE.

Tabela 17 - Coeficientes da variável relacionada à hipótese H7

\begin{tabular}{|l|c|}
\hline Modelo & N_Cursos \\
\hline Geral & 0,004 \\
\hline Públicas & 0,005 \\
\hline Privadas & 0,003 \\
\hline
\end{tabular}

A hipótese $\mathbf{H 7}$ não foi rejeitada por nenhum dos três modelos, devido à inclusão, em todos eles, da variável independente N_Cursos com coeficientes positivos. Desta forma, foi confirmada a relação positiva entre o número de cursos (das diversas áreas) ofertados por uma IES e o desempenho dos concluintes de seus cursos de graduação em Administração.

Conforme proposto no Capítulo 1.2, a oferta de um número maior de cursos demandaria, da IES, mais ampla estrutura disponível aos alunos (em termos de salas de aula, bibliotecas e espaços de convívio, entre outros) e um número maior de docentes 'em exercício'. À vista disso, nas IES que ofertam um número maior de cursos, seria promovida a diversidade no ambiente estudantil e nas redes de contatos dos alunos; além de maiores oportunidades para a promoção de abordagens interdisciplinares. 


\section{CONCLUSÃO}

O crescimento quantitativo da educação superior no Brasil (tanto no número de IES quanto nos volumes de cursos e de matrículas), impulsionado por políticas públicas que flexibilizaram e incentivaram este processo, transformou o foco da política educacional brasileira na busca pela melhoria da qualidade do ensino. Assim, este estudo se propôs a explorar as influências das características do corpo docente sobre o desempenho dos alunos dos cursos de Administração no ENADE (instrumento nacional de avaliação periódica dos estudantes do ensino superior).

A partir dos dados disponibilizados pelo INEP (os Microdados ENADE 2012 e os Microdados Censo da Educação Superior 2012), foi criado um banco de dados que serviu ao desenvolvimento de três modelos de regressão múltipla: 'Geral', modelo genérico que analisou os dados de 1.286 IES que ofertaram cursos de graduação em Administração em 2012; 'Públicas', que explorou os dados de 123 IES públicas; e 'Privadas', correspondente a 1.163 IES privadas.

A variável dependente empregada na construção destes modelos estatísticos (DESEMPENHO) foi criada por meio de uma análise fatorial, pelo método de componentes principais, a partir de cinco variáveis métricas que mensuravam objetivamente os resultados alcançados pelos alunos concluintes de cada IES.

As variáveis independentes do banco de dados incluíam medidas objetivas do nível de escolaridade e do regime de trabalho do corpo docente, bem como a proporção de docentes por curso ofertados pela IES, o volume de cursos ofertados pela IES, o volume de concluintes de cursos de Administração da IES e dummys de variáveis não-métricas que representavam: a categoria administrativa da IES, a organização acadêmica da IES, a região do Brasil onde eram ofertados os cursos da IES e a localização da reitoria ou sede administrativa da IES (capital de UF brasileira ou não).

O melhor dos três modelos de regressão múltipla desenvolvidos, em termos de poder explicado e de ajuste geral, foi o modelo 'Públicas', que explicou 60,6\% da variância total de DESEMPENHO das 123 IES públicas do banco de dados (com $\mathrm{R}^{2}$ ajustado: 0,589, e erro padrão: 0,8031).

O modelo indica o desempenho superior das IES públicas das regiões Sudeste e Sul do Brasil e, segundo critérios de importância relativa, teve destaque a variável independente que representa a proporção do corpo docente "em exercício" em regime de dedicação Integral. 
Apesar das semelhanças entre suas variáveis estatísticas de regressão (seis variáveis independentes em comum), decorrente da proporção das IES privadas no banco de dados $(90,4 \%)$, os modelos 'Geral' e 'Privadas' diferem substancialmente em relação à quantidade explicada de variância na variável dependente: enquanto o modelo 'Geral' explicou 23,9\% da variância total de DESEMPENHO das 1.286 IES do banco de dados, o modelo 'Privadas' explicou apenas 9,0\% da variância total de DESEMPENHO das 1.163 IES privadas.

Quanto ao medíocre desempenho do modelo de regressão múltipla 'Privadas', foram apontadas as possibilidades de uma limitação não-identificada da variável dependente, ou da baixa relevância das variáveis abordadas por esta pesquisa para o desempenho dos alunos de Administração das IES privadas no ENADE 2012.

Em ambos os modelos ('Geral' e 'Privadas'), a variável de maior importância relativa correspondia à proporção de docentes "em exercício" com nível de escolaridade Especialização (pós-graduação Lato Sensu). Além disso, foi apontado o desempenho inferior no ENADE 2012 das IES privadas com sede administrativa ou reitoria localizada nas capitais dos Estados Brasileiros.

Quadro 9 - Resultados das hipóteses de pesquisa, baseados na composição dos modelos

\begin{tabular}{|c|c|c|c|}
\hline Hipótese & Geral & Públicas & Privadas \\
\hline H1 & Não rejeita & Rejeita & Não rejeita \\
\hline H2 & Não rejeita & Rejeita & Não rejeita \\
\hline H3 & Não rejeita & Não rejeita & Rejeita \\
\hline H4 & Não rejeita & Rejeita & Rejeita \\
\hline H5 & Não rejeita & Não rejeita & Não rejeita \\
\hline H6 & Não rejeita & Rejeita & Rejeita \\
\hline H7 & Não rejeita & Não rejeita & Não rejeita \\
\hline
\end{tabular}

Concluiu-se que o nível de escolaridade do corpo docente tem relação significativa com o desempenho dos concluintes de cursos de Administração no ENADE 2012. Como proposto pelas hipóteses $\mathbf{H 1}$ e H2, a proporção de docentes com Doutorado tem impacto positivo sobre o desempenho discente; e, em contrapartida, a proporção de docentes com pósgraduação Lato Sensu tem impacto negativo sobre o desempenho discente (Capítulo 5.1).

O impacto positivo do número de profissionais docentes "em exercício" por curso de graduação ofertado pela IES para o desempenho dos concluintes de Administração no ENADE 2012, proposto pela hipótese H5, foi comprovado, a partir dos resultados obtidos pelos três modelos de regressão múltipla desenvolvidos. 
Da mesma forma, atestou-se a relação positiva e a capacidade preditiva do volume de cursos de graduação oferecidos pela IES (das diversas áreas) sobre o desempenho dos concluintes de cursos de Administração no ENADE 2012, como proposto pela hipótese H7.

Por outro lado, sobre a hipótese H6, que propôs uma relação positiva entre o total de concluintes dos cursos de Administração da IES e o desempenho destes no ENADE 2012, os resultados foram inconclusivos - a hipótese não foi rejeitada pelo modelo 'Geral', mas foi veementemente rejeitada tanto pelo modelo 'Públicas' quanto pelo modelo 'Privadas'.

Os resultados obtidos nas investigações de $\mathbf{H 3}$ ("a proporção de regime de dedicação Integral no corpo docente da IES tem relação positiva com o desempenho discente no ENADE”) e H4 (“a proporção de regime de dedicação Parcial no corpo docente da IES tem relação negativa com o desempenho discente no ENADE”) também são controversos.

A hipótese H3 não foi rejeitada pelos modelos 'Geral' e 'Públicas'. De fato, a variável relacionada ao regime de dedicação Integral é a mais importante no modelo 'Públicas'. Desta forma, é possível afirmar, com propriedade, que existe relação positiva entre a proporção do corpo docente em regime de dedicação Integral e o desempenho discente no contexto das IES públicas.

A variável relacionada à dedicação Parcial, por sua vez, aparece no modelo 'Geral' (e portanto, H4 não foi rejeitada por este) e foi ocultada no modelo 'Públicas', por trazer pouca contribuição ao modelo, dada a predominância do regime de dedicação Integral nas IES públicas. Pode-se afirmar, portanto, que a proporção do corpo docente em regime de dedicação Parcial tem capacidade preditiva do desempenho dos concluintes de cursos de Administração oferecidos por IES públicas.

O modelo 'Privadas', no entanto, rejeitou as duas hipóteses (H3 e H4). Desta forma, conclui-se que variáveis relacionadas ao regime de dedicação do corpo docente não têm capacidade preditiva do desempenho discente dos concluintes de Administração de IES privadas.

Como principal sugestão para o desenvolvimento de novos estudos que complementem os resultados alcançados, é apontada uma análise metodologicamente similar, referente ao ENADE 2015, que reavaliou o curso de Administração, quando os Microdados ENADE 2015 e os Microdados Censo da Educação Superior 2015 forem disponibilizados pelo INEP. Tal estudo permitirá uma análise da consistência das conclusões aqui obtidas, e evidenciará possíveis modificações nos efeitos que as variáveis estudadas tiveram sobre o desempenho discente, três anos depois. 
Além disso, recomendam-se novas pesquisas que explorem outras variáveis independentes objetivas que podem influenciar o desempenho discente dos concluintes de cursos de Administração no ENADE - como, por exemplo, a tradição da IES na área (evidenciada pelo ano de criação do seu primeiro curso de Administração), as características pessoais e profissionais do coordenador do curso, a estrutura curricular e os elementos que compõem o seu projeto pedagógico.

Especificamente quanto aos cursos de graduação em Administração ofertados por IES privadas, sugere-se a criação de novos modelos de regressão múltipla, compostos por variáveis independentes relacionadas às características demográficas e ao background do corpo discente, buscando explicar uma proporção maior da variância do desempenho dos seus concluintes no ENADE.

Estudos de caso a respeito dos cursos de Administração oferecidos pela USP - em São Paulo (FEA-SP), em Ribeirão Preto (FEA-RP) e em Piracicaba (ESALQ), que não são avaliados pelo ENADE, porém têm sólida reputação no mercado de trabalho - e pelas quatro IES excluídas durante a análise de outliers das variáveis independentes métricas (Faculdade de Administração da Fundação Armando Álvares Penteado, Escola de Administração de Empresas de São Paulo, Universidade Luterana do Brasil e Universidade Norte do Paraná) podem gerar contribuições relevantes para a ampliação do conhecimento científico.

Por fim, recomenda-se uma pesquisa quantitativa que explore a percepção que os alunos concluintes dos cursos de Administração têm sobre o ENADE e as suas motivações para um bom desempenho no exame poderia prover inputs significativos para a compreensão do desempenho discente inferior de IES com sede administrativa ou reitoria localizada em capitais estaduais no modelo 'Privadas', bem como do desempenho discente superior de IES das regiões Sudeste e Sul no modelo 'Públicas'.

Todos os objetivos propostos por este estudo foram alcançados. O conhecimento científico sobre a influência das características do corpo docente e da IES sobre o desempenho discente, no tocante aos cursos de Administração, foi consideravelmente ampliado. Mais importante do que isto, espera-se que estes resultados estimulem a geração e exploração de novas hipóteses, consolidando a relevância da linha de pesquisa e trazendo contribuições práticas que promovam, de fato, uma melhoria contínua da qualidade do ensino de Administração no Brasil. 


\title{
REFERÊNCIAS BIBLIOGRÁFICAS
}

\author{
ANDERSON, D. R.; SWEENEY, D. J.; WILLIAMS, T. A. Estatística aplicada à \\ administração e economia. 2. ed. São Paulo: Cengage Learning, 2011. 597 p.
}

ANDRADE, E. C. Rankings em educação: tipos, problemas, informações e mudanças: análise dos principais rankings oficiais brasileiros. Estudos Econômicos, São Paulo, v. 41, n. 2, p. 323-343, abr.-jun. 2011. Disponível em: 〈http://www.scielo.br/pdf/ee/v41n2/a05v41n2.pdf>. Acesso em: 23 nov. 2015.

ARAÚJO, E. A. T. et al. Desempenho acadêmico de discentes do curso de ciências contábeis: uma análise dos seus fatores determinantes em uma IES privada. Revista Contabilidade Vista \& Revista, Belo Horizonte, v. 24, n. 1, p. 60-83, jan.-mar. 2013. Disponível em: $<$ http://revistas.face.ufmg.br/index.php/contabilidadevistaerevista/article/view/1181/pdf_45>. Acesso em: 26 nov. 2015.

BITTENCOURT, H. R. et al. Uma análise da relação entre os conceitos ENADE e IDD. Estudos em Avaliação Educacional, v. 19, n. 40, p. 247-262, maio-ago. 2008. Disponível em: <http://www.fcc.org.br/pesquisa/publicacoes/eae/arquivos/1439/1439.pdf>. Acesso em: 16 nov. 2015.

BRASIL. Congresso Nacional. Câmara dos Deputados. Lei no 9.394, de 20 de dezembro de 1996. Estabelece as diretrizes e bases da educação nacional. Diário Oficial da União, Brasília, 23 dez. 1996. Seção1, p. 27833-27841. Disponível em: <http://www.planalto.gov.br/ccivil_03/LEIS/L9394.htm>. Acesso em: 09 out. 2015.

Lei $n^{\circ}$ 10.861, de 14 de abril de 2004. Institui o Sistema Nacional de Avaliação da Educação Superior - SINAES e dá outras providências. Diário Oficial da União, Brasília, DF, 15 abr. 2004. Seção 1, p. 3. Disponível em:

<http://www.planalto.gov.br/ccivil_03/_ato2004-2006/2004/lei/110.861.htm>. Acesso em: 19 nov. 2015.

Conselho Nacional de Educação. Câmara de Educação Superior. Resolução no 4, de 13 de julho de 2005. Institui as Diretrizes Curriculares Nacionais para o Curso de Graduação em Administração, bacharelado, e dá outras providências. Diário Oficial da União, Brasília, 19 jul. 2005. Seção 1, p. 26-27. Disponível em:

<http://portal.mec.gov.br/cne/arquivos/pdf/rces004_05.pdf>. Acesso em: 09 out. 2015.

Ministério da Educação. Gabinete do Ministro. Portaria Normativa $n^{\circ} 40$, de 12 de dezembro de 2007. Institui o e-MEC, sistema eletrônico de fluxo de trabalho e gerenciamento de informações relativas aos processos de regulação, avaliação e supervisão da educação superior no sistema federal de educação, e o Cadastro e-MEC de Instituições e Cursos Superiores e consolida disposições sobre indicadores de qualidade, banco de avaliadores (Basis) e o Exame Nacional de Desempenho de Estudantes (ENADE) e outras disposições.

Diário Oficial da União, Brasília, DF, 29 dez. 2010. Seção 1, p. 23. Disponível em: <http://download.inep.gov.br/download//superior/2011/portaria_normativa_n40_12_dezembr o_2007.pdf>. Acesso em: 18 nov. 2015. 
Ministério da Educação. Gabinete do Ministro. Portaria Normativa ${ }^{\circ}$ 6, de 14 de março de 2012. Diário Oficial da União, Brasília, DF, 15 mar. 2012. Seção 1, p. 5. Disponível em: <http://download.inep.gov.br/educacao_superior/enade/legislacao/2012/portaria_normativa_n 6_14032012.pdf>. Acesso em: 18 nov. 2015.

Ministério da Educação. Instituto Nacional de Estudos e Pesquisas Educacionais Anísio Teixeira. Portaria ${ }^{\mathbf{o}}$ 201, de 22 de junho de 2012. Diário Oficial da União, Brasília, DF, 25 jun. 2012. Seção 1, p. 14. Disponível em: <http://download.inep.gov.br/educacao_superior/enade/legislacao/2012/portarias_diretrizes_e nade_2012.pdf >. Acesso em: 18 nov. 2015.

BRITO, M. R. F. O SINAES e o ENADE: da concepção à implantação. Avaliação: Revista da Avaliação da Educação Superior, Sorocaba, v. 13, n. 3, p. 841-850, nov. 2008. Disponível em: <http://www.scielo.br/pdf/aval/v13n3/14.pdf>. Acesso em: 20 nov. 2015.

CLOSS, L. Q.; ARAMBURU, J. V.; ANTUNES, E. D. Produção científica sobre o ensino em administração: uma avaliação envolvendo o enfoque do paradigma da complexidade. Revista Eletrônica de Gestão Organizacional, Recife, v. 7, n. 2, p. 150-169, maio-ago. 2009. Disponível em: <http://www.revista.ufpe.br/gestaoorg/index.php/gestao/article/view/27>. Acesso em: 11 out. 2015.

COSTA, G. M. T. Projeto politico-pedagógico: elementos de sua identidade e situações pedagógicas do cotidiano que são provocadoras de um processo de ressignificação. Revista de Educação do IDEAU, Getúlio Vargas, v. 6, n. 14, jul.-dez. 2011. Disponível em: <http://www.ideau.com.br/getulio/restrito/upload/revistasartigos/144_1.pdf>. Acesso em: 13 nov. 2015.

DAMETTO, J.; ESQUINSANI, R. S. S. Avaliação educacional em larga escala: performatividade e perversão da experiência educacional. Educação (UFSM), Santa Maria, v. 40, n. 3, set.-dez. 2015. Disponível em: < http://cascavel.ufsm.br/revistas/ojs2.2.2/index.php/reveducacao/article/view/13742/pdf>. Acesso em: 24 nov. 2015.

DIAS, C. L.; HORIGUELA, M. L. M.; MARCUELLI, P. S. Políticas para a avaliação da qualidade do ensino superior no Brasil: um balanço crítico. Educação e Pesquisa, v. 32, n. 3, p. 435-64, 2006. Disponível em: 〈http://www.scielo.br/pdf/ep/v32n3/a02v32n3.pdf>. Acesso em: 18 nov. 2015.

DIAS SOBRINHO, J. Avaliação e transformações da educação superior brasileira (19952009): do Provão ao SINAES. Avaliação: Revista da Avaliação da Educação Superior, Sorocaba, v. 15, n. 1, p. 195-224, mar. 2010. Disponível em: <http://www.scielo.br/pdf/aval/v15n1/v15n1a11.pdf>. Acesso em: 27 nov. 2015.

ENGWALL, L. The anatomy of management education. Scandinavian Journal of Management, v. 23, n. 1, p. 4-35, Mar. 2007. Disponível em: <http://www.sciencedirect.com/science/article/pii/S0956522106001060>. Acesso em: 25 set. 2015.

FIELD, A. Descobrindo a estatística usando SPSS. Tradução de Lorí Viali. 2. ed. Porto Alegre: Artmed, 2009. 688 p. 
HAIR Jr., J. F. et al. Fundamentos de métodos de pesquisa em Administração. Tradução de Lene Balon Ribeiro. Porto Alegre: Bookman, 2005. 471 p.

HAIR Jr., J. F. et al. Análise multivariada de dados. Tradução de Adonai Schlup Sant'Anna. 6. ed. Porto Alegre: Bookman, 2009. 688 p.

GOMES; D. F. N.; BARRETO, M. S. P. Currículo e estratégias de ensinagem em administração: reflexões sobre o grau de aderência de pesquisadores da área. Revista Diálogos Interdisciplinares, Mogi das Cruzes, v. 3, n. 2, p. 84-99, 2014. Disponível em: <http://www3.brazcubas.br/ojs2/index.php/dialogos/article/view/54>. Acesso em: 13 nov. 2015.

INEP. Diretoria de Avaliação da Educação Superior. Nota Metodológica, Brasília/DF, out. 2013. Disponível em:

<http://download.inep.gov.br/educacao_superior/enade/notas_tecnicas/2012/nota_metodologi ca_indicadores_2012.pdf>. Acesso em: 16 nov. 2015.

LEMOS, K. C. S.; MIRANDA, G. J. Alto e baixo desempenho no ENADE: que variáveis explicam? Revista Ambiente Contábil, Natal, v. 7, n. 2, p. 101-118, jul.-dez. 2015.

Disponível em:

$<$ http://ccsa.ufrn.br/ojs/index.php?journal=contabil\&page=article\&op=view\&path\%5B $\% 5 \mathrm{D}=$ 546\&path\%5B\%5D=522>. Acesso em: 13 dez. 2015.

LOURENÇO, C. D. S. et al. Produção científica brasileira sobre ensino de administração: 1997-2010. Revista Pensamento Contemporâneo em Administração, Niterói, v. 6, n. 1, p. 4-22, jan.-mar. 2012. Disponível em: <http://www.uff.br/pae/pca/article/view/119>. Acesso em: 11 out. 2015.

MIRANDA, G. J.; CASA NOVA, S. P. C.; CORNACCHIONE Jr., E. B. Ao mestre com carinho: relações entre as qualificações docentes e o desempenho discente em contabilidade.

Revista Brasileira de Gestão de Negócios, São Paulo, v. 15, n. 48, p. 462-481, jul.-set. 2013. Disponível em: <http://rbgn.fecap.br/RBGN/article/download/1351/pdf_14>. Acesso em: 01 dez. 2015.

MIRANDA, G. J. et al. Determinantes do desempenho acadêmico na área de negócios.

Revista Meta: Avaliação, Rio de Janeiro, v. 7, n. 20, p. 175-209, maio-ago. 2015. Disponível em: <http://revistas.cesgranrio.org.br/index.php/metaavaliacao/article/view/264/pdf>. Acesso em: 02 dez. 2015.

MORICONI, G. M.; NASCIMENTO, P. A. M. M. Fatores associados ao desempenho dos concluintes de engenharia no ENADE 2011. Estudos em Avaliação Educacional, São Paulo, v. 25, n. 57, p. 248-278, jan.-abr. 2014. Disponível em:

<http://publicacoes.fcc.org.br/ojs/index.php/eae/article/view/2831>. Acesso em: 09 dez. 2015.

MOURA, B. A.; MOURA, L. B. A. Ranqueamento de universidades: reflexões acerca da construção de reconhecimento institucional. Acta Scientiarum. Education, Maringá, v. 35, n. 2, p. 213-222, jul.-dez. 2013. Disponível em:

<http://dialnet.unirioja.es/servlet/articulo?codigo=4864798>. Acesso em: 30 nov. 2015. 
NUNES, E. Desafio estratégico da política pública: o ensino superior brasileiro. Revista de Administração Pública, Rio de Janeiro, v. 41, p. 103-147, 2007. Número especial. Disponível em: <http://www.scielo.br/pdf/rap/v41nspe/a08v41sp.pdf>. Acesso em: 12 nov. 2015.

OLIVEIRA, A. L.; LOURENÇO, C. D. S.; CASTRO, C. C. Ensino de administração nos EUA e no Brasil: uma análise histórica. Revista Pretexto, Belo Horizonte, v. 16, n. 1, p. 11 22, jan.-mar. 2015. Disponível em:

<http://www.fumec.br/revistas/pretexto/article/view/1830>. Acesso em: 12 out. 2015.

PESTANA, M. H.; GAGEIRO, J. N. Análise de dados para ciências sociais: a complementaridade do SPSS. 5. ed. Lisboa: Edições Sílabo, 2008. 692 p.

POLIDORI, M. M. Políticas de avaliação da educação superior brasileira: Provão, SINAES, IDD, CPC, IGC e...outros índices. Avaliação: Revista da Avaliação da Educação Superior, Sorocaba, v. 14, n. 2, p. 439-452, jul. 2009. Disponível em:

<http://www.scielo.br/pdf/aval/v14n2/a09v14n2.pdf>. Acesso em: 04 nov. 2015.

RIBEIRO, D. A.; SACRAMENTO, A. R. S. Ensino e currículo em administração: a opção brasileira. Revista Gestão e Planejamento, Salvador, v. 10, n. 2, p. 193-205, jul.-dez. 2009. Disponível em: <http://www.revistas.unifacs.br/index.php/rgb/article/view/751/769>. Acesso em: 02 out. 2015.

SAMPIERI; R. H.; COLLADO, C. F.; LUCIO, P. B. Metodologia de Pesquisa. 3. ed. Tradução de Fátima Conceição Murad, Melissa Kassner e Sheila Clara Dystyler Ladeira. São Paulo: McGraw-Hill, 2006. 583 p.

STARKEY, K.; HATCHUEL, A.; TEMPEST, S. Rethinking the business school. Journal of Management Studies, v. 41, n. 8, p. 1521-1531, Dec. 2004. Disponível em:

<http://onlinelibrary.wiley.com/doi/10.1111/j.1467-6486.2004.00485.x/abstract>. Acesso em: 25 set. 2015.

UNIVERSIDADE DE SÃO PAULO. USP assina acordo com MEC e INEP para participar do Enade. 07 ago. 2013. Disponível em:

<http://www.usp.br/imprensa/?p=32567>. Acesso em: 16 nov. 2015.

ZONATTO, V. C. S. et al. Evidências da relação entre qualificação docente e desempenho acadêmico: uma análise à luz da Teoria do Capital Humano. Sociedade, Contabilidade e Gestão, Rio de Janeiro, v. 8, n. 1, p. 6-25, jan.-abr. 2013. Disponível em: <http://www.atena.org.br/revista/ojs-2.2.3-08/index.php/ufrj/article/viewFile/1642/1463>. Acesso em: 05 dez. 2015. 
APÊNDICE A - Crescimento da Educação Superior no Brasil (1985-2014)

\begin{tabular}{|c|c|c|c|}
\hline Ano & IES & Cursos & Matrículas \\
\hline 1985 & 859 & 3.923 & 1.367 .609 \\
\hline 1986 & 855 & N/D & 1.418 .196 \\
\hline 1987 & 853 & 4.188 & 1.470 .555 \\
\hline 1988 & 871 & 4.288 & 1.503 .555 \\
\hline 1989 & 902 & 4.453 & 1.518 .904 \\
\hline 1990 & 918 & 4.712 & 1.540 .080 \\
\hline 1991 & 893 & 4.908 & 1.565 .056 \\
\hline 1992 & 893 & 5.081 & 1.535 .788 \\
\hline 1993 & 873 & 5.280 & 1.594 .668 \\
\hline 1994 & 851 & 5.562 & 1.661 .034 \\
\hline 1995 & 894 & 6.252 & 1.759 .703 \\
\hline 1996 & 922 & 6.644 & 1.868 .529 \\
\hline 1997 & 900 & 6.132 & 1.945 .615 \\
\hline 1998 & 973 & 6.950 & 2.125 .958 \\
\hline 1999 & 1.097 & 8.878 & 2.369 .945 \\
\hline 2000 & 1.180 & 10.585 & 2.694 .245 \\
\hline 2001 & 1.391 & 12.155 & 3.036 .113 \\
\hline 2002 & 1.637 & 14.399 & 3.520 .627 \\
\hline 2003 & 1.859 & 16.453 & 3.936 .933 \\
\hline 2004 & 2.013 & 18.644 & 4.223 .344 \\
\hline 2005 & 2.165 & 20.407 & 4.567 .798 \\
\hline 2006 & 2.270 & 22.101 & 4.883 .852 \\
\hline 2007 & 2.281 & 23.488 & 5.250 .147 \\
\hline 2008 & 2.252 & 24.719 & 5.808 .017 \\
\hline 2009 & 2.314 & 27.827 & 5.954 .021 \\
\hline 2010 & 2.378 & 28.577 & 6.379 .299 \\
\hline 2011 & 2.365 & 30.420 & 6.739 .689 \\
\hline 2012 & 2.416 & 31.866 & 7.037 .688 \\
\hline 2013 & 2.391 & 32.049 & 7.305 .977 \\
\hline 2014 & 2.368 & 32.878 & 7.828 .013 \\
\hline
\end{tabular}


APÊNDICE B - Crescimento das IES (1985-2014)

\begin{tabular}{|c|c|c|c|}
\hline Ano & IES (total) & IES públicas & IES privadas \\
\hline 1985 & 859 & 233 & 626 \\
\hline 1986 & 855 & 263 & 592 \\
\hline 1987 & 853 & 240 & 613 \\
\hline 1988 & 871 & 233 & 638 \\
\hline 1989 & 902 & 220 & 682 \\
\hline 1990 & 918 & 222 & 696 \\
\hline 1991 & 893 & 222 & 671 \\
\hline 1992 & 893 & 227 & 666 \\
\hline 1993 & 873 & 221 & 652 \\
\hline 1994 & 851 & 218 & 633 \\
\hline 1995 & 894 & 210 & 684 \\
\hline 1996 & 922 & 211 & 711 \\
\hline 1997 & 900 & 211 & 689 \\
\hline 1998 & 973 & 209 & 764 \\
\hline 1999 & 1.097 & 192 & 905 \\
\hline 2000 & 1.180 & 176 & 1.004 \\
\hline 2001 & 1.391 & 183 & 1.208 \\
\hline 2002 & 1.637 & 195 & 1.442 \\
\hline 2003 & 1.859 & 207 & 1.652 \\
\hline 2004 & 2.013 & 224 & 1.789 \\
\hline 2005 & 2.165 & 231 & 1.934 \\
\hline 2006 & 2.270 & 248 & 2.022 \\
\hline 2007 & 2.281 & 249 & 2.032 \\
\hline 2008 & 2.252 & 236 & 2.016 \\
\hline 2009 & 2.314 & 245 & 2.069 \\
\hline 2010 & 2.378 & 278 & 2.100 \\
\hline 2011 & 2.365 & 284 & 2.081 \\
\hline 2012 & 2.416 & 304 & 2.112 \\
\hline 2013 & 2.391 & 301 & 2.090 \\
\hline 2014 & 2.368 & 298 & 2.070 \\
\hline
\end{tabular}


APÊNDICE C - Crescimento dos cursos de graduação (Gerenciamento e Administração)

\begin{tabular}{|c|c|c|c|c|}
\hline Ano & $\begin{array}{c}\text { Cursos } \\
\text { presenciais }\end{array}$ & $\begin{array}{c}\text { Cursos } \\
\text { presenciais } \\
\text { (IES públicas) }\end{array}$ & $\begin{array}{c}\text { Cursos } \\
\text { presenciais } \\
\text { (IES privadas) }\end{array}$ & $\begin{array}{c}\text { Cursos à } \\
\text { distância }\end{array}$ \\
\hline 2000 & 989 & 156 & 833 & N/D \\
\hline 2001 & 1.205 & 166 & 1.039 & N/D \\
\hline 2002 & 1.413 & 182 & 1.231 & N/D \\
\hline 2003 & 1.710 & 192 & 1.518 & N/D \\
\hline 2004 & 2.046 & 221 & 1.825 & N/D \\
\hline 2005 & 2.484 & 230 & 2.254 & N/D \\
\hline 2006 & 2.836 & 279 & 2.557 & N/D \\
\hline 2007 & 2.886 & 287 & 2.599 & N/D \\
\hline 2008 & 3.207 & 305 & 2.902 & N/D \\
\hline 2009 & 3.958 & 357 & 3.601 & 186 \\
\hline 2010 & 3.855 & 372 & 3.483 & 217 \\
\hline 2011 & 3.933 & 439 & 3.494 & 273 \\
\hline 2012 & 4.088 & 538 & 3.550 & 311 \\
\hline 2013 & 4.111 & 538 & 3.573 & 370 \\
\hline 2014 & 4.232 & 561 & 3.671 & 413 \\
\hline
\end{tabular}


APÊNDICE D - Relação das IES excluídas do banco de dados

IES excluídas na criação do banco de dados:

- Escola Superior de Engenharia e Gestão de São Paulo;

- Faculdade Anhanguera de Caxias do Sul;

- Faculdade Brasília de São Paulo;

- Faculdade Centro Paulista;

- Faculdade de Administração São Paulo;

- Faculdade de Balsas;

- Faculdade de Educação e Ciências Gerenciais de Sumaré;

- Faculdade de Educação e Cultura Montessori;

- Faculdade do Centro Leste;

- Faculdade do Norte Novo de Apucarana;

- Faculdade Magister;

- Faculdade Presidente Antônio Carlos de Nova Lima;

- Faculdade Presidente Antônio Carlos de São João Del Rei;

- Faculdade Unilagos;

- Faculdades Integradas de Cruzeiro;

- Faculdades Integradas de Pedro Leopoldo;

- Faculdades Integradas de São Carlos;

- Instituto de Ensino Superior Thathi.

IES excluídas na análise de outliers das variáveis independentes métricas:

- Faculdade de Administração da Fundação Armando Álvares Penteado;

- Escola de Administração de Empresas de São Paulo;

- Universidade Luterana do Brasil;

- Universidade Norte do Paraná. 
APÊNDICE E - Distribuição das variáveis dependentes
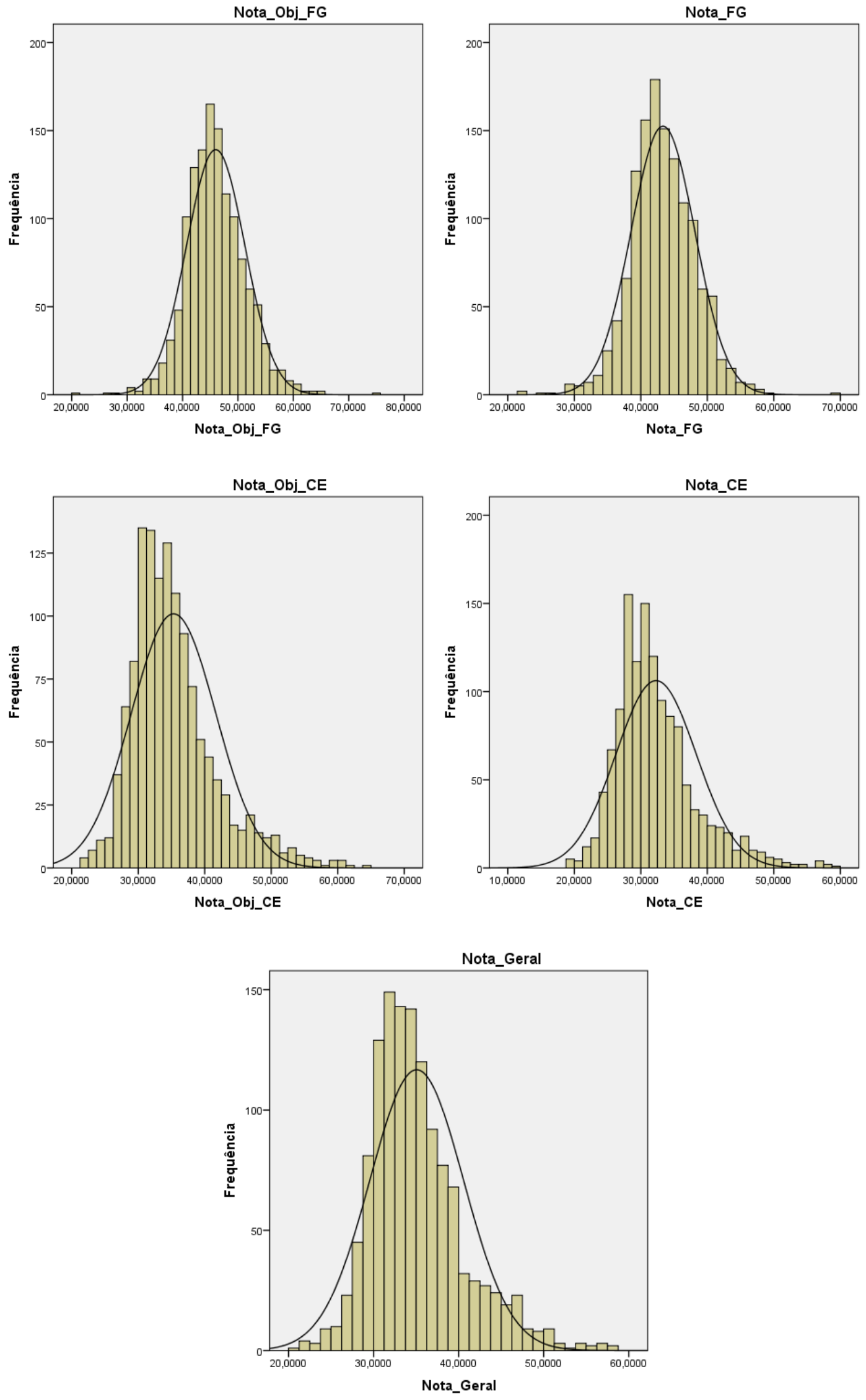
APÊNDICE F - Distribuição das variáveis independentes
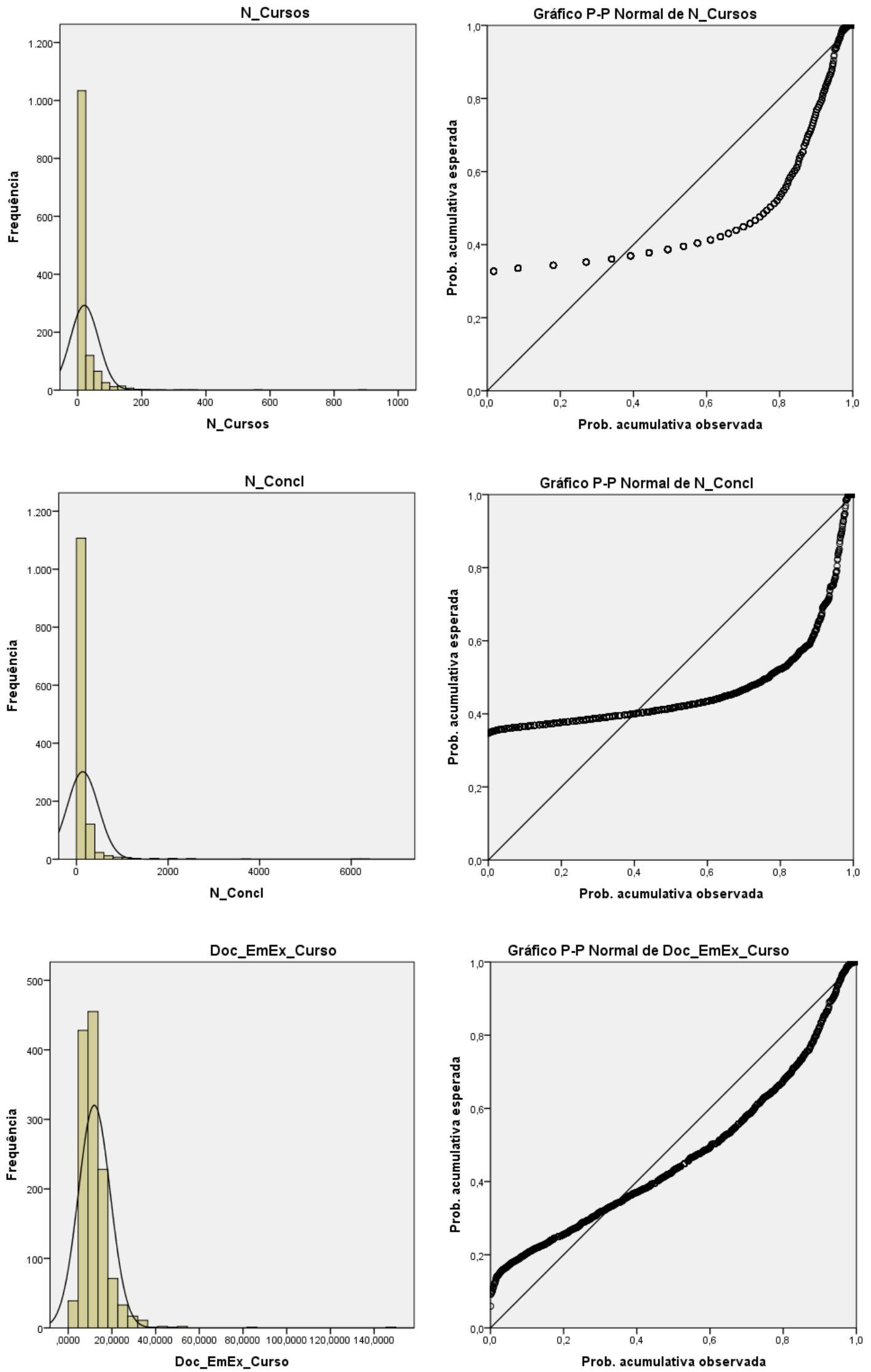


$$
\frac{17}{17}
$$



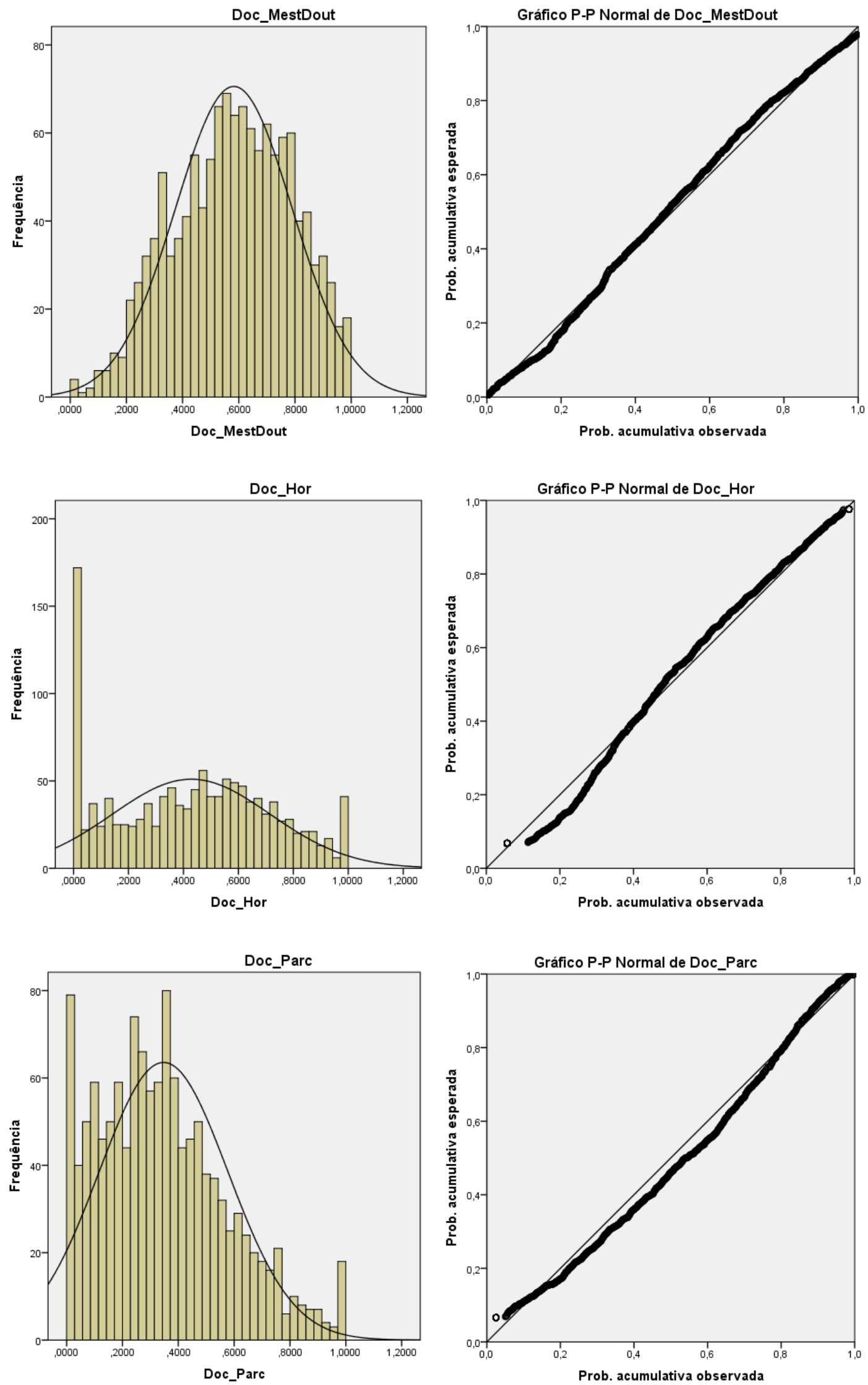

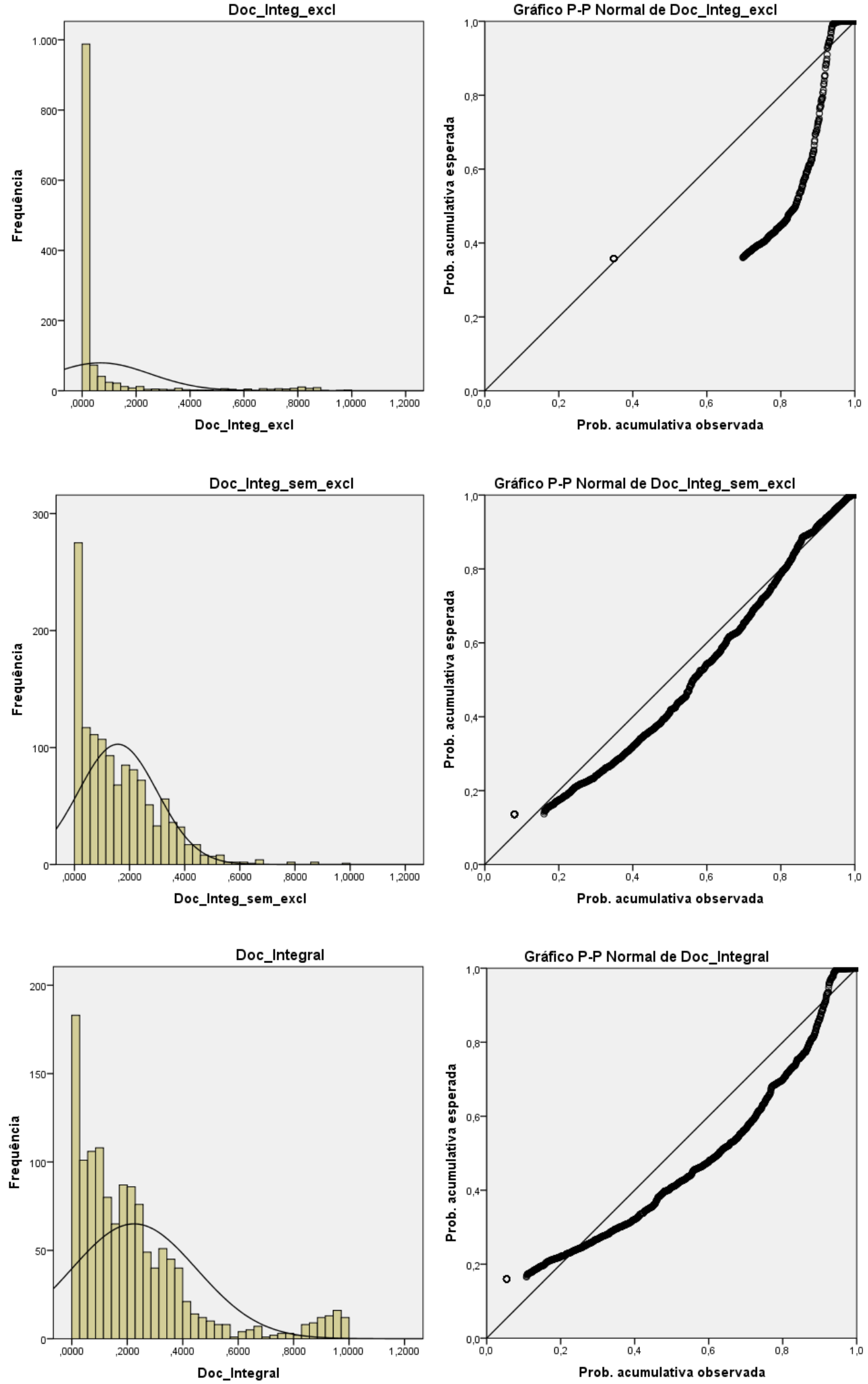
APÊNDICE G - Diagramas de dispersão das correlações significantes entre as variáveis independentes e a variável dependente
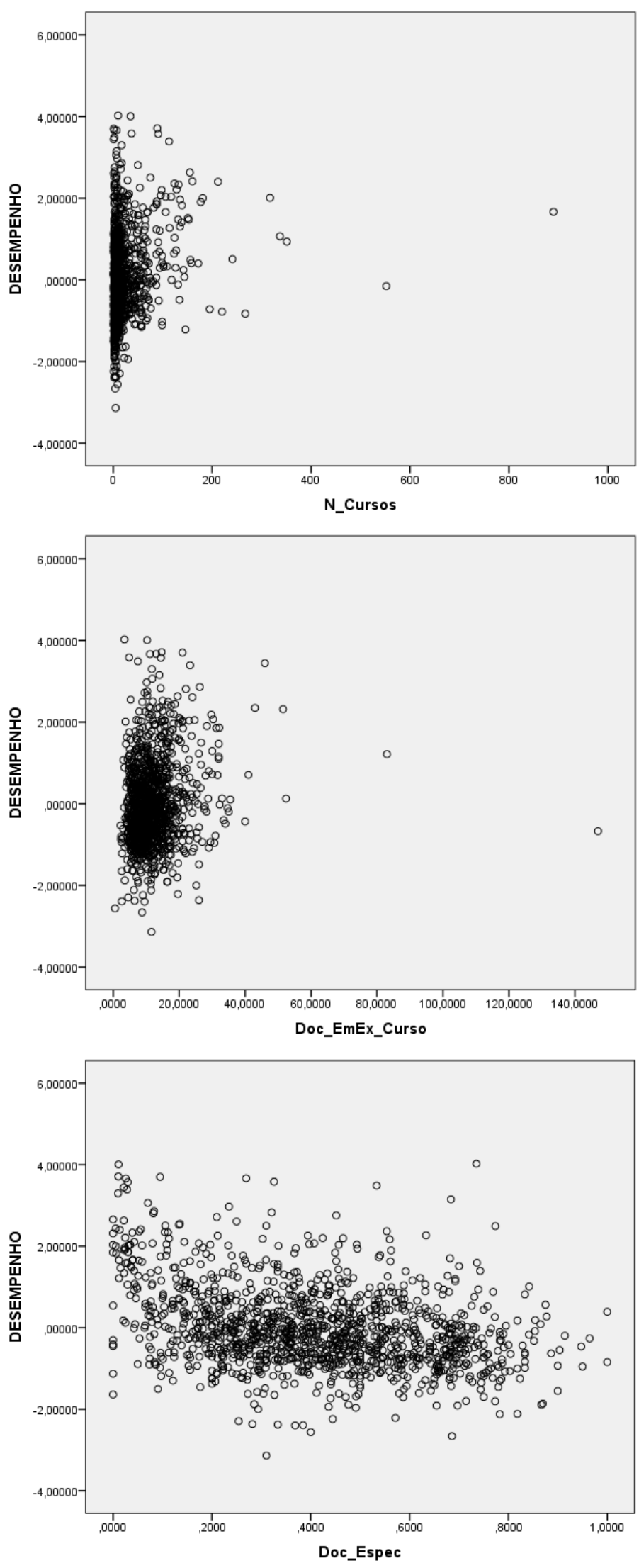

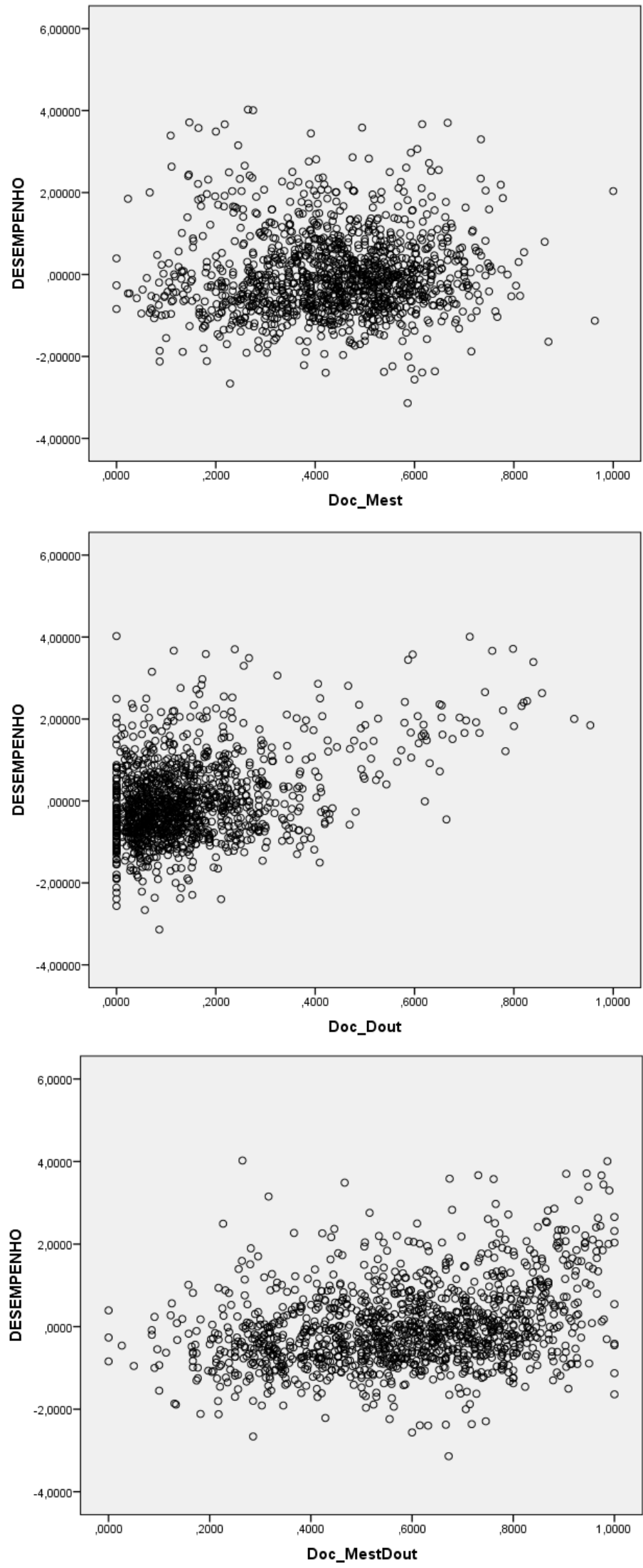

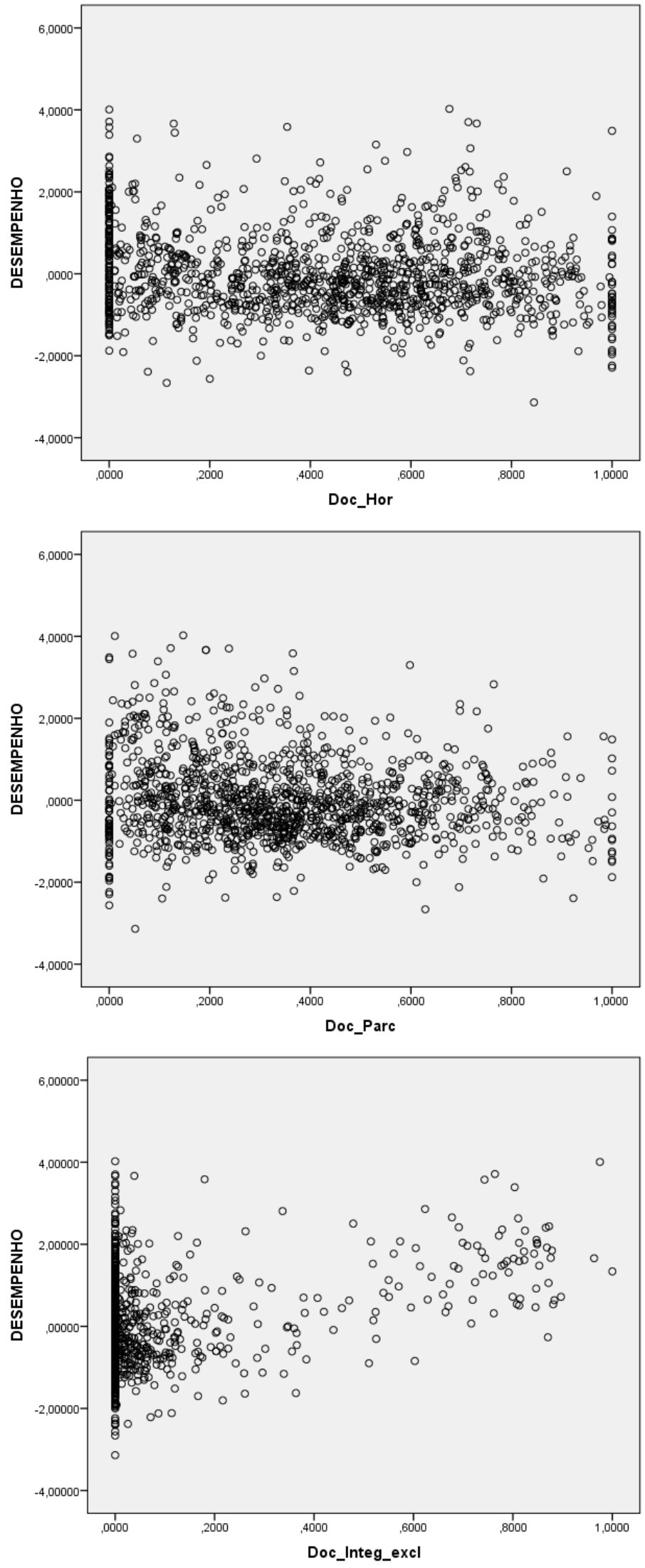

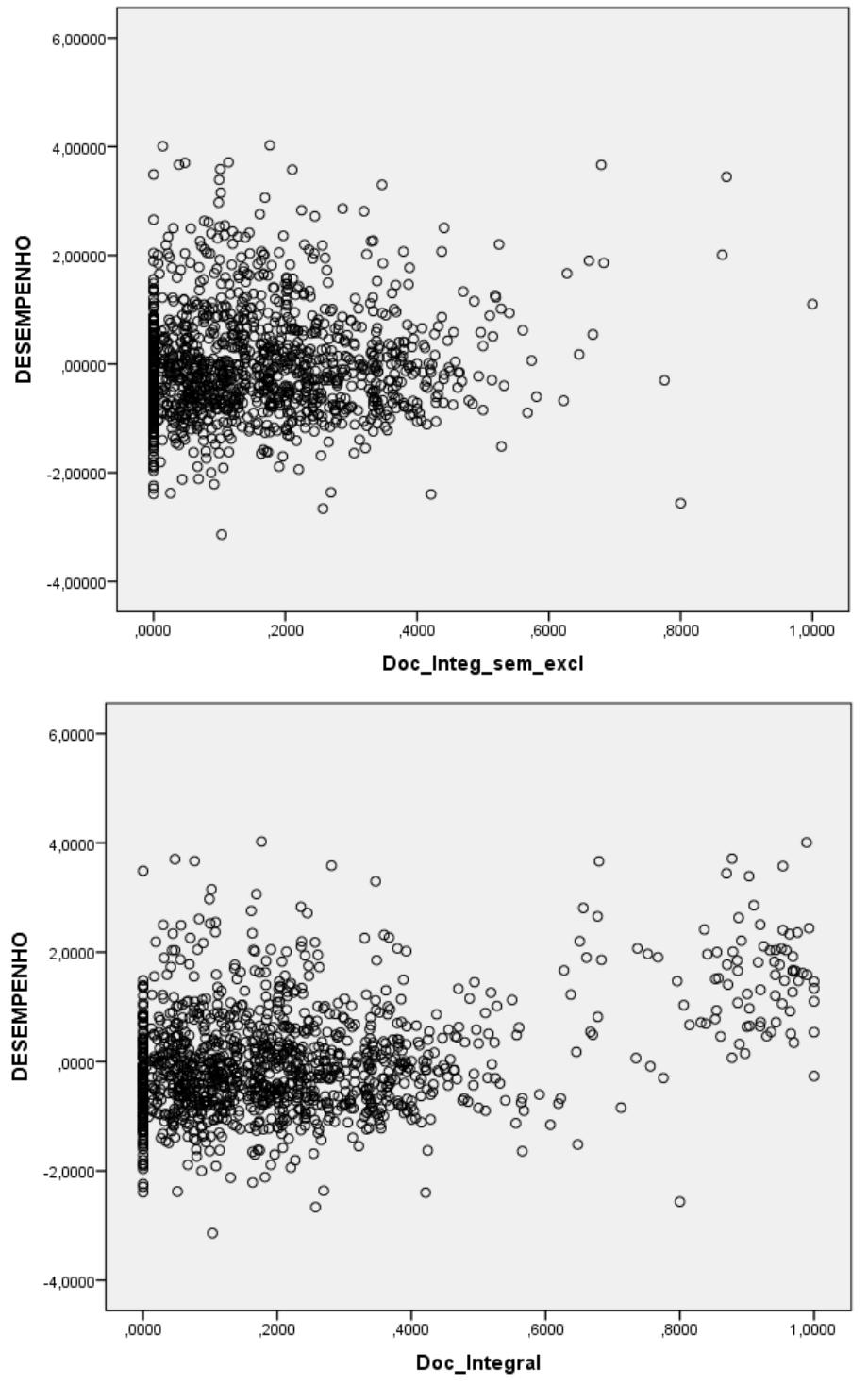